PEDRO PALUDETTO SILVA DE PAULA LOPES

A CFD Investigation on the Flow around a Low Aspect Ratio Vertical Cylinder: Modeling Free Surface and Turbulent Effects 

PEDRO PALUDETTO SILVA DE PAULA LOPES

\title{
A CFD Investigation on the Flow around a Low Aspect Ratio Vertical Cylinder: Modeling Free Surface and Turbulent Effects
}

\author{
Dissertation presented to the Escola \\ Politécnica da Universidade de São Paulo \\ towards the degree of Master of Sciences
}



PEDRO PALUDETTO SILVA DE PAULA LOPES

\section{A CFD Investigation on the Flow around a Low Aspect Ratio Vertical Cylinder: Modeling Free Surface and Turbulent Effects}

Dissertation presented to the Escola Politécnica da Universidade de São Paulo towards the degree of Master of Sciences

Area:

Naval Architecture and Ocean Engineering

Supervisor:

Prof. Dr. Celso Pupo Pesce

Co-supervisor:

Dr. Rodolfo Trentin Gonçalves 

Autorizo a reprodução e divulgação total ou parcial deste trabalho, por qualquer meio convencional ou eletrônico, para fins de estudo e pesquisa, desde que citada a fonte.

Este exemplar foi revisado e corrigido em relação à versão original, sob responsabilidade única do autor e com a anuência de seu orientador.

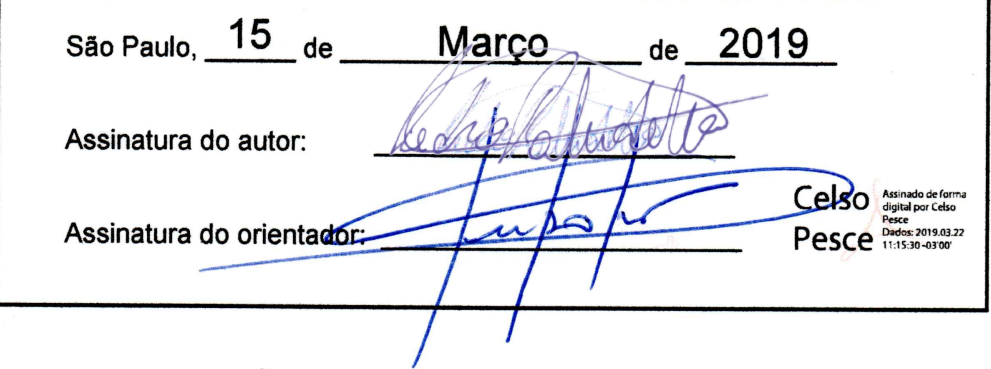

\section{Catalogação-na-publicação}

Lopes, Pedro

A CFD Investigation on the Flow around a Low Aspect Ratio Vertical Cylinder: Modeling Free Surface and Turbulent Effects / P. Lopes -- versão corr. - São Paulo, 2019.

$107 \mathrm{p}$.

Dissertação (Mestrado) - Escola Politécnica da Universidade de São Paulo. Departamento de Engenharia Naval e Oceânica.

1.CFD 2. Turbulence Modeling 3.Finite Cylinder 4.Three-dimensional Flow I.Universidade de São Paulo. Escola Politécnica. Departamento de Engenharia Naval e Oceânica II.t. 



\section{Dedication}

To my parents, Eduardo and Marina, for the support and incentive they gave me to reach all my objectives and dreams.

To my beloved fiancée Maria Eduarda whose without her support and love, this work would not have been possible. 



\section{ACKNOWLEDGMENTS}

Gostaria de agradecer, primeiramente, a meu orientador Prof. Celso Pupo Pesce, por ter me orientado com excelência, tendo paciência e ter estado sempre solícito para sanar minhas dúvidas e ter ido além, orientando minha vida acadêmica. Agradeço profundamente meu co-orientador e amigo Rodolfo Trentin Gonçalves, por todas as oportunidades e ensinamentos providos. A meus supervisores de estágio no MARIN, Arjen Koop e Guilherme Vaz por terem me dado oportunidade de vivência em um laboratório de renome mundial e guiado tecnicamente minha pesquisa. Aos professores Shinichiro Hirabayashi e Hideyuki Suzuki da Universidade de Tóquio, por terem me dado a oportunidade de conhecer essa grande universidade. Agradeço também aos Professores Kazuo Nishimoto e Pedro Cardozo de Mello, por terem disponibilizado a infraestrutura necessária para minha pesquisa, por terem confiado em mim e me convidado para diversos projetos de pesquisa no laboratório TPN-USP, que me engrandeceram como pesquisador. Agradeço a Guilherme Feitosa Rosetti e ao Prof. Rafael Gioria por seus comentários e observações em meu exame de qualificação, clareando o caminho a ser seguido. Sou grato a todas as oportunidades que o Departamento de Engenharia Naval e Oceânica da USP me proporcionou e a todos os funcionários e Professores que de alguma forma participaram desta caminhada. À CAPES, Coordenação de Aperfeiçoamento de Pessoal de Nível Superior, ao MARIN e a Petrobrás, por terem me dado o suporte financeiro que possibilitou minha total dedicação à pesquisa. À minha noiva Maria Eduarda, que há nove anos me motiva e me engrandece como pessoa e como pesquisador. Sem você nada disso teria sido possível! Deixo aqui meus agradecimentos aos meus sogros, Evandro e Cláudia, que me receberam como um filho; Sem esquecer da minha querida cunhada Maria Antônia, que deixa nossos dias muito mais divertidos. Aos meus queridos amigos que fiz na Universidade e que estarão para sempre na minha vida, Rodrigo Michels, Fabiano, Evelyne, Pedro Budny e Flávia. Ao meu amigo Benoit LeBlanc, por todas as jantas, passeios, longas conversas, e por ter ajudado excelentemente na revisão de meu texto. Finalmente, agradeço à minha família. Meus pais Eduardo e Marina, que sempre me deram total suporte, acreditaram e tornaram possível tudo o que conquistei até hoje. Aos meus irmãos, Guilherme, Rodrigo, Ana Luiza, Leonardo e Mariana, por fazerem parte da minha caminhada. Por último, mas não menos importante, ao meu padrinho e tio José Orlando, que sempre deixou as portas de sua casa aberta para mim. 



\section{RESUMO}

O escoamento ao redor de corpos rombudos é um tópico essencial na dinâmica de fluidos. O escoamento é caracterizado por regiões com grande vorticidade que se separam do corpo e causam oscilações das forças de arrasto e sustentação sobre a estrutura. O escoamento ao redor de cilindros longos é um tema que tem sido extensivamente estudado com muitos trabalhos encontrados na literatura. Entretanto, o cilindro com baixa razão de aspecto perfurante à superfície livre é um caso pouco estudado, apesar desta estrutura ser encontrada em várias estruturas oceânicas flutuantes. Esta dissertação apresenta cálculos numéricos para o escoamento ao redor de um cilindro fixo, que trespassa a superfície livre com razão de aspecto $L / D$ igual a 2 . O problema é estudado em um regime subcrítico de turbulência, com número de Reynolds igual a $4.3 \times 10^{4}$. Uma vasta metodologia de verificação e validação foi seguida para avaliar a confiabilidade dos resultados obtidos numericamente. Para investigar os efeitos da superfície livre nas cargas hidrodinâmicas, duas abordagens são consideradas: condição de simetria de duplo corpo e um método de captura de interface Volume of Fluid. Além disso, dois modelos de turbulência foram investigados: o modelo não linear Explicit Algebraic Reynolds Stress Model (EARSM), e o modelo de turbulência Improved Delayed Detached Eddy Simulation (IDDES). Os resultados relacionados aos coeficientes de arrasto e sustentação são apresentados a partir de análise estatística, complementados através de ilustrações que permitem visualizar os campos de escoamento e pressão. Com base nos resultados de casos em que a superfície livre é modelada com uma condição de contorno de simetria, conclui-se que o modelo de turbulência não é adequado para este tipo de escoamento, pois o modelo amortece a dinâmica do escoamento devido à superprodução de viscosidade turbulenta. Consequentemente, as oscilações na força de sustentação não são capturadas usando este modelo. Entretanto, resultados dos campos médios do escoamento mostram-se concordantes com imagens experimentais obtidas com técnicas de $P I V$ - Particle Image Velocimetry. Resultados do caso modelado com o modelo de turbulência EARSM mostram melhores concordâncias na comparação dos parâmetros estatísticos com experimentos do que o modelado com o modelo EARSM. Nos casos em que a superfície livre é modelada com o método VoF, o modelo de turbulência EARSM mostra resultados semelhantes para o arrasto, enquanto as flutuações da sustentação apresentam-se uma ordem de grandeza menores, quando comparadas ao caso de duplo corpo. Resultados usando o modelo de turbulência IDDES e VoF apresentam melhores comparações aos resultados experimentais, tanto para os parâmetros estatísticos quando para as visualizações do escoamento. 



\section{ABSTRACT}

The flow around bluff bodies is an essential topic in fluid dynamics. This flow is characterized by large vortical flow regions separating from the surface of the bluff body, and they cause oscillating drag and lift forces on the structure. The flow around an infinite long cylinder is a well-known case being studied in the literature. However, a cylinder with low aspect-ratio piercing the free surface has not been studied much although such an arrangement can be found in many floating offshore structures. In this thesis the results of CFD calculations are presented for a fixed, free surface piercing cylinder with an aspect-ratio $L / D$ equals to 2 . The Reynolds number was equal to $4.3 \times 10^{4}$ indicating that the flow is in the sub-critical turbulent regime. An extensive methodology of verification and validation is followed to investigate the reliability of the results. To investigate the effect of the free surface on the calculated hydrodynamic loads, two approaches have been considered: a double-body symmetry condition and an interface capturing Volume-ofFluid (VoF) method. Additionally, two turbulence models are investigated: a non-linear Explicit Algebraic Reynolds Stress Model (EARSM); and the Improved Delayed Detached Eddy Simulation (IDDES) turbulence model. The results are presented in terms of integral results (drag and lift coefficients) and flow visualizations. Based on the results of the cases in which the free surface was modeled as a double body symmetry boundary condition, it is concluded that the model is not suitable for this type of flow as the model damps out the flow dynamics due to over-production of eddy-viscosity. Hence, the characteristic oscillating lift forces are not captured using this turbulence model. However, this turbulence model showed good agreements regarding the flow fields in comparison with experimental PIV measurements. Results of the case modeled with EARSM turbulence model shows better agreement with the experimental results compared with the turbulence model. In the cases where the free-surface is considered, results with the EARSM turbulence model show similar results for the drag forces whereas the lift fluctuations were one order of magnitude smaller, compared with the double body case. Lastly, the results using the IDDES turbulence model and free-surface VoF modeling are shown to produce the best comparison with the experimental results, regarding both, integral values and flow field results. 



\section{LIST OF FIGURES}

1.1 Low aspect ratio cylinders in engineering. Left: floating wind turbine. Right: mono-column floater for oil and gas production . . . . . . . . . . 2

2.1 Experimental visualization of the flow around a bluff and a smooth body. Source: Adapted from Van Dyke (1982) . . . . . . . . . . . . . . . . 6

2.2 Sketch of the regions in a disturbance flow. Source: Adapted from Zdravkovich

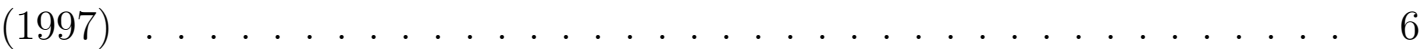

2.3 Topology of flow patterns (a) initial; (b to e) temporal developments. Source:Taneda (1956 apud SUMNER, 2013, p.-43). . . . . . . . . . 8

2.4 Flow visualization of the eddy linking model. Source: (SLAOUTI; GER-

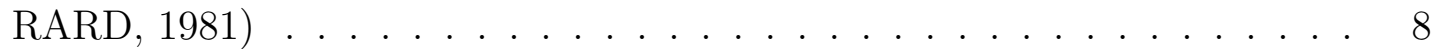

3.1 Schematic model of the flow around finite cylinders. Source: Kawamura et al. $(1984) \ldots \ldots \ldots \ldots \ldots \ldots$

3.2 Time averaged velocity field three-dimensional visualization with the free end region in the vicinity. Source:Adapted from Leder et al. (2003) . . . . 14

3.3 Left: Experimental Setup.; Right: PIV measured plane positions (a) horizontal mid-span plane at $\mathrm{z} / \mathrm{L}=-0.5$, (b) horizontal plane near the cylinder free end at $\mathrm{z} / \mathrm{L}=-0.75$ and $(\mathrm{c})$ vertical plane at $\mathrm{y} / \mathrm{D}=0$. Source: Gonçalves et al. $(2015) \ldots \ldots \ldots \ldots$. . . . . . . . . . . . . . . . . 17

3.4 Cx values in function of Reynolds number for each cylinder aspect ratio. Source: Gonçalves et al. (2015) . . . . . . . . . . . . . . . . . . . 17

3.5 Averaged $C y$ rms values and respective standard deviation for $R e$ ranging between 10,000 and 50,000 as function of cylinder aspect ratio. Source: Gonçalves et al. (2015) . . . . . . . . . . . . . . . . . . 18

3.6 Averaged St values and respective standard deviation for Re ranging between 10,000 and 50,000 in function of cylinder aspect ratio. Source: Gonçalves et al. (2015) . . . . . . . . . . . . . . . . . . . . . . . 19

4.1 TST-B applied to a disturbed signal. Source: (BROUWER; TUKKER; RIJSBERGEN, 2015) . . . . . . . . . . . . . . . . . . 31 
4.2 TST-B with areas identified. Source: (BROUWER; TUKKER; RIJSBER-

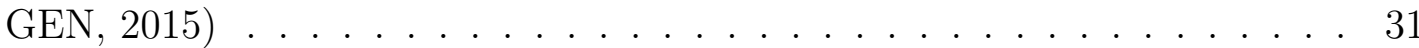

4.3 Grid refinement examples for (a) refinement level 2; (b) refinement level 3; (c)refinement level 4; Source: (CREPIER, 2017) . . . . . . . . . . . . . . 33

5.1 Sketch of the problem evaluated. . . . . . . . . . . . . 35

5.2 Domain and boundaries of the symmetric case. . . . . . . . . . . . . 36

5.3 Domain of the FS cases. . . . . . . . . . . . . . . . . . . 37

5.4 Zoom of the set of meshes for the grid refinement study: (a) Grid-0; (b) Grid-1; (c) Grid-2; (d) Grid-3 . . . . . . . . . . . . . . . . . . . . . . 38

5.5 Zoom of the set of meshes for the grid refinement study of the FS case: (a) Grid-1; (b) Grid-2; (c) Grid-3; (d) Grid-4 . . . . . . . . . . . . . . . . . . . 39

6.1 Temporal series of the SYM case with EARSM turbulence model for (a) Drag coefficient and (b) Lift coefficient . . . . . . . . . . . . . . . . . . 45

6.2 Integral results of the SYM case with EARSM turbulence model for (a)average drag and (b) rms of lift coefficients. . . . . . . . . . . . . . . . 46

6.3 Residuals behavior of the EARSM-SYM calculations for the entire set of grids and time-step tested. . . . . . . . . . . . . . . . . . 46

6.4 Temporal series of the VoF case with EARSM turbulence model for (a) Drag coefficient and (b) Lift coefficient . . . . . . . . . . . . . . . . . 47

6.5 Integral results of the VoF case with EARSM turbulence model for (a)average drag of coefficient and (b) rms of lift coefficient. . . . . . . . . . . . . . . 47

6.6 Residuals behavior of the EARSM-VoF calculations for the entire set of grids and time-step tested. . . . . . . . . . . . . . . . . . . . . 48

6.7 Temporal series of the VoF case with IDDES turbulence model for (a) Drag coefficient and (b) Lift coefficient . . . . . . . . . . . . . . . . . . . . 48

6.8 Integral results of the VoF case with IDDES turbulence model for (a)average drag of coefficient and (b) rms of lift coefficient. . . . . . . . . . . . . . . . 49

6.9 Residuals behavior of the IDDES-VoF calculations for the entire set of grids and time-step tested. 
6.10 TST-B of the original signals of the SYM cases with EARSM turbulence model. . . . . . . . . . . . . . . . . . . 50 50

6.11 TST-B of the filtered signals of the SYM cases with EARSM turbulence model. . . . . . . . . . . . . . . . . . . . . 51

6.12 TST-B of the original signals of the VoF case with EARSM turbulence model. 51

6.13 TST-B of the filtered signals of the VoF case with EARSM turbulence model. 52

6.14 TST-B of the original signals of the VoF case with IDDES turbulence model. 52

6.15 TST-B of the filtered signals of the VoF case with IDDES turbulence model. 53

6.16 Experimental TST-A of the original signal of drag force. Source: Gonçalves et al. (2015) . . . . . . . . . . . . . . . . . . . . 54

6.17 Experimental TST-B of the original signal of drag force. Source: Gonçalves et al. (2015) . . . . . . . . . . . . . . . . . . . . . 5 54

6.18 Experimental TST-A of the original signal of lift force. Source: Gonçalves et al. (2015) . . . . . . . . . . . . . . . . . . . . 55

6.19 Experimental TST-B of the original signal of lift force. Source: Gonçalves et al. (2015) . . . . . . . . . . . . . . . . . . . . . 55

6.20 TST-B of the filtered signal of the lift force. . . . . . . . . . . . . . . 56

6.21 TST-A of the filtered signal of the lift force. . . . . . . . . . . . . 56

6.22 Magnitude velocity at $y=0$ plane: (a) EARSM-SYM; (b) EARSM-FS; (c) IDDES-FS (d) Experimental Gonçalves et al. (2015) . . . . . . . . . . . . . 58

$6.23 \mathrm{x}$-velocity component map at the $\mathrm{y}=0$ plane and streamlines: (a) EARSMSYM; (b) EARSM-FS; (c) IDDES-FS (d) Experimental Gonçalves et al. $(2015) ; \ldots \ldots \ldots \ldots \ldots \ldots \ldots$

$6.24 \mathrm{x}$-velocity component map at mid span and streamlines: (a) EARSM-SYM; (b) EARSM-FS; (c) IDDES-FS (d) Experimental Gonçalves et al. (2015); . 60

7.1 Time averaged $C_{p}$ maps onto the y=0 plane for (a) EARSM-SYM; (b) EARSM-FS; (c) IDDES-FS . . . . . . . . . . . . . . . . . . 61

7.2 Time averaged $C_{p}$ maps onto the $\mathrm{z}=0$ plane for (a) EARSM-SYM; (b) EARSM-FS; (c) IDDES-FS 
7.3 Time averaged $\frac{W_{y} D}{V}$ intensity onto the $\mathrm{y}=0$ plane for (a) EARSM-SYM;

(b) EARSM-FS; (c) IDDES-FS . . . . . . . . . . . . . . . 63

7.4 Time averaged $\frac{W_{z} D}{V}$ intensity onto the $\mathrm{z}=0$ plane for (a) EARSM-SYM; (b) EARSM-FS; (c) IDDES-FS . . . . . . . . . . . . . . . . . . . . . 64

7.5 Instantaneous $\frac{W_{z} D}{V}$ intensity onto the $\mathrm{z}=0$, plane for (a) EARSM-SYM; (b) EARSM-FS; (c) IDDES-FS . . . . . . . . . . . . . . . . . . . . 65

7.6 $Q=3$ iso-surfaces, colored by $V^{*}$, for the case with EARSM and SYM Left: Perspective view; Right: Zoom of the free end region. . . . . . . . . . 66

7.7 $Q=3$ iso-surfaces, colored by $V^{*}$, for the case with EARSM and VoF Left: Perspective view; Right: Zoom of the free end region. . . . . . . . . . 67

7.8 $Q=3$ iso-surfaces, colored by $V^{*}$, for the case with IDDES and VoF - Left: Perspective view; Right: Zoom of the free end region. . . . . . . . . . . . . 67 


\section{LIST OF TABLES}

1 List of important references on flow around finite cylinders. . . . . . . . . . 11

2 Main parameters of the problem. . . . . . . . . . . . . 36

3 Grids size, $\lambda$ and $y^{+}$of the Symmetry case . . . . . . . . . . . . 38

4 Grids size, $\lambda$ and $y^{+}$of the FS case . . . . . . . . . . . . 39

5 Time-step size chosen for the discretization analysis. . . . . . . . . . . . . . 40

$6 \quad$ Averaged drag coefficient comparison between numerical and experimental results. . . . . . . . . . . . . . . . . . . 57

7 Comparison between numerical and experimental results for root mean square of lift coefficients. . . . . . . . . . . . . . . . . . . 57

8 Comparison between numerical and experimental results for Strouhal number. 58 



\section{LIST OF SYMBOLS}

\begin{tabular}{|c|c|}
\hline$C_{x x, \text { biased }}$ & Auto-covariance factor corrected for a signal trend \\
\hline$\gamma$ & Coefficient of surface-tension \\
\hline $\mathbf{F}$ & Resulting Force Vector \\
\hline $\mathbf{u}$ & Vector of Velocities \\
\hline$\mu$ & Viscosity \\
\hline$\mu_{t}$ & Eddy Viscosity \\
\hline$\overline{C_{x}}$ & Time Averaged Drag Coefficient \\
\hline$\rho$ & Density \\
\hline$c_{i}$ & Volume Fraction \\
\hline$C_{x}$ & Drag Coefficient \\
\hline$C_{y}$ & Lift Coefficient \\
\hline$C_{y}$ & Root Mean Square of Lift Coefficient \\
\hline$D$ & Diameter of the Cylinder \\
\hline$F_{x}$ & Drag Force \\
\hline$F_{y}$ & Lift Force \\
\hline$k$ & Turbulent Kinetic Energy \\
\hline$L$ & Length of the Cylinder \\
\hline$L / D$ & Aspect Ratio \\
\hline$L / D_{\text {crit }}$ & Critical Aspect Ratio \\
\hline$p$ & Total Pressure \\
\hline$p_{a t m}$ & Atmospheric pressure \\
\hline
\end{tabular}


$R_{1}, R_{2}$

V

NUA
Radii of curvature of the intercepts of the surface by two orthogonal planes containing the axis $O_{z}$

Free-Stream Velocity

Numerical Uncertainty Analysis Tool 


\section{GLOSSARY}

CFD Computer Fluid Dynamics

DES Detached Eddy Simulation

DNS Direct Numerical Simulation

EARSM Explicit Algebraic Reynolds Stress Model

FLT First Layer Thicnkess

FOWT Floating Offshore Wind Turbine

IDDES Improved Delayed Detached Eddy Simulation

LDA Laser Doppler Anemometer

LES Large Eddy Simulation

NDF Nucleus of Dynamics and Fluids

PIV Particle Image Velocimetry

PSD Power Spectrum Density

RANS Reynolds-Average Navier-Stokes

ReFRESCO Reliable \& Fast Rans Equations solver for Ships and Constructions Offshore

TST Transiente Scanning Techinique

VIM Vortex Induced Vibrations

VoF Volume of Fluid 



\section{CONTENTS}

1 Introduction 1

2 Theoretical Basis 3

2.1 Governing Equations . . . . . . . . . . . . . . . . 3

2.1.1 Navier-Stokes Equations of Motion . . . . . . . . . . . . . . 3

2.1.2 Boundary Conditions . . . . . . . . . . . . . . . 4

2.1.2.1 No-Slip Condition . . . . . . . . . . . . . . 4

2.1.2.2 Free-Surface Condition . . . . . . . . . . . . . . . 5

2.2 Flow around Bluff Bodies . . . . . . . . . . . . . . . 5

2.2 .1 Free end . . . . . . . . . . . . . . . . 7

3 Literature Review $\quad 11$

3.1 Experimental Background . . . . . . . . . . . . . . . . 11

3.2 Previous Numerical Simulations . . . . . . . . . . . . . . . . . . . . . 14

3.3 Experimental Data for Comparison . . . . . . . . . . . . . . 16

4 Numerical Methods $\quad 21$

4.1 (U)RANS Solver ReFRESCO . . . . . . . . . . . . . . 21

4.2 Turbulence Approach . . . . . . . . . . . . . . . . . . . . . 22

4.2.1 Background: DNS, LES and RANS . . . . . . . . . . . . . . 22

4.2.2 Explicit Algebraic Reynolds Stress Model . . . . . . . . . . . . . 23

4.2.3 Improved Delayed Detached Eddy Simulation - IDDES . . . . . . . 23

4.3 Vortex Identification Method: $Q_{\text {criterium }} \ldots \ldots . . . . . . . . . .24$

4.4 Volume of Fluid $(\mathrm{VOF}) \ldots \ldots \ldots \ldots \ldots \ldots$

4.4 .1 VoF method . . . . . . . . . . . . . . . 25 
4.5 Verification and Validation . . . . . . . . . . . . . 26

4.5 .1 Round-off errors . . . . . . . . . . . . . . . . . . . . 27

4.5 .2 Iterative errors . . . . . . . . . . . . . . . . . 27

4.5.3 Discretization errors . . . . . . . . . . . . . . . 28

4.5.4 Signal Stationarity Errors . . . . . . . . . . . . . . . . . . 29

4.5 .5 Grids . . . . . . . . . . . . . . . . . . . . 32

5 Numerical Setup $\quad 35$

5.1 Geometry and Main Parameters . . . . . . . . . . . . . . . . . . 35

5.2 Computational Domain and Boundary Conditions . . . . . . . . . . . 36

5.3 Grids and Temporal Discretization . . . . . . . . . . . . . . 37

5.3 .1 Grids . . . . . . . . . . . . . . . . . . 37

5.3 .2 Time Discretization . . . . . . . . . . . . . . . . . 40

5.4 Numerical models and settings . . . . . . . . . . . . . . . . . . . . . . 40

6 Verification Procedures and Comparison with Experiments 43

6.1 Chapter Remarks . . . . . . . . . . . . . . . . . . . . . . 43

6.2 Verification Procedures . . . . . . . . . . . . . . . . . . . . 44

$6.2 .1 \quad$ Iterative Convergence . . . . . . . . . . . . . . . . . . . . . 44

6.2.1.1 EARSM - SYM case . . . . . . . . . . . 45

6.2.1.2 EARSM - VoF case . . . . . . . . . . . . . 47

6.2 .2 Signal Stationarity . . . . . . . . . . . . . . . . 50

6.2.2.1 EARSM - VoF Case . . . . . . . . . . . . 50

6.2.2.2 EARSM - VoF case . . . . . . . . . . . . 51

6.3 Comparison with Experimental Data . . . . . . . . . . . . 53

6.3.1 Experimental Uncertainty Analysis . . . . . . . . . . . . . . 53

6.3.2 Integral Quantities . . . . . . . . . . . . . . . 56

6.3 .3 Flow Fields . . . . . . . . . . . . . . . . . . . . . . . . 58 
7 Discussion

7.1 Pressure Coefficient . . . . . . . . . . . . . . . . . . . . 61

7.2 Vorticity Fields . . . . . . . . . . . . . . . . . . . . 63

7.3 Three-dimensional Vortical Structures . . . . . . . . . . . . . . . . 65

8 Conclusions $\quad 69$

8.1 Thesis Overview . . . . . . . . . . . . . . . . . . 69

8.2 Main Conclusions . . . . . . . . . . . . . . . . . . . 70

8.3 Further Studies Recommendations . . . . . . . . . . . . . . . . . . . 71

$\begin{array}{ll}\text { References } & 73\end{array}$ 



\section{INTRODUCTION}

The flow around bluff bodies is an essential topic in fluid dynamics. This flow is characterized by large vortical flow regions separating from the surface of the bluff body, and they cause oscillating drag and lift forces on the structure. The flow around an infinitely long cylinder is a well-known case studied in the literature. However, the problem of a cylinder with low aspect-ratio piercing the free-surface has not been examined much, although in many floating offshore structures this case is found. This study shows its importance as a fundamental problem connected with the vortex-induced vibrations, related to several offshore constructions such as underwater pipelines, electric transmission cables, mooring lines, and floating platforms, for instance.

The study of fluid-structure interaction problems in floating structures has gained importance in the last decades. Vortex detachments in floating structures may induce motion of the platform, which is called Vortex-Induced Motion (VIM). This phenomenon is a critical issue for the design of mooring lines and risers in offshore structures, for instance. Several structures are faced with this problem such as semi-submersible, spar and mono-column platforms. Nowadays, VIM investigation gets more attention, due to the rising demand for floating offshore wind turbines, FOWT. Figure 1.1 shows some examples of low aspect ratio cylinders in marine engineering.

Aiming to fill the gap of disabilities on experimental methods for three-dimensional flow visualization, this research proposes a numerical investigation on the three-dimensional aspects of the flow around a finite cylinder. To reach this goal, a numerical sensitivity analysis of turbulence model and free-surface modeling were performed as well as a comparison with experimental data to assure the reliability of the results.

Two approaches were considered to examine the effect of the free-surface on the hydrodynamic load calculations: a double-body symmetry condition and an interface capturing Volume-of-Fluid (VoF) method. Additionally, two turbulence models were examined: the non-linear Explicit Algebraic Reynolds Stress Model (EARSM) and the Improved Delayed Detached Eddy Simulation (IDDES) turbulence model. This research addresses integral 


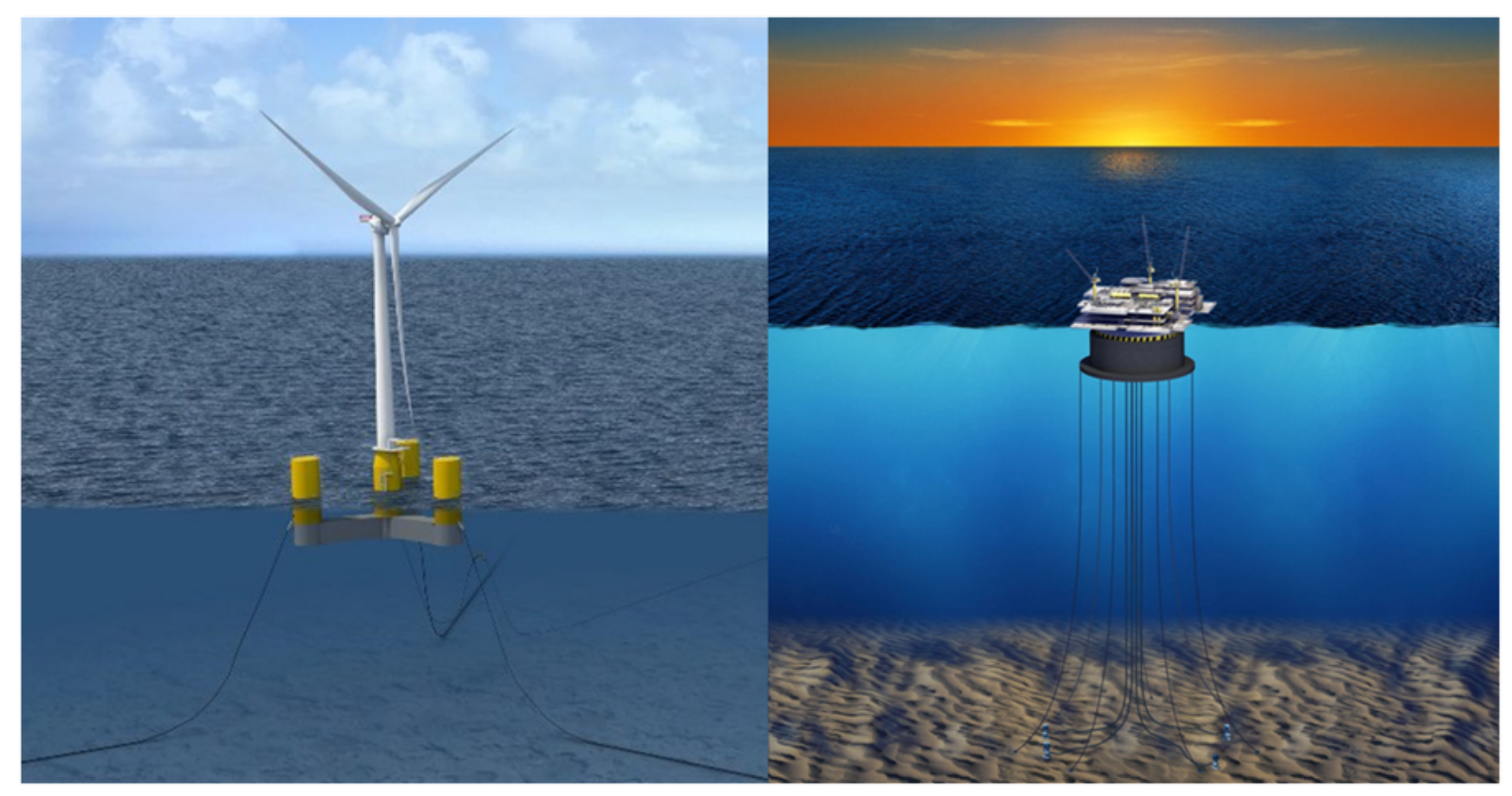

Figure 1.1: Low aspect ratio cylinders in engineering. Left: floating wind turbine. Right: mono-column floater for oil and gas production

results of drag and lift coefficients, that help us to understand aspects of the free end and free surface effects on the cylinder. These results are complemented by flow visualizations of pressure, vorticity, and velocity, which give a qualitative idea of the flow pattern around the cylinder. Finally, with a method for vortices identification $Q_{\text {criterium }}$, three-dimensional iso-surfaces of the flow are presented.

This introduction starts by outlining the background information about low aspect ratio cylinders and conclude by highlighting the methods and structure of this research. Chapter 2 focuses on understanding the theoretical formulation of the problem and gives a phenomenological description of the flow around a bluff body with finite height. This is followed by a brief review on the literature within the subject in Chapter 3. Chapter 4 discusses the numerical methods used in this study. Chapter 5 introduces the numerical setup. Chapter 6 presents a methodology to evaluate the numerical errors and an comparison with experimental data. Chapter 7 presents a discussion over the flow fields and three-dimensional vortex structures and the influence of the tip-vortices and free surface effects. Finally, conclusions and recommendations are presented in Chapter 8. 


\section{THEORETICAL BASIS}

This chapter exhibits a brief review of essential points related to this thesis. Firstly, the equations governing the problem are discussed. Furthermore, a study of the phenomenology of the flow around bluff bodies is given, followed by a brief introduction about the free end case.

\subsection{Governing Equations}

This section aims to present the equations which govern the problem and their necessary boundary conditions. Viscous flow in the presence of free surface is not trivial to model mathematically and is usually neglected by authors when considering potential flow simplifications.

\subsubsection{Navier-Stokes Equations of Motion}

The Navier-Stokes equations are used for this problem. The assumptions taken are: two-phase incompressible flow, atmospheric pressure at the interface: viscous effects are taken into effect, using a constant viscosity for each fluid. Therefore, after the considerations, the Navier-Stokes equations regarding conservation of mass and conservation of momentum are given by Equations 2.1 and 2.2, respectively. (BATCHELOR, 1967)

$$
\begin{gathered}
\frac{\partial u_{i}}{\partial x_{i}}=0 \\
\frac{\partial \rho u_{i}}{\partial t}+\operatorname{div}\left(\rho u_{i} \mathbf{u}\right)=-(\nabla p)_{i}+\operatorname{div}\left(\sigma_{i}\right)+\rho g_{i}
\end{gathered}
$$

Where $\mathbf{u}$ is the velocity vector, $\mathrm{t}$ is time, $\mathrm{p}$ is the total pressure, and $\sigma_{i}$ is the stress tensor. 


\subsubsection{Boundary Conditions}

According to Batchelor (1967), there are, in general, two transitory relations at a material surface interface, that can be either a solid-fluid or a fluid-fluid interface. One is the continuity of an appropriate intensity across the material surface, the other is that the normal component of flux vector is continuous ${ }^{1}$. For the case considered in this study, the fluid momentum is the transportable quantity to be considered. Thus, the associated intensity is the velocity, and the flux vector is the stress tensor.

Therefore, the first transition relation is that the tangential component of the velocity is continuous across a material boundary, separating the fluid and another medium. However, the continuity of velocity is not an exact law, but a statement of what may be expected to happen in normal circumstances ${ }^{2}$. The viscous stress is responsible for the smoothness of the transition on the velocity between the two phases. There are some individual cases in which the viscous stresses are relatively weak, resulting in a steep gradient of velocity that might lead to consider the problem as discontinuous. (BATCHELOR, 1967)

The second transition relation, according to Batchelor (1967, p.568 ), says that "the difference between the values of stress on two surface elements parallel to the boundary and immediately on either side of it is a normal force due wholly to surface-tension(...)". This means that, except for effects of surface-tension, the pressure across the surface should be continuous.

\subsubsection{No-Slip Condition}

The no-slip condition at a fluid-solid interface is a problem present in several hydrodynamic problems. In this condition, following the first transition aforementioned, the tangential and normal velocity across a material surface should be continuous, meaning that the velocity at the solid part of the interface should be kept constant at the fluid portion.

This consideration was a significant source of doubt about whether the molecular interaction at the solid surface conducts the momentum transfer with the same nature as the fluid surface. However, it has been validated empirically, and had been widely accepted by the fluid dynamics community as can be seen in Batchelor (1967). On the other hand, the stresses on a rigid body are, in most of the cases, unknown, and there is

\footnotetext{
${ }^{1}$ With allowance for the effect of surface-tension

${ }^{2}$ Circumstances considered in most practical cases.
} 
no usable boundary condition on the stress continuity available.

\subsubsection{Free-Surface Condition}

Another boundary condition to be considered is relative to a material surface interface between water and air. (BATCHELOR, 1967) proposed two relations considering the viscous term. This case leads to a complex relation, containing the deviatoric stress tensor.

In the water-air interface, the viscosity and density of the air are much smaller than those of a liquid. If we look at the Equation 2.2, the magnitude of the pressure variations in a generic fluid decays with $\rho$ and $\mu$. Thus, the magnitude of velocity and the derivative of velocities on both water and air are comparable. On the other hand, the pressure and the frictional stresses in the air are much smaller than those in the water.

Batchelor (1967) formulate two equations to model the boundary conditions associated with the free-surface. They are given in Equations 2.3 and 2.4, to follow the author nomenclature. The equations are presented in indicial notation.

$$
\begin{gathered}
\frac{1}{2}\left(\frac{\partial u_{i}}{\partial x_{j}}+\frac{\partial u_{j}}{\partial x_{i}}\right) \mathbf{t}_{\mathbf{i}} \mathbf{n}_{\mathbf{j}}=0 \\
p-2 \mu\left(\frac{1}{2}\left(\frac{\partial u_{i}}{\partial x_{j}}+\frac{\partial u_{j}}{\partial x_{i}}\right) \mathbf{n}_{\mathbf{i}} \mathbf{n}_{\mathbf{j}}-\frac{1}{3} \frac{\partial u_{i}}{\partial x_{i}}\right)=p_{a t m}-\gamma\left(\frac{1}{R_{1}}+\frac{1}{R_{2}}\right)
\end{gathered}
$$

Here, $\mathbf{t}_{\mathbf{i}}$ is the unit tangential vector, $\mathbf{n}_{\mathbf{j}}$ the normal unit vector. On the right side of the Equation 2.4, the last term represents the effects of the surface tension, where $R_{1}$ and $R_{2}$ are the radii of curvature of the intercepts of the surface by two orthogonal planes containing the axis $O_{z}$.

Finally, for large-scale problems such as the open-channel case, the free-surface deforms only slightly, and the surface-tension effects are negligible. Therefore, the last term vanishes.

\section{$2.2 \quad$ Flow around Bluff Bodies}

A bluff body is defined by (BEARMAN, 1984) as a body that when placed in a fluid stream generate separated flow over a substantial portion of the surface. On continuous bluff bodies, such as circular cylinders, the separation point depends on the shape of the 
body and the boundary layer state. Figure 2.1 shows the difference between a streamlined body and a bluff body.
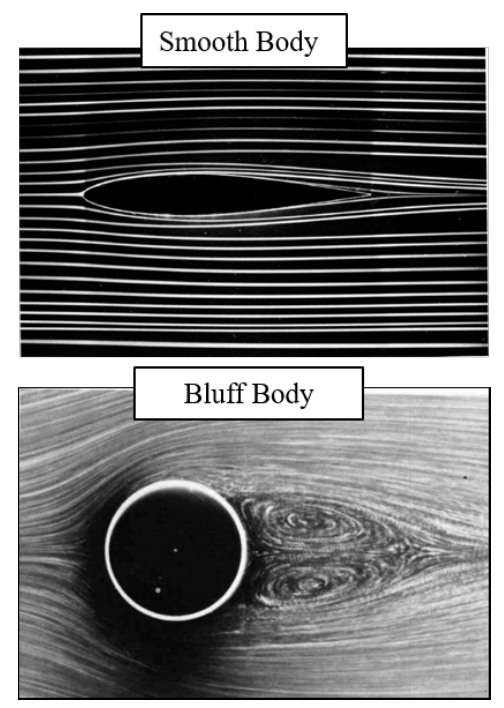

Figure 2.1: Experimental visualization of the flow around a bluff and a smooth body. Source: Adapted from Van Dyke (1982)

Zdravkovich (1997) split the region of the flow around a bluff body into four areas, as shown in Figure 2.2.

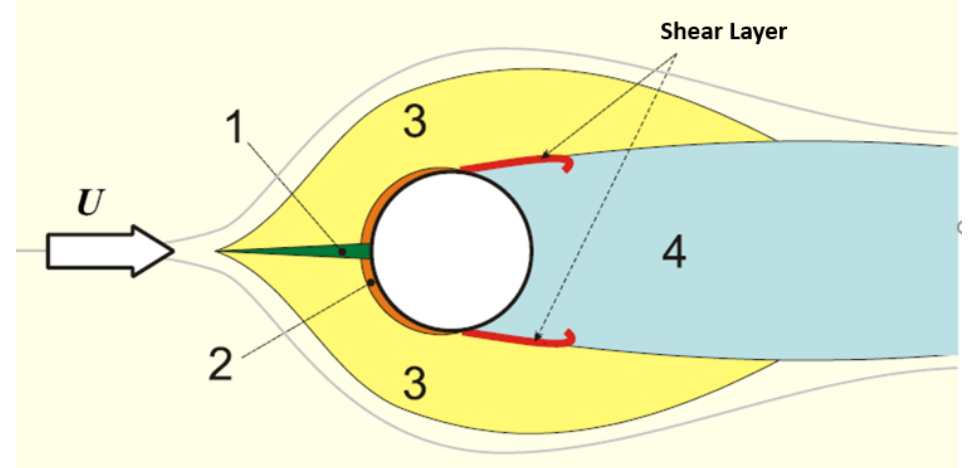

Figure 2.2: Sketch of the regions in a disturbance flow. Source: Adapted from Zdravkovich (1997)

The region 1 is defined by Zdravkovich (1997) as the region where the upstream flow is retarded. The velocity fields into this region present high fluctuations. Zone 2 represents boundary layers attached to the cylinder surface. The cylinder surface is subjected to a favorable pressure gradient which turns into an adverse pressure gradient before separation. The separated boundary layers continue to develop as free shear layers.

The shear layers separate the displaced flow (region 3) from the wake (region 4). Low intensity of pressure characterizes the displaced flow region. Consequently, the velocities 
there are higher than in the free stream. According to Zdravkovich (1997), a wake region is described by large flow structures formed in the near wake and, gradually, decaying along the wake. Its formation and reduction depends on the state of the flow, i.e., laminar, transitional, or turbulent.

Reynolds (1883) experimented the flow within a smooth pipeline and discovered that the transition from laminar to turbulent flow showed dependency with three parameters: fluid density, $\rho$; fluid viscosity, $\mu$; and flow velocity. From the dimensionless analysis, a characteristic length is required for the closure. Rayleigh ${ }^{3}$ considered the length as the diameter, $D$, based in experiments with cylinders and spheres. This correlation represents the ratio between the inertial and viscous forces and is called Reynolds number, Re (Equation 2.5).

$$
R e=\frac{\rho V D}{\mu}
$$

Regarding the importance of parameters on flow around a circular cylinder, Zdravkovich (1997) considers two groups: into governing and influencing ones. Governing parameter is $R e$, as far as an ideal problem is concerned. For practical problems, a wide variety of disturbances can affect the flow. He defined several influencing parameters. One parameter was considered essential to be taken into account by this thesis, the existence of free end.

\subsubsection{Free end}

Taneda (1956) was the pioneer at the study of the finite cylinder experimentally. To visualize the flow, he used aluminum particles which if illuminated make the flow visible. Based on this flow visualizations, he offered a topological interpretation of the flow pattern, Figure 2.3.

\footnotetext{
${ }^{3}$ Information extracted from Zdravkovich (1997)
} 


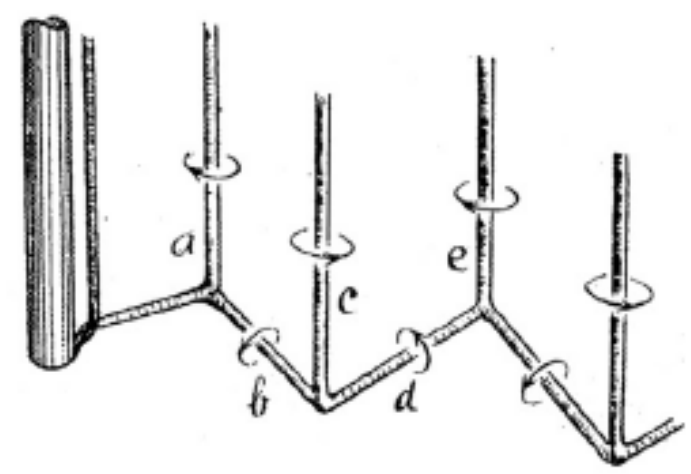

(a)

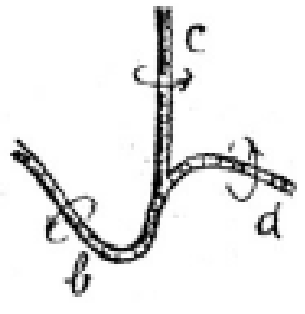

(b)

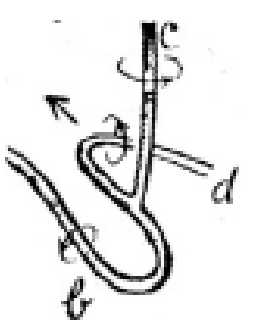

(c)

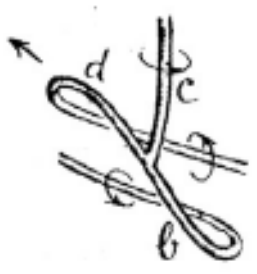

(d)

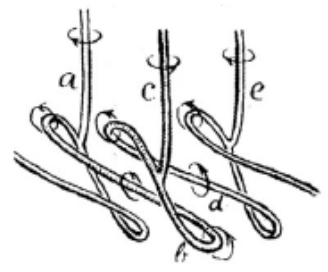

(e)

Figure 2.3: Topology of flow patterns (a) initial; (b to e) temporal developments. Source:Taneda (1956 apud SUMNER, 2013, p.-43).

The parallel eddy filaments $a, c$ and $e$ link behind the free end $b$ and $d$. After linked, the eddy structures induces its own deformation Figure 2.3(b, c and d). The entire cluster $a-e$ is represented in Figure 2.3(e). The eddy linking was seen in the experiments carried out by Slaouti \& Gerrard (1981), with die visualization (Figure 2.4).

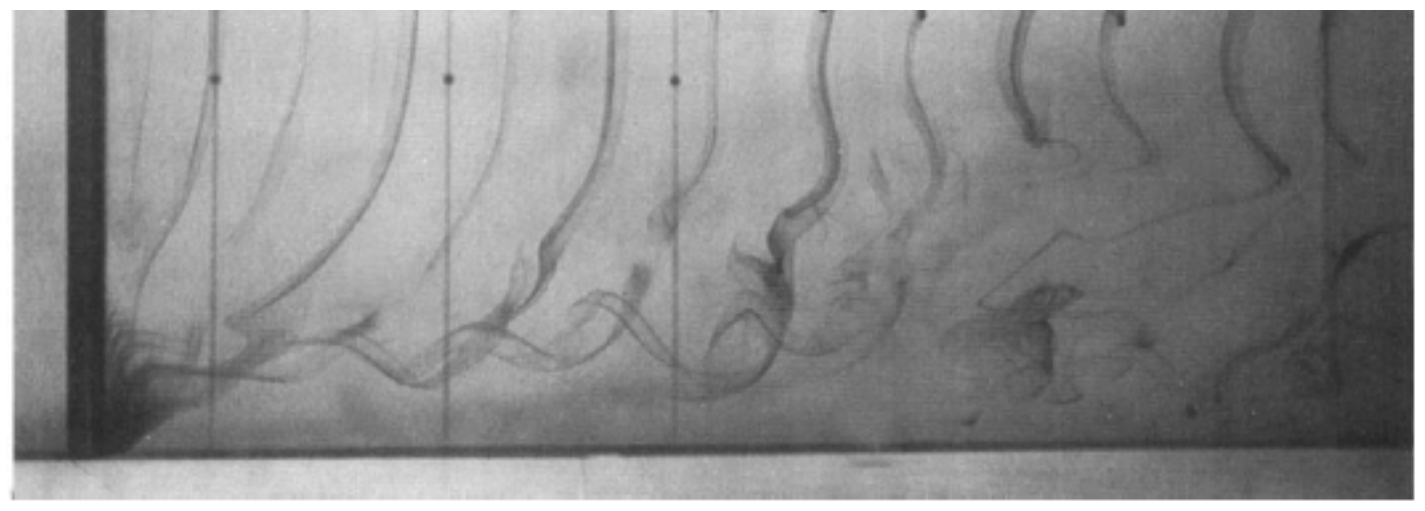

Figure 2.4: Flow visualization of the eddy linking model. Source: (SLAOUTI; GERRARD, 1981)

An essential characteristic of the flow around a two-dimensional cylinder is the presence of high drag forces. The difference of pressures between the free stream and base pressures justify it. These two points are separated physically by material surfaces. In cylinders with a finite length, the physical boundary between the free stream and base 
pressures at the free end surface does not exist and the gradient of pressure is null. Consequently, the difference between the pressure near to the free end and on the downstream wall of the cylinder induces a secondary flow. (ZDRAVKOVICH, 2003).

The secondary flow elongates the eddy formation region and flares the near wake, resulting in a decrease of the Strouhal number. If the secondary flow is very intense, it might displace the start of eddy shedding downstream. If the aspect ratio is too small, the secondary flow becomes the primary flow. 


\section{LITERATURE REVIEW}

The flow around finite cylinders has been among the interests of several research groups for a long time. This section summarizes a literature review of the most relevant investigations in this area. Table 1 lists the main works regarding finite cylinders.

Table 1: List of important references on flow around finite cylinders.

\begin{tabular}{cccccc}
\hline Author & Year & Approach & AR & Cd & Re*10 \\
\hline Okamoto \& Yagita & 1973 & Experimental & 2 & 0.75 & 1.33 \\
Farivar & 1981 & Experimental & 1.98 & 0.57 & 7 \\
Sarode et al. & 1981 & Experimental & 1 to 10 & & \\
Sakamoto \& Oiwake & 1984 & Experimental & 2 & 0.68 & 5.6 \\
Kawamura et al. & 1984 & Experimental & 1 to 8 & & \\
Baban \& So & 1991 & Experimental & $0.5-2$ & & \\
Okamoto \& Sunabashi & 1992 & Experimental & 2 & $\sim 0.75$ & $2.5-4.7$ \\
Luo; Gan \& Chew & 1996 & Experimental & 4 to 8 & & 3.3 \\
Lee & 1997 & Experimental & 1 to 15 & & 0.3 to 1.5 \\
Leder & 2003 & Experimental & 2 & & 20 \\
Roh \& Park & 2003 & Experimental & $1.3 ; 4.3$ & & $0.6 ; 14.8$ \\
Sunmer et al. & 2004 & Experimental & 3 to 9 & & 6 \\
Frohlich \& Rodi & 2004 & Numerical & 2.5 & & 4.3 \\
Pattenden et al. & 2005 & Experimental & 1 & & 20 \\
Pattenden et al. & 2006 & Numerical & 1 & & 20 \\
Palau-Slavador et al. & 2010 & Numerical/Experimental & $2.5 ; 5$ & & $4.3 ; 2.2$ \\
Iungo, Pii \& Buresti & 2012 & Experimental & 3 & 0.73 & 5 \\
Rosetti et al. & 2013 & Numerical & 2 & 0.821 & \\
Gonçalves et al. & 2014 & Experimental & 2 & 1.02 & 4.3 \\
Benitz et al. & 2016 & Numerical/Experimental & 2 & 0.7 & 0.29 \\
\hline
\end{tabular}

Source: Author

\subsection{Experimental Background}

Okamoto \& Yagita (1973) tested in a wind tunnel the flow around a low aspect-ratio cylinder placed on a flat plate. The aspect-ratio range from 1 to 12.5 and the Reynolds 
number was $1.33 * 10^{4}$. The flat plate boundary layer influence and the three-dimensional structures due to the free end were investigated. It was figured out that the separation point moves forward with the decreasing of $L / D$. For the Re investigated, the drag coefficient showed a significant increase on the cylinders with $L / D=6$ and 7 . The free end secondary flow from the free end starts showing more substantial influence on the drag forces at this step of ratios, suppressing the shedding frequency. Therefore, the Strouhal number diminishes with $L / D$.

Farivar (1981) carried out similar experiments, suggesting that the free end effects are restricted only to the near free end region. The hypothesis was based on integrating the measuring of the pressures fluctuation at the cylinder surface. Sarode et al. (1981) evaluated the flow over a finite cylinder placed on a flat plate for $L / D$ ranging from 1 to 10. He showed that the mean drag forces increase as the cylinder becomes slender, proving what Okamoto \& Yagita (1973) and Farivar (1981) concluded on the free end effects.

Kawamura et al. (1984) experimented the same case and measured the pressure on the surface and performed flow visualization. The $L / D$ was varied from 1 to 8 , and the Re was of order of $10^{4}$. A new pair of trailing vortices was discovered arising from the side wall near the free end region. This pair of vortices adds itself to the secondary flow from the tip surface. A critical aspect-ratio, $L / D_{\text {crit }}$, was proposed, below which the free end effects start suppressing the alternation of the vortex detachment. Figure 3.1 shows a sketch of the flow around a cylinder for $L / D$ larger and smaller than $L / D_{\text {crit }}$. Furthermore, it was discovered that the drag coefficient has a length dependence, caused mainly by an increase of the separation angle at the side wall flow, close to the free end. 

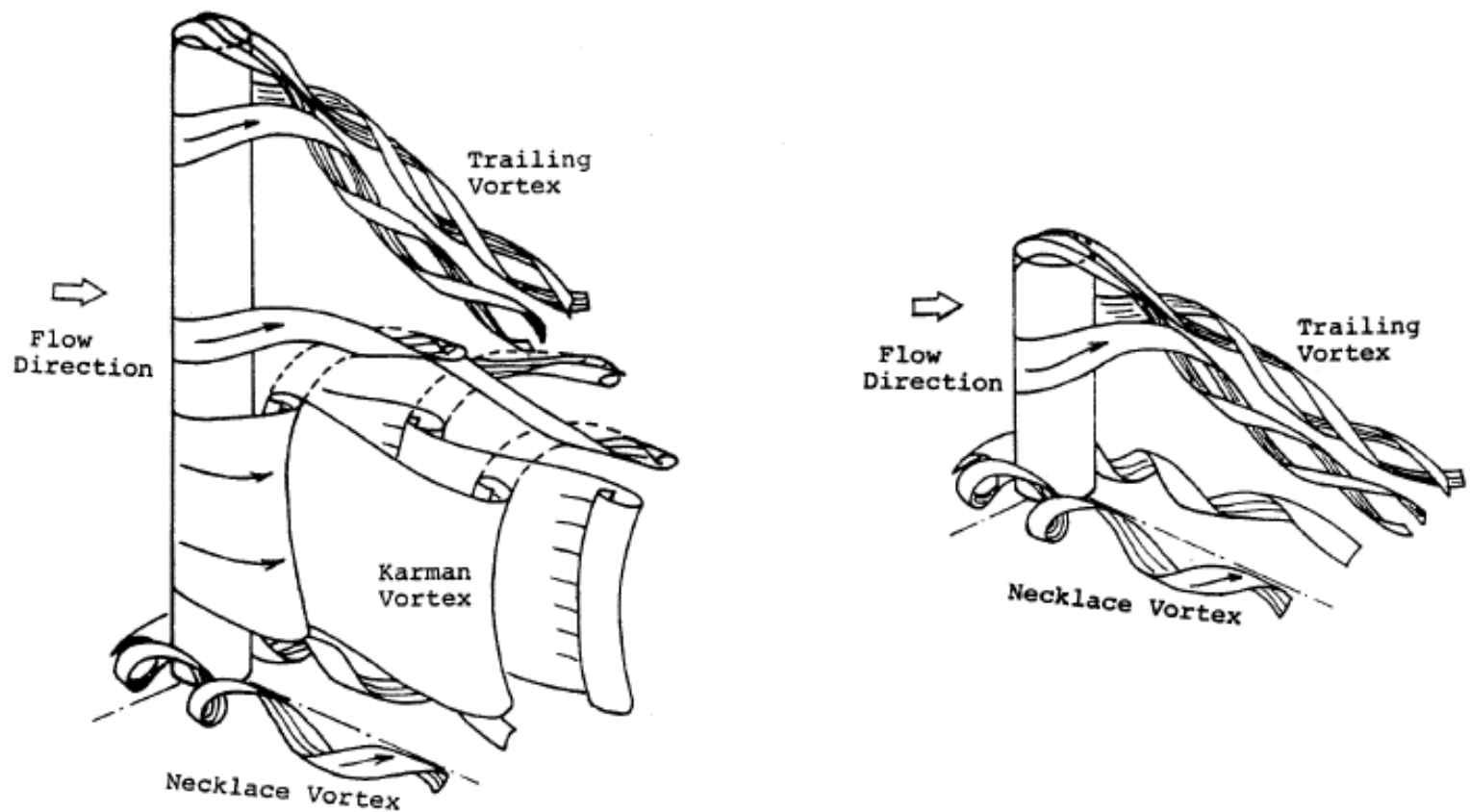

Figure 3.1: Schematic model of the flow around finite cylinders. Source: Kawamura et al. (1984)

Baban, So \& Ötügen (1989) correlated the flow-induced forces with the velocity fluctuations in the downstream region of finite cylinders $(L / D=2$ and 3$)$. The experiments showed that the lift fluctuation decreases towards the free end, indicating that the free end separated flow suppressed the alternating shedding. On the other hand, the drag fluctuation increases when the span approaches the free end. Okamoto \& Sunabashiri (1992) tested a broad range of aspect-ratios, from 0.5 to 23.75 and also concluded that the drag coefficient decreases with the aspect-ratio and the vortex pattern starts to be symmetrical for cylinders with $L / D$ crit $=2$.

Leder et al. (2003) showed flow visualizations captured by a Laser Doppler Anemometer (LDA) system. A complex three-dimensional fluid motion was identified in the regions of separated flow for a cylinder with $L / D=2$ for $\operatorname{Re} 2 \times 10^{5}$. Two separate flow regions were detected: one small separation recirculating bubble on the free end surface; and a sizable separated flow downstream the model (Figure 3.2). 


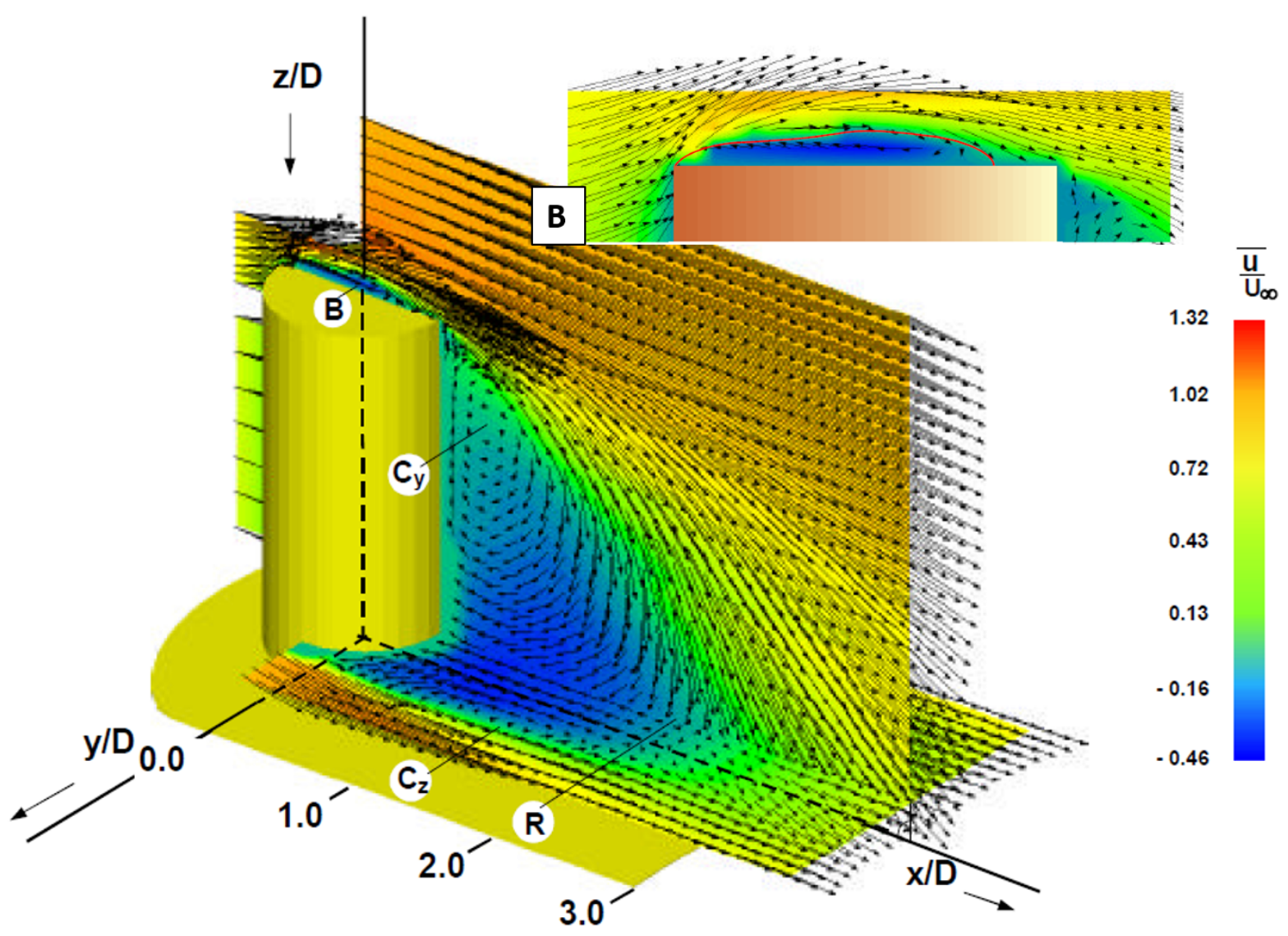

Figure 3.2: Time averaged velocity field three-dimensional visualization with the free end region in the vicinity. Source:Adapted from Leder et al. (2003)

\subsection{Previous Numerical Simulations}

Fröhlich \& Rodi (2004) carried out a numerical investigation on the flow around finite cylinders using two models of Large Eddy Simulation, LES: a Smagorinsky model; and a dynamic Smagorinsky model. The velocity was set up to a sub-critical regime of turbulence $(R e=43,000)$ and $L / D=2.5$. They studied the influence of a set of two grids, finding out that the coarser grid $\left(10^{6}\right.$ cells $)$ showed insufficient resolution. The finer grid, $6 \times 10^{6}$ cells, brought reasonable results with the Smagorinsky model. The drag fluctuation on the model downstream agreed with what was found out by Baban, So \& Ötügen (1989); low fluctuations close the symmetry plane and high at the free end.

Pattenden et al. (2007) proposed a numerical investigation of unsteady flow using LES and DES turbulence models for $R e=200,000$ and $L / D=1$. They modeled the turbulence with both LES and DES turbulence models. A comparison of the results was performed with experimental particle image velocimetry, PIV, measurements, Pattenden, Turnock \& Zhang (2005). In the LES case, due to the high Reynolds number, the grid 
resolution was not high enough to capture the 3D structures. Nonetheless, turbulence model showed an improvement in the results with less computation resources; even so, the simulation still requiring finer grids.

Palau-Salvador et al. (2010) evaluated numerically and experimentally the study of surface-mounted finite cylinder, for $L / D=2.5$ and 5 , and $\operatorname{Re}=43,000$ and 22,000, respectively. Flow fields were measured with Doppler velocimeters and visualized with dyeing techniques. LES with Immersed Boundary Method, IBM, modeled the numerical approach. Differently from Pattenden et al. (2007) and Fröhlich \& Rodi (2004), the simulations were performed with considerably more cells $\left(45 \times 10^{6}\right.$ cells $)$, with more refined clustering around the free end and ground region. The maximum Courant number was 0.83, which means that the time discretization was sufficient for such fine grid. Flow fields visualization, 3d-structures and limiting streamlines at the free end surface formed the presented results.

Rosetti et al. (2013) evaluated a numerical/experimental study which most agreed with the present study. The study addressed an investigation on the flow around a freesurface piercing finite cylinder with $L / D=2$ and $\operatorname{Re}=43,000$. The experiments were carried out on a recirculating channel. A load cell and PIV were used as measuring systems. A numerical investigation was performed using unsteady Reynolds averaged Navier-Stokes (URANS) calculations modeling the turbulence with a $k \omega-S S T$ model. Verification procedures were performed to evaluate the reliability of the results using three grids, with sizes up to $7.5 \times 10^{6}$ cells.

Furthermore, a comparison between the numerical results and experiments (Validation) was done. The work aimed to evaluate the free end and free surface effects on the separated flow. For the free surface modeling, a two-phase interface capture method was applied. Three different setups were tested: first, an infinite cylinder piercing the free surface, to investigate the effects of the free surface without the free end influence; followed by a finite cylinder with a symmetry boundary condition at the top; finally, a free surface piercing finite height cylinder.

Recently, Benitz et al. (2016) proposed a numerical investigation of the free surface effects and aspect ratio influence on the finite cylinder. The modeling of the turbulence was done with the one-equation turbulence model Spalart-Allmaras and the free surface with a volume of fluid method. The aspect ratio ranged from 1 to 19 having the drag and lift forces monitored. The vortex shedding was suppressed completely for cylinders with $L / D_{\text {crit }}$ below than three. Furthermore, the drag coefficient decreased significantly 
in cylinders with $L / D=2$, due to the high influence of the free surface on the separated flow.

\subsection{Experimental Data for Comparison}

Finally, a detailed review of the experimental investigation proposed by Gonçalves et al. (2015) is presented, to show an overview of the data used to compare with numerical results.

Gonçalves et al. (2015) conducted a comprehensive experimental study regarding the flow around a fixed cylinder piercing the free-surface, varying the aspect ratios. The experiments were carried out in a recirculating water channel, NDF - Nucleus of Dynamics and Fluids - facilities, at the University of São Paulo. The dimensions of the test section are $7500 \times 700 \times 700 \mathrm{~mm}^{3}$. The free-stream velocity can reach $0.4 \mathrm{~m} / \mathrm{s}$ and the turbulence intensity reaches a maximum of $2 \%$. Assi (2005) presented a study of the developed boundary layer of the tank, showing that its influence on the present study is not significant and may be neglected.

The model with diameter $D=125 \mathrm{~mm}$ was built with PVC - polyvinyl chloride and placed at the center line of the channel. A six degree of freedom load cell ATI, Mini40 model, measured the forces. The uncertainty of the measured forces is $1 / 200 N$, and the total forces range between $1 / 125 N$ and $2.5 N$. Each test run lasted for $180 \mathrm{~s}$ with a sampling frequency of $100 \mathrm{~Hz}$ and the load cell positioned at the top of the cylinder as in Figure 3.3.

Gonçalves et al. (2015) evaluated 8 different cylinders with aspect-ratio , $L / D=$ $0.1,0.2,0.3,0.5,0.75,1,1.5$ e 2 . The forces were measured projected onto cross-flow and in-line directions and over several velocities, corresponding to a Re between 10,000 and 50,000. Flow fields were monitored just for the cases with aspect ratio $L / D=0.3,0.5,1$ and 2 with a PIV system. Drag, lift, and Strouhal number as integral results, such as time averages, root mean square $(r m s)$, and power spectrum density (PSD) analysis, are presented. The flow fields of the cases are presented for velocities, vorticity, and its fluctuations. Average of the drag forces of each case and velocity were plotted on the same graph to show the influence of both Re and $L / D$ (Figure 3.4). 
(a)
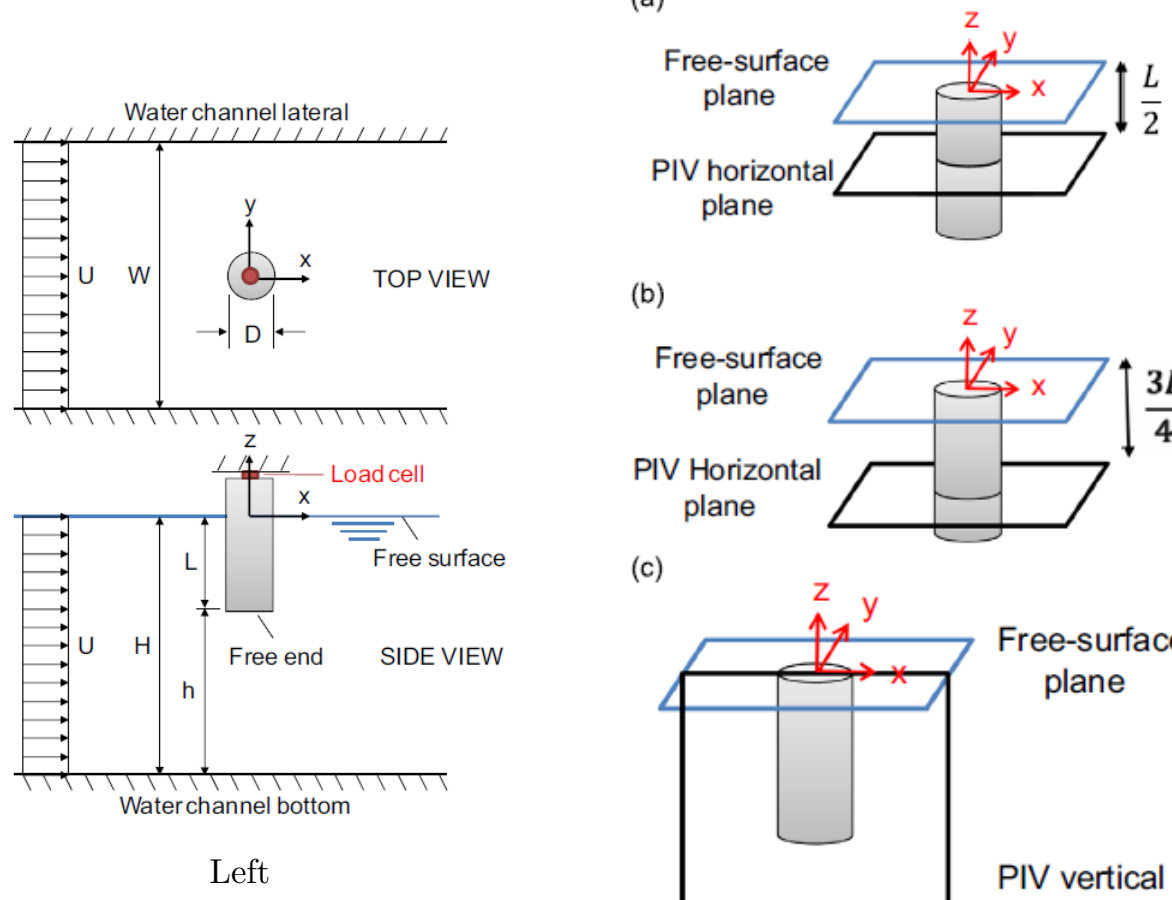

(b)

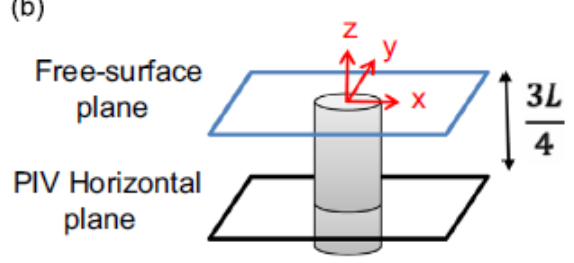

(c)

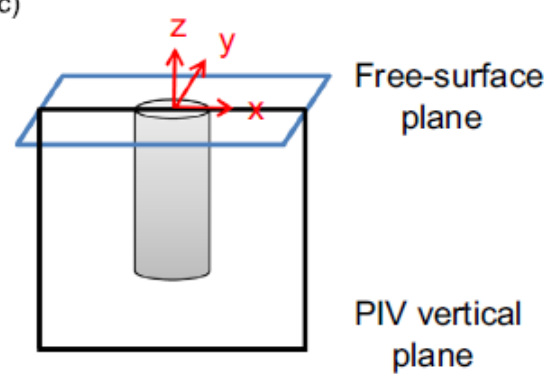

Right

Figure 3.3: Left: Experimental Setup.; Right: PIV measured plane positions (a) horizontal mid-span plane at $\mathrm{z} / \mathrm{L}=-0.5$, (b) horizontal plane near the cylinder free end at $\mathrm{z} / \mathrm{L}=-0.75$ and (c) vertical plane at $\mathrm{y} / \mathrm{D}=0$. Source: Gonçalves et al. (2015)

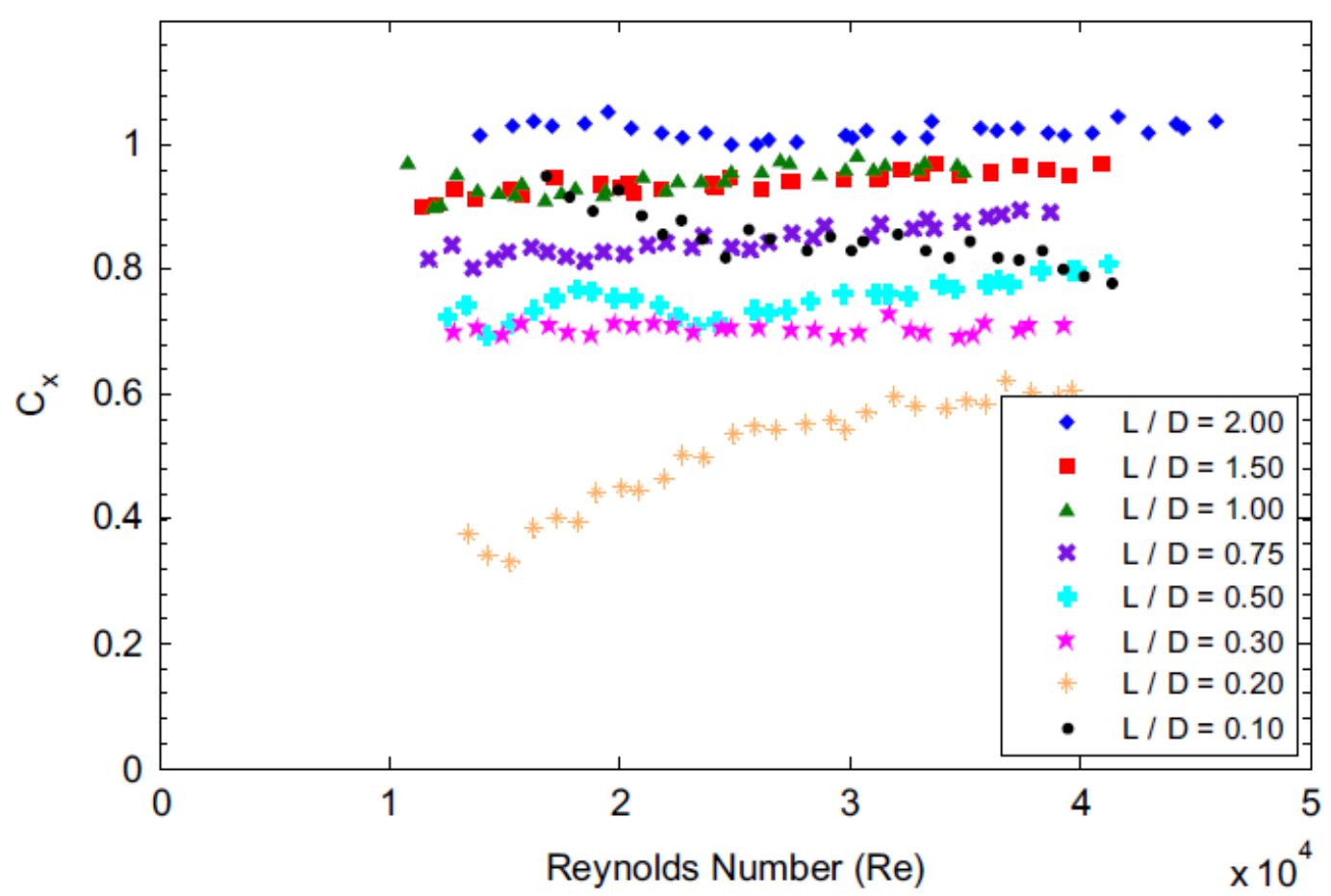

Figure 3.4: Cx values in function of Reynolds number for each cylinder aspect ratio. Source: Gonçalves et al. (2015) 
In the experimental range, no significant influence of Re on the drag forces results were observed, except for $L / D \leq 0.2$. The aspect ratio, however, had a marked influence on the results. The drag forces decreased as a function of the aspect ratio. However, $L / D=0.1$ presented higher drag than aspect ratios $0.2,0.3$ and 0.5 . The $L / D$ is small, the force in the in-line direction is dominated by free surface effects.

Averages of the rms of the lift forces for each velocity were plotted as a function of the aspect ratio, with the standard deviation bars. Figure 3.5 shows the data from Gonçalves et al. (2015).

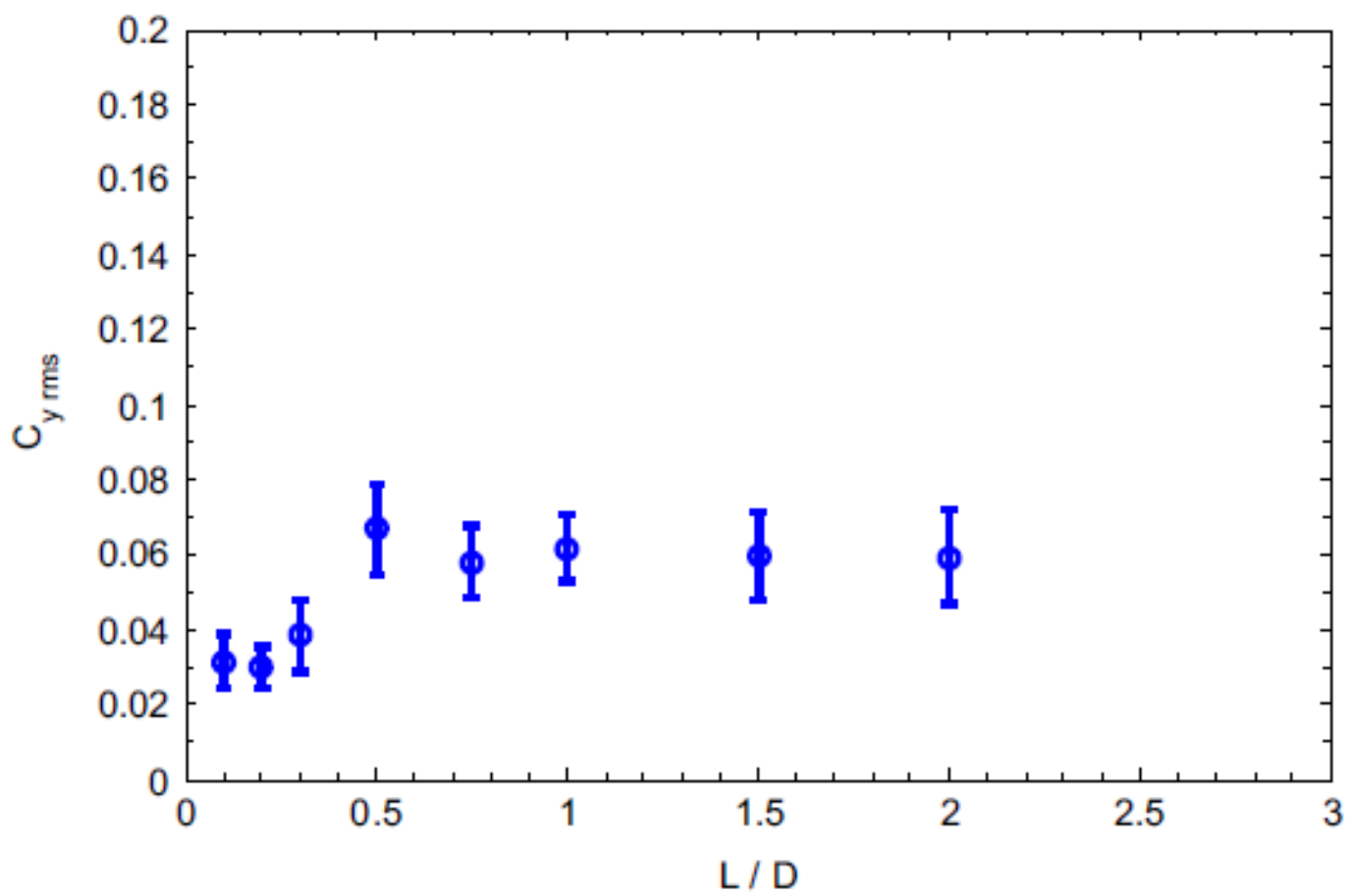

Figure 3.5: Averaged $C y \mathrm{rms}$ values and respective standard deviation for Re ranging between 10,000 and 50,000 as function of cylinder aspect ratio. Source: Gonçalves et al. (2015)

The three smaller cylinders showed different behavior. In these cases, the fluctuation of the lift forces is very low, indicating a not so well defined vortex shedding. Strouhal number against the aspect ratio were also plotted, Figure 3.6, showing a transition between $L / D=0.75$ and 0.5 . 


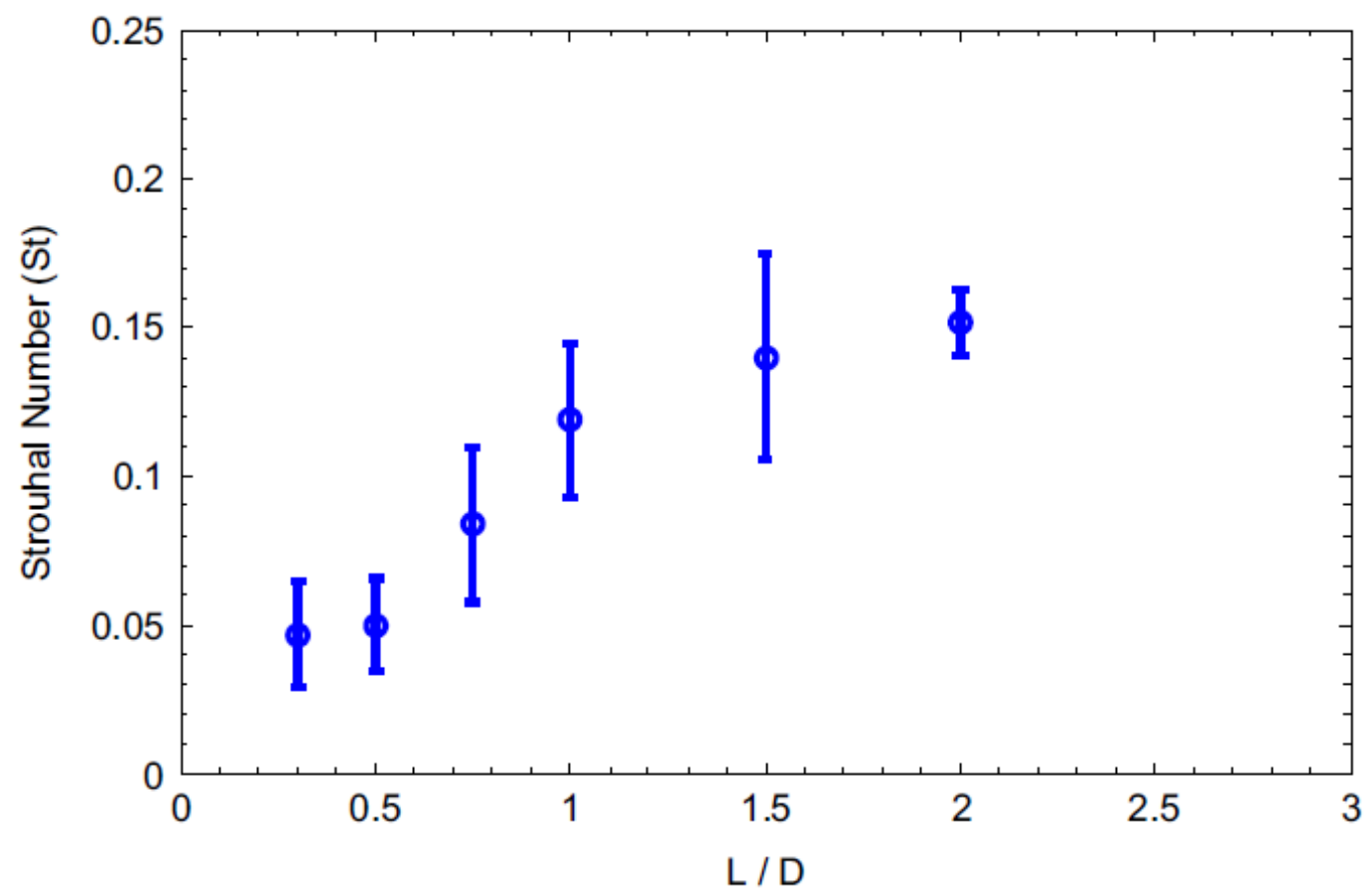

Figure 3.6: Averaged St values and respective standard deviation for Re ranging between 10,000 and 50,000 in function of cylinder aspect ratio. Source: Gonçalves et al. (2015)

Gonçalves et al. (2015) defined a new $L / D_{\text {crit }}=1$, different from that proposed by Kawamura et al. (1984), and smaller than the one presented in Benitz et al. (2016). 


\section{NUMERICAL METHODS}

\section{$4.1 \quad$ (U)RANS Solver ReFRESCO}

ReFRESCO (www.refresco.org) is a community-based open-usage/open-source CFD code for the Maritime World. It solves multi-phase (unsteady) incompressible viscous flows using the Navier-Stokes equations, complemented with turbulence models and volumefraction transport equations for different phases; Vaz, Jaouen \& Hoekstra (2009). The equations are discretized using a finite-volume approach with cell-centered collocated variables, in strong-conservation form, and a pressure-correction equation based on the SIMPLE algorithm is used to ensure mass conservation; Klaij \& Vuik (2013). Time integration is performed implicitly with first or second-order backward schemes. At each implicit timestep, the non-linear system for velocity and pressure is linearised with Picard's method and either a segregated or coupled approach is used; Klaij \& Vuik (2013).

The implementation is face-based, which permits grids with elements consisting of an arbitrary number of faces (hexahedral, tetrahedral, prisms, pyramids, etc.), and if needed h-refinement (hanging nodes). State-of-the-art CFD features such as moving, sliding and deforming grids, as well automatic grid adaptation (refinement and/or coarsening) are also available. Coupling with rigid-body (rigid-body 6DOF) and flexible-body structural equations-of-motions (FSI, or Fluid-Structure-Interaction) is also possible. For turbulence modeling, both RANS/URANS and Scale-Resolving Simulations (SRS) models such as SAS, DDES/IDDES, XLES, PANS, and LES approaches can be used. The code is parallelized using MPI and subdomain decomposition and runs on Linux workstations and HPC clusters.

$\operatorname{REFRESCO}(v 2.4 .0)$ is currently being developed, verified and its several applications validated at MARIN (in the Netherlands) in collaboration with IST (in Portugal), Pereira (2018); USP-TPN (University of São Paulo, Brasil), Rosetti, Vaz \& Fujarra (2012); TUDelft (Technical University of Delft, the Netherlands), Klaij \& Vuik (2013); UoS (University of Southampton, UK), Hawkes et al. (2014); UTwente (University of Twente, the 
Netherlands), Jongsma, Weide \& Windt (2016); Chalmers (Chalmers University, Sweden), Gharraee et al. (2015); UMaine (University of Maine, USA), Mcelman \& Goupee (2016); Texas A\&M (Texas A\&M University, USA), Mcelman \& Goupee (2016); UPB (Universidad Pontificia Bolivariana, Colombia), Ramírez-Macías et al. (2016); UDE (University of Duisburg-Essen, Germany), Burmester et al. (2017); and WUR (Wageningen University and Research, the Netherlands).

\subsection{Turbulence Approach}

A flow involved in any practical application will likely involve turbulence. A turbulent flow is characterized by a wide range of temporal and spatial scales with which interaction is highly non-linear. The boundary conditions determine the large scales of turbulence and contain most of the kinetic energy. The small turbulent structures are responsible for dissipating energy and exhibit an isotropic behavior. According to Pereira (2018), Taylor and Von Karman (1937 apud WILCOX, 1993, p.21-22) defined turbulence as "(..) an irregular motion which in general makes its appearance in fluids, gaseous or liquid when they flow past solid surfaces or even when neighboring streams of the same fluid flow past or over one another".

This Section briefly presents a description of methods used to deal with the turbulence issue numerically.

\subsubsection{Background: DNS, LES and RANS}

Direct Numerical Simulation, DNS, is a method of numerical solution of the NavierStokes equations without any turbulence modeling. This solving requires a grid element size smaller than the length scale to be resolved. This approach is not practical ${ }^{1}$ in most of the engineering cases, due to the high turbulence levels and complex geometries.

Nonetheless, Large Eddy Simulations, LES, proposed by Smagorinsky (1963), is a mathematical model that solves the Navier-Stokes equations following the same approach as in DNS. However, the small ${ }^{2}$ length scales are filtered out with a low-pass filter. For some applications, the neglect of such scales imply in a considerable modeling error. Thus, the method proposes to represent the smaller scales through a statistical relation. Though LES methods save considerable computational time when compared with DNS, their

\footnotetext{
${ }^{1}$ Due to the computational capacity available nowadays.

2 Smaller than the element size.
} 
application is still extensively demanding for most of the practical engineering problems.

As an alternative to solving the small scales of turbulence, the Reynolds-Average Navier-Stokes method, RANS, was first proposed by Reynolds (1895). This mathematical model treats the turbulence with an entirely statistical description, in which all quantities are expressed as the sum of the mean and fluctuating parts. The approach reduces the computational cost considerably, being the most often used method to model practical problems (WILCOX, 1993).

\subsubsection{Explicit Algebraic Reynolds Stress Model}

The Explicit Algebraic Reynolds Stress Model, EARSM was proposed by Hellsten (2004). The model is a modified version of the baseline $k-\omega$ turbulence model, proposed by Menter (1994). This turbulence model suggests a change in the linear Boussinesq ${ }^{3}$ hypothesis, modeling a constitutive relation between the Reynolds stress tensor, meanvelocity gradient and turbulent length scales, resulting an anisotropic term, $a_{i j}^{e x} \rho k$, on the Reynolds Stress Tensor (Equation 4.1).

$$
\tau_{i j}^{\prime}=-\rho \overline{u_{i}^{\prime} u_{j}^{\prime}}=\mu_{t}\left(2 S_{i j}-\frac{2}{3} \delta_{i j} \frac{\partial U_{k}}{\partial x_{k}}\right)-\frac{2}{3} \delta_{i j} p k-a_{i j}^{e x} \rho k
$$

$\tau_{i j}^{\prime}=-\rho \overline{u_{i}^{\prime} u_{j}^{\prime}}$ is the Reynolds Stress Tensor, which is a second-order symmetric tensor, (ROSETTI et al., 2013). $\mu_{t}$ is the eddy viscosity and $k$ is the turbulent kinetic energy.

The anisotropic term improves the modeling of the rotational fields, if compared with classic turbulence models such as $k-\omega$ or $k-\epsilon$. Thus, the model is a better approach to capture the three-dimensional structures of the flow with a considerably lower computational demand.

\subsubsection{Improved Delayed Detached Eddy Simulation - IDDES}

The IDDES, proposed by Gritskevich et al. (2012), was presented as an improvement of the DDES. The main idea of the DES-type turbulence models is to switch between RANS and LES model formulations based on the local grid spacing and turbulent scale. This turbulence model is part of a new class, the so-called hybrid models. The goal of this class is to combine the virtues of RANS with those of LES in a zonal manner, (PEREIRA, 2018). It is a combination of a $k \omega-S S T$ RANS turbulence model in the boundary layer

\footnotetext{
${ }^{3}$ A detailed review of the Boussinesq's turbulent viscosity hypothesis is presented by Schmitt (2007)
} 
region and a LES model further away from the cylinder.

\subsection{Vortex Identification Method: $Q_{\text {criterium }}$}

The vortex identification method $Q_{\text {criterium }}$ is a method based on the velocity gradient tensor, $\bar{D}$ that can be written in indicial notation given by Equation 4.2.

$$
D_{i j}=\frac{\partial u_{i}}{\partial x_{j}}
$$

This is a second order tensor, and can be decomposed into a symmetric and a skewsymmetric part, $D_{i j}=S_{i j}+\Omega_{i j}$ where $S_{i j}=\frac{1}{2}\left(\frac{\partial u_{i}}{\partial x_{j}}+\frac{\partial u_{j}}{\partial x_{i}}\right)$, and $\Omega_{i j}=\frac{1}{2}\left(\frac{\partial u_{i}}{\partial x_{j}}-\frac{\partial u_{j}}{\partial x_{i}}\right)$. $S_{i j}$ is known as the rate-of-strain tensor and $\Omega_{i j}$ is the vorticity tensor.

The Characteristic equation for $\nabla u$ is given by Equation 4.3.

$$
\lambda^{3}+P \lambda^{2}+Q \lambda+R=0
$$

where $\mathrm{P}, \mathrm{Q}$, and $\mathrm{R}$ are the three invariant of the velocity gradient tensor. These invariant can be written as given by Equations 4.44 .5 , and 4.6 by using the decomposition into symmetric and anti-symmetric parts.

$$
\begin{gathered}
P=\bar{D}^{T} \\
Q=\frac{1}{2}\left\|\Omega_{i j}\right\|^{2}-\left\|S_{i j}\right\|^{2} \\
R=-\operatorname{det}(\bar{D})
\end{gathered}
$$

Following the review performed by Holmén (2012), "the $Q_{\text {criterium }}$ defines a vortex as a connected fluid region with a positive second invariant of $\nabla u^{\prime \prime}$, i.e $Q>0$ ".

If we look at the second invariant Q definition, Q represents the local balance between shear-strain-rate and vorticity magnitude. Thus "vortices are areas where the vorticity magnitude is greater than the magnitude of rate-of-strain", (HOLMÉN, 2012, p 13). 


\subsection{Volume of Fluid (VOF)}

In the early 80s, Hirt \& Nichols (1981) introduced the concept of Volume of Fluid, VoF, as a method to solve the free boundaries in an Eulerian approach. The motivation of the study was that for problems where the free boundaries suffer a large deformation, such as free surfaces, material interfaces, shock waves, or interfaces between a fluid and deformable structures, a Lagrangian approach cannot be used.

The authors define free boundaries as "surfaces on which discontinuity exist in one or more variables" (HIRT; NICHOLS, 1981, p 201). There are three problems associated with discontinuities in numerical modeling: their discrete representation; the time evolution; and the manner in which the boundaries conditions are imposed.

The development of the method accelerated with the introduction of the finite-volume method for unstructured grids. The interface-capturing and interface-tracking schemes were proposed following this method, by discretizing the advective terms of the equations, (TEZDUYAR, 2004). Interface-tracking techniques require that only one phase is modeled on each mesh and that the interface is updated as the flow evolves, by deforming the meshes. In the interface-capturing method the two phases are marked by a scalar, and the interface is marked as a certain location where this scalar has a given value. The method available in ReFRESCO is the interface-capturing method using the volume fraction as the marked parameter. The method is called Volume of Fluid, VoF.

\subsubsection{VoF method}

The baseline model method consists in modeling the governing equations on the continuum level, as seen in Klaij, Hoekstra \& Vaz (2018). Afterward, the method presents some variations of the baseline model to deal with more complex problems.

The flow should be considered a multi-fluid flow, by adopting a single continuum fluids with velocity, $\boldsymbol{u}$, pressure, p, density, $\rho$, and viscosity, $\mu$, which can vary in space and time. For a free surface case, the two fluids considered are water and air. The density and viscosity are given as a linear combination, showed in Equations 4.7 and 4.8

$$
\begin{gathered}
\rho=\rho_{\text {air }} c_{\text {air }}+\rho_{\text {water }} c_{\text {water }} \\
\mu=\mu_{\text {air }} c_{\text {air }}+\mu_{\text {water }} c_{\text {water }}
\end{gathered}
$$


The volume fraction $c_{i}$ is the ratio between the volume $V_{i}$ occupied by the phase $\mathrm{i}$ and the total control volume (Equation 4.9).

$$
c_{i}=\frac{V_{i}}{\sum_{i=1}^{n} V_{i}}
$$

"Notice that the volume fraction is a dimensionless variable bounded by zero (no phase i) and unity (only phase i) changing discontinuously from one media to another due to their immiscibility." (KLAIJ; HOEKSTRA; VAZ, 2018, p. 325). The sum of the $c_{i}$ for all the phases should be one.

The volume fraction $c_{i}$ of each material particle is kept constant, i. e., $c_{i}$ moves with the fluid and is modeled as a material derivative (Equation 4.10).

$$
\frac{D c_{i}}{D t}=0 \leftrightarrow \frac{\partial c_{i}}{\partial t}+\mathbf{v} \cdot \nabla c_{i}=0
$$

The model is completed by conservation of mass, Equation 4.11, and the conservation of momentum, Equation 4.12.

$$
\begin{gathered}
\frac{\partial \rho}{\partial t}+\operatorname{div}\left(\rho u_{i} \mathbf{u}\right)=0 \\
\frac{\partial \rho u_{i}}{\partial t}+\operatorname{div}\left(\rho u_{i} \mathbf{u}\right)=-(\nabla p)_{i}+\operatorname{div}\left(\sigma_{i}\right)+\rho g_{i}
\end{gathered}
$$

In the equations above, $u_{i}$ denotes the $\mathrm{i}$-th component of $\mathbf{v}$ and $\sigma$ is the viscous part of the stress tensor. The only body force considered is due to the gravitational acceleration vector g. A very detailed description of the VoF method is shown in Klaij, Hoekstra \& Vaz (2018).

\subsection{Verification and Validation}

Investigation of the numerical uncertainties of CFD results is required to assess the reliability of the results. These uncertainties are estimated by a verification procedure and validated with a comparison between numerical models and experiments. Roache (1998) defined verification as "Verification is a purely mathematical exercise that intends to show that we are solving the equations right" and Validation as "(..)a science/engineering activity that intends to show that we are solving the right equations". Another important 
definition is the difference between error and uncertainty. Eça \& Hoekstra (2014) define error and uncertainty as "an error requires the knowledge of the truth/exact solution and has a sign" and "an uncertainty defines an interval that should contain the truth/exact solution with a certain degree of confidence and is defined with a plus-minus sign."

Verification procedures are divided into two parts: code verification and verification of calculations. The goal of the code verification is to verify if the code solves the equations correctly by error evaluations, based on a well-known problem. On the other hand, verification of the results aims to estimate the error of the numerical solution, in the absence of a known exact solution, through mathematical modeling.

Verification of the solutions is a mathematical procedure to estimate the numerical uncertainties. According to Eça \& Hoekstra (2009), there are three types of numerical errors: round-off error, which is consequence of the finite precision of the machines; iterative errors, related with the residuals of the iterative solving of non-linear terms; and the discretization error associated with simplifications on the spatial and temporal discretization ${ }^{4}$.

\subsubsection{Round-off errors}

Round-off error is a consequence of the finite precision with which the computers operate arithmetic calculations. This error becomes more significant with grid refinement. For the cases evaluated in the present investigation, double precision of the arithmetic calculations is assumed to be small enough, such that this error may be seen as negligible.

\subsubsection{Iterative errors}

Iterative errors are related to the iterative solving of the non-linear terms in the Navier-Stokes equations. According to Eça \& Hoekstra (2009), the primary sources of this error are convective terms, which takes, usually, procedures such as Picard or Newton methods; the deferred corrections of the discretization schemes on the continuity and momentum equations; velocity derivatives of the convective terms; and turbulence models. The procedure to avoid this error is to reduce it to the same level of the machine precision. However, this procedure may not be possible for complex physical problems, such as threedimensional, multi-phase and turbulent flows, for instance. This error could be estimated by the infinity norm, which calculates the iterative error as the maximum error for a

\footnotetext{
${ }^{4}$ Usually the major contributor to the numerical errors
} 
specific quantity in the entire domain (Equation 4.13),

$$
L_{\infty}(\Delta \phi)=\max \left(\left|\phi^{n}-\phi^{n-1}\right|\right), \quad 1 \leq i \leq N_{p}
$$

or by the root mean square, rms, normalization of the whole domain (Equation 4.14) of the residuals.

$$
L_{r m s}=\sqrt{\frac{\sum_{i=1}^{N_{p}}\left(\phi^{n}-\phi^{n-1}\right)^{2}}{N_{p}}}
$$

$N_{p}$ is the total numbers of elements on the grid, $\Delta \phi$ is the local change of the flow quantity $\phi$.

Either the infinity or rms norm could result in poor estimation of the iterative error estimation. Nevertheless, iterative errors are orders of magnitude smaller than the discretization error, thus, negligible (ROSETTI, 2015). To ensure that the residuals are controlled and do not influence the results, an iterative convergence analysis was proposed. Integral results such as the average of drag and rms of lift forces should converge asymptotically as the convergence becomes less relaxed.

\subsubsection{Discretization errors}

The discretization error is the major contributor to the numerical uncertainty. It is a consequence of the approximations to transform the partial differential equations of the continuum formulation into a system of algebraic equations, such as in finite-volume, finite-difference or finite-element methods, for instance. According to Pereira (2018), discretization uncertainty can be quantified in two different main strategies: a spatial and temporal discretization, which needs at least five solutions (varying grids and time-steps) or a calculation of the error directly from the transport equation.

The discretization analysis performed here is going to be based on the first approach, following procedures proposed by Eça \& Hoekstra (2014). For unsteady problems, the error estimation is based on Richardson Extrapolation, given by Equation 4.15.

$$
\delta_{R E}=\phi_{i}-\phi_{0}=\alpha_{x} h_{i}^{p}+\alpha_{t} t_{i}^{q}
$$

In this equation, $h_{i}$ is the typical cell size, $t_{i}$ is the time-step of the calculations, $p$ and $q$ are the observed order of accuracy of space and time discretization, respectively. 
$\alpha_{x}$ and $\alpha_{t}$ are constants of the expansion and $\phi_{0}$ is the estimated exact solution. To solve this system of equations, at least five unknowns should be calculated, which require at least five data points, with varying time-step and grid size.

Is necessary to assume two conditions to apply the procedure: iterative and roundoff errors are negligible compared to the discretization error; and the data should show monotonic convergence behavior, Eça \& Hoekstra (2014). The goal of the uncertainty analysis is to estimate with $95 \%$ of confidence the discretization error, Equation 4.16.

$$
\phi_{i}-U\left(\phi_{i}\right) \leq \phi_{\text {exact }} \leq \phi_{i}+U\left(\phi_{i}\right)
$$

$U\left(\phi_{i}\right)$ is the uncertainty obtained from the estimated discretization error. For more detailed explanation, see Eça \& Hoekstra (2009), Eça, Oñate \& García-Espinosa (2013), Eça et al. (2014) and Rosetti, Vaz \& Fujarra (2012). The uncertainty analysis of the discretization error will be done using a tool available in (www.refresco.org) called $\mathrm{Nu}$ merical Uncertainty Analysis Tool, NUA.

The method requires the dimensionless quantities of grid size and time-step, given by the relations of the Equations 4.17 and 4.18.

$$
\frac{h_{i}}{h_{1}}=\sqrt[3]{\frac{n_{1}}{n_{i}}}
$$

$n_{1}$ is the finer grid. The cubic root is due to the fact that the problem is threedimensional.

$$
\frac{t_{i}}{t_{1}}=\frac{n_{t_{1}}}{n_{t_{i}}}
$$

$n_{t_{1}}$ is the finer time-step.

\subsubsection{Signal Stationarity Errors}

A proper way to estimate the uncertainty of experimental data is carrying out repeatedly the same case, determining the uncertainty based on the variance of the results. Though, due to the high cost of experimental tests, this approach is not affordable most of the time. Thus, trying to find different approaches to estimate the experimental uncertainties, some authors have proposed methods to estimate the error based on a statistical analysis of a finite length signal. Brouwer, Tukker \& Rijsbergen (2013) presented two ways to estimate the uncertainty of a finite length random signal: the auto-covariance 
method; and the segment method.

The segment method consists of splitting the signal and calculating the time average for each segment. This method is not used in the scope of this study. The auto-covariance method lies in the estimation of the random uncertainty of the mean of a sample record based on the auto-covariance statistical function. The uncertainty is estimated as shown in Equation 4.19.

$$
u_{1}=\sqrt{\frac{1}{T} \int_{0}^{T}\left(1-\frac{\tau}{T}\right) C_{x x, \text { biased }}(t) d \tau}
$$

$\mathrm{T}$ is the size of the signal and $C_{x x \text {,biased }}$ is the auto-covariance factor corrected for a signal trend. More about the method is shown in Brouwer, Tukker \& Rijsbergen (2013).

The auto-covariance method is presented as an initial step of the identification of the stationarity of temporal series. Numerical calculations introduce instabilities of the results at the beginning of the signal, which should not be considered in the analyses. These instabilities are associated with the iterative solving process and should be filtered. The majority of the numerical investigations filter the signal out intuitively, by observation. Brouwer, Tukker \& Rijsbergen (2015) proposes a method, based on the auto-covariance method, that identifies which part of the signal should be extracted from the data. The method is called Transient Scanning Technique, TST.

The main idea is to split the signal into $n$ equally-spaced windows. With the autocovariance method, the uncertainty of the windows is calculated cumulatively, i. e., calculated for the first window, then for the second window plus the first one and continuing until the end of the signal. From the auto-covariance definition, the larger the signal, the smaller the uncertainty. Brouwer, Tukker \& Rijsbergen (2015) define that the signal has attained stationarity if the trend of the uncertainty estimation forms a line with a slope of minus one in a log-log scale, the $\mathrm{x}$-axis being the window size and the y-axis being the uncertainty estimation.

TST can be applied in two ways: firstly, called TST-A, calculating the cumulative $u_{1}$ from the beginning of the signal towards to the end; and TST-B, which calculates $u_{1}$ from the end of the signal to the beginning. Each way aims to estimate the stationarity of the signal at the end or at the beginning of the signal, respectively.

To illustrate the method, Brouwer, Tukker \& Rijsbergen (2015) applied a start-up disturbance in a stationary signal. The TST-B is then applied to try to identify the disturbance, Figure 4.1. 


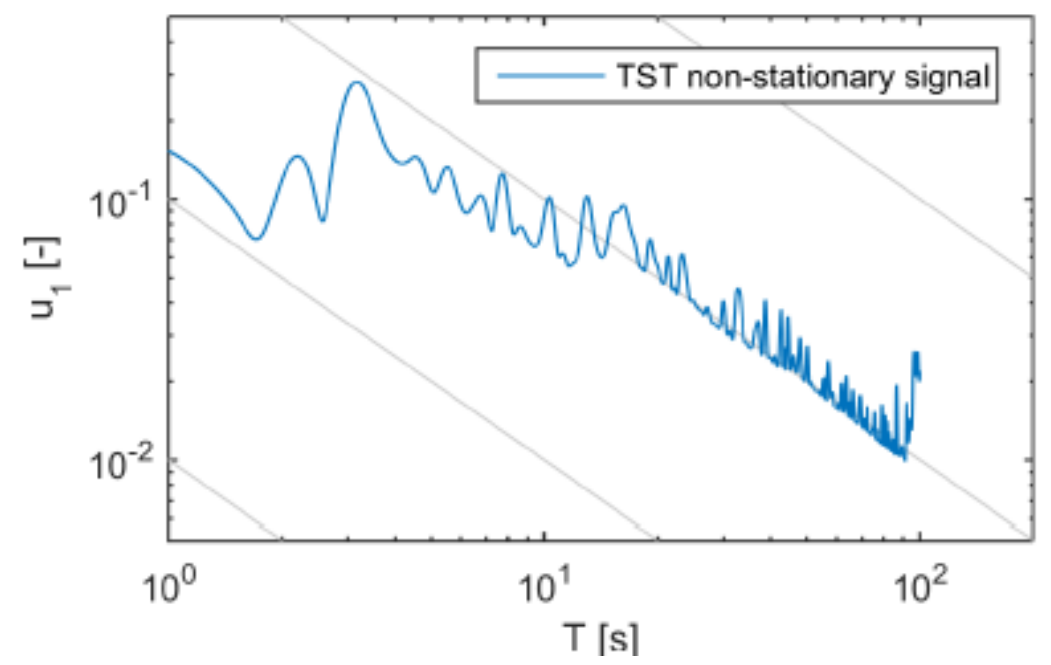

Figure 4.1: TST-B applied to a disturbed signal. Source: (BROUWER; TUKKER; RIJSBERGEN, 2015)

The first $15 \mathrm{~s}$ of the plot in Figure 4.1 (relative to the last 15 seconds of the signal) showed that the section is too small for the method. After $15 \mathrm{~s}$ the uncertainty starts to decay linearly until 90 seconds. The author calls this region as the stationary range of the signal. The position where the signal reaches the minimum uncertainty determines the optimal section. After that, the uncertainty starts to increase abruptly. This region is called the hockey-stick region, and is related to the start-up disturbance. This region should be excluded from the analysis. The three regions above mentioned are highlighted in Figure 4.2

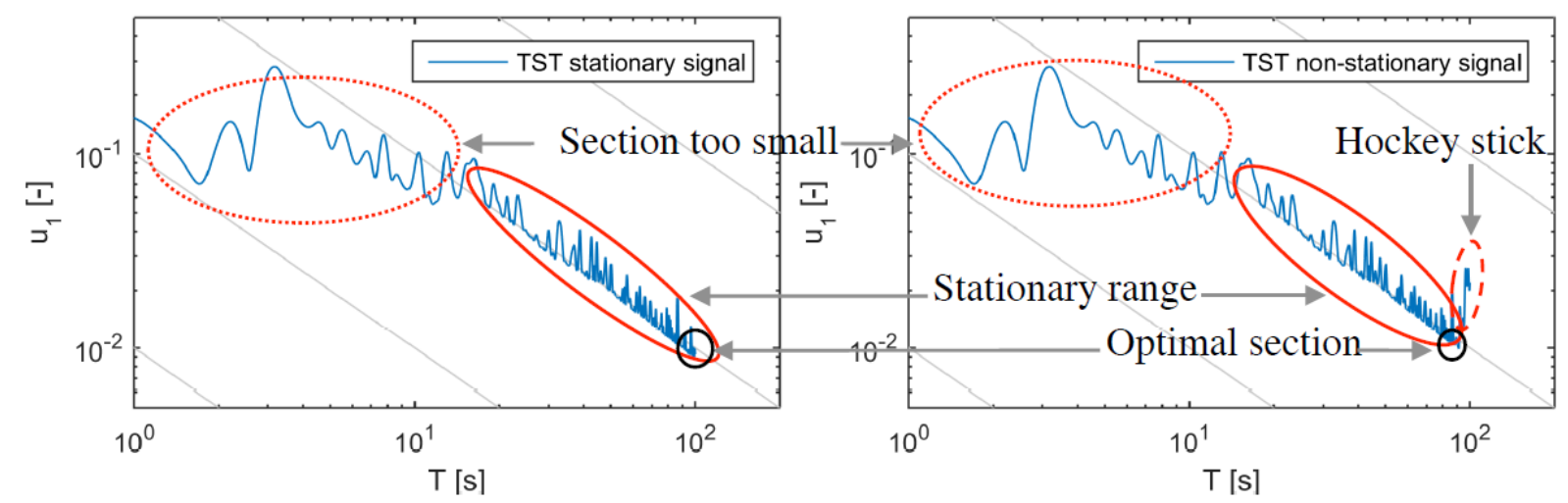

Figure 4.2: TST-B with areas identified. Source: (BROUWER; TUKKER; RIJSBERGEN, 2015)

The present thesis proposes that the TST-B has to be applied in the lift force time series, to filter the start-up effects. Beyond that, the TST-A is used on the filtered signal to estimate the associated uncertainty of the finite length signal, identified on the 
cumulative uncertainty of the whole signal.

\subsubsection{Grids}

To estimate the discretization errors, a set of meshes was generated. The grids were created with Hexpress, which makes non-conformal body-fitted full hexahedral unstructured meshes on complex arbitrary geometries. It has an advanced smooth capability which provides high-quality meshing in the boundary layer insertion. Refining blocks give the refinement level of the grid, correlated by a diffusion depth.

The methodology proposed by Eça \& Hoekstra (2014) to estimate the discretization uncertainty is based on a grid refinement study of geometrically similar grids. Producing the appropriate set of grids is straightforward when using the structured grids. For unstructured grids, however, the refinement study requires more attention.

Crepier (2017) proposed a study to define a methodology to generate the grids for the refinement study in hexahedral unstructured meshes. The KLVCC2 ship was chosen as a well-known case to be tested, due to plenty of data available in the literature. To obtain grids that are geometrically similar, Crepier (2017) proposed the following method. Each item of this methodology is stated below:

1. "The initial cell size is decreased by a factor 2, 3, 4 and 5 in each direction by using 2,3,4 or 5 times more cells in each direction."

2. "The surface refinement degree is kept constant throughout the sets: if, for instance, 6 refinements levels are set in the initial coarse grid, the same 6 successive refinements are performed for the other grids."

3. 'The size of the transition region, so-called diffusion depth dd, is adapted such that it matches the expected final size of the grid."

4. "The anisotropic sub-layer settings are adapted to account for the refinement performed."

To explain the steps 1 and 2, it is necessary to introduce the software deals with the refinement levels, n. The grid refinement occurs in levels. For each level, the base cell will be divided by $2^{n}$, isotropically, in the three directions. Figure 4.3 shows an example of two-dimensional grid refinement. 


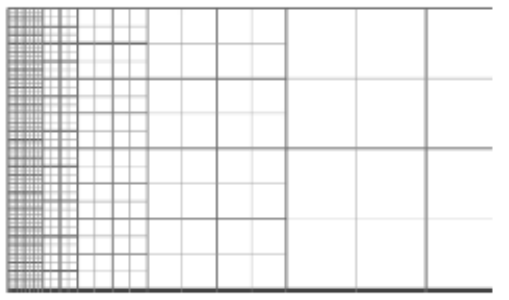

(a) 2 refinement levels

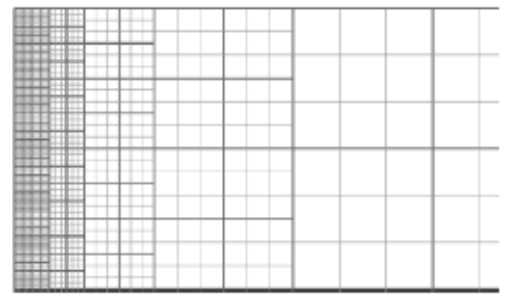

(b) 3 refinement levels

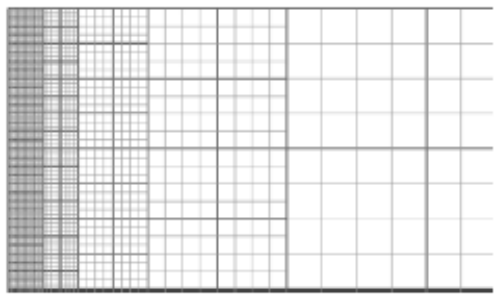

(c) 4 refinement levels

Figure 4.3: Grid refinement examples for (a) refinement level 2; (b) refinement level 3; (c)refinement level 4; Source: (CREPIER, 2017)

Step 2 of the method states that once divided, the grid refinement level of the coarser case should be kept for the finer one. Thus, the only parameter used for the grid refinement study is the initial cell size, as shown in step 1. The initial cell size should be divided, in each direction, by a factor $\lambda$. This factor is defined as a relation between the coarser grid and the one to be generated. If the number of elements of the coarser grid is $g_{1}$ and the required grid is $g_{i}$, considering a three-dimensional case, $\lambda$ is calculated as shown in Equation 4.20 .

$$
\lambda=\sqrt[3]{\frac{g_{i}}{g_{1}}}
$$

The transition between the initial cell size and the n-refinement level is made by the diffusion depth, dd, 3. This parameter sets the number of transition cells required to change from one level of refinement to another. To keep the geometry similar the diffusion depth should be set as shown in Equation 4.21.

$$
d d=3 \lambda-1
$$

The last requirement is to keep the grids similar geometrically, regarding the insertion of the boundary layer (step 4). In Hexpress, two main parameters should be selected, the first layer thickness, FLT, which is directly related with the $Y^{+}$, and the growth ratio, $r_{\lambda}$, which aims to make the transition smooth in the boundary layer region. The $F L T_{i}$ of the required grid is function of the $F L T_{1}, \lambda$ and $r_{1}$. The subscript 1 is related to the coarser grid. Equation 4.22 shows the $F L T_{i}$ Equation and Equation 4.23 the $r_{i}$.

$$
F L T_{i}=F L T_{1} \frac{1-r_{1}^{\frac{1}{\lambda}}}{1-r_{1}}
$$




$$
r_{i}=r_{1}^{\frac{1}{\lambda}}
$$

$F L T_{1}$ and $r_{1}$ should be chosen according to the physical problem to be simulated. In this thesis, the FLT was chosen to keep the $y^{+}$below 0.5 based on the study done by Eça, Pereira \& Vaz (2018), which evaluated the influence of the $y^{+}$for high Re on a flat plate, a KVLCC2 tanker and a NACA0012 airfoil. 


\section{NUMERICAL SETUP}

This section presents the numerical setup evaluated in this thesis. The set-ups are presented divided into two approaches: Symmetry Boundary Condition and VoF method. Two turbulence models for each case were tested.

\subsection{Geometry and Main Parameters}

Cylinder dimensions were based on the experiments proposed by Gonçalves et al. (2015). The modeling of the geometry was built with modeling software Rhinocerosß. The corner edge of the free end was rounded to increase the mesh quality. This simplification should not interfere in the physical behavior of the flow. The rounded radius chosen for this simplification was $1 \%$ of the cylinder diameter. Figure 5.1 shows a sketch of the faced problem.

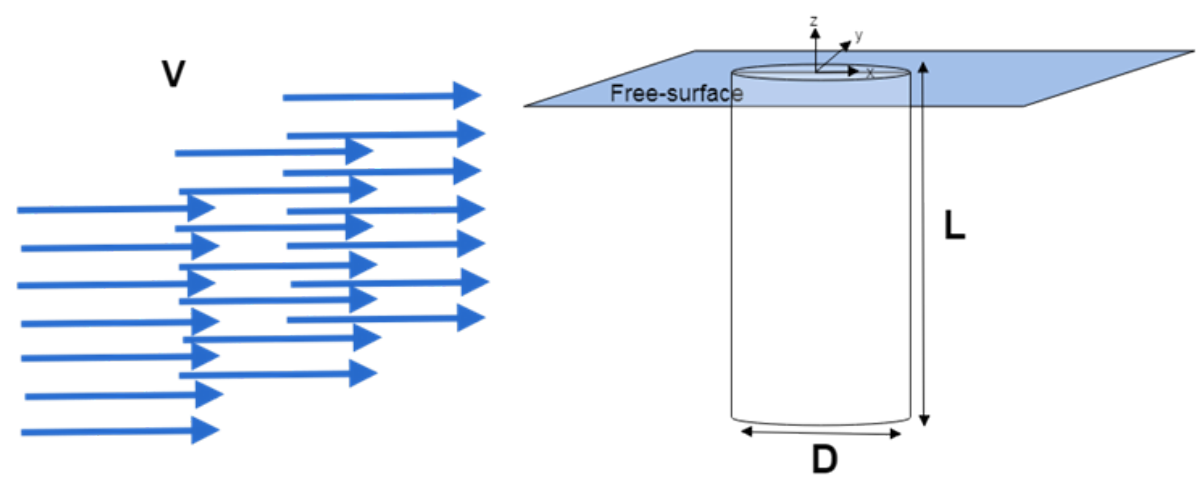

Figure 5.1: Sketch of the problem evaluated.

The main parameters of the problem were defined following Gonçalves et al. (2015), given in Table 2. 
Table 2: Main parameters of the problem.

\begin{tabular}{ccc}
\hline \multicolumn{3}{c}{ Main Parameters } \\
\hline$V$ & 0.35 & $\mathrm{~m} / \mathrm{s}$ \\
$D$ & 0.125 & $\mathrm{~m}$ \\
$L$ & 0.25 & $\mathrm{~m}$ \\
$T_{r e f}$ & 0.36 & $\mathrm{~s}$ \\
$g$ & 9.81 & $\frac{m}{s^{2}}$ \\
$R e$ & $4.3 \mathrm{E} 6$ & - \\
\hline
\end{tabular}

$V$ is the free stream velocity. The proposed problem is over a sub-critical regime of turbulence. The parameter $T_{r e f}$ is used to make time dimensionless and is calculated as the ratio of $D$ over $V$, given by Equation 5.1.

$$
T_{r e f}=\frac{D}{V}
$$

\subsection{Computational Domain and Boundary Conditions}

The domain boundaries and boundary conditions, BC, were modeled aiming to reach a fair agreement with the experimental setup. Distance between the cylinder and the channel walls, and between the cylinder and the channel bottom followed exactly the experimental setup. The inlet and outlet surfaces of the domain were set from 20 diameters upstream and 40 diameters downstream of the cylinder center line, respectively. The distance from the free-surface interface to the bottom was 6 diameters of length and the distance between the center of the cylinder and side walls, 3 diameters. Figures 5.2 and 5.3 show the domain of the two cases which were investigated.

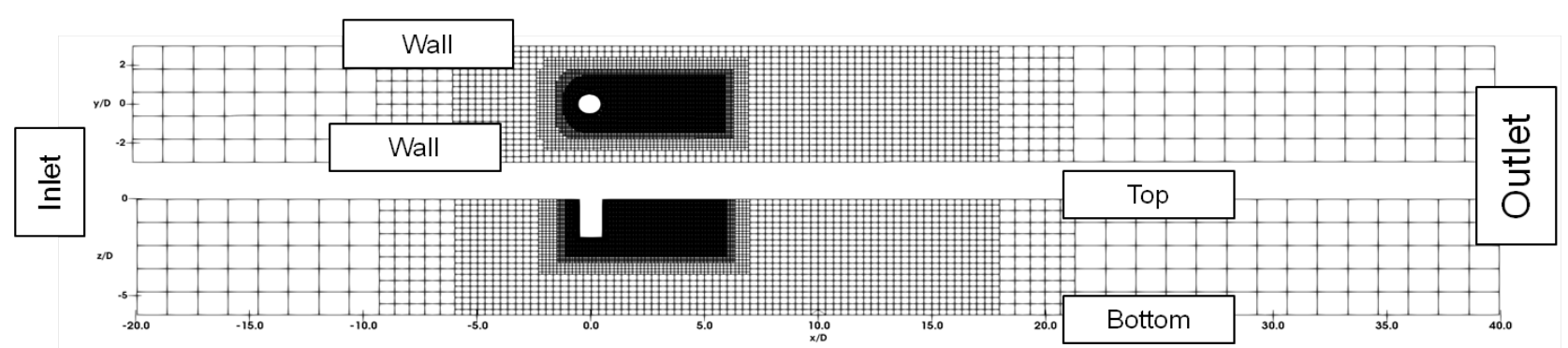

Figure 5.2: Domain and boundaries of the symmetric case. 


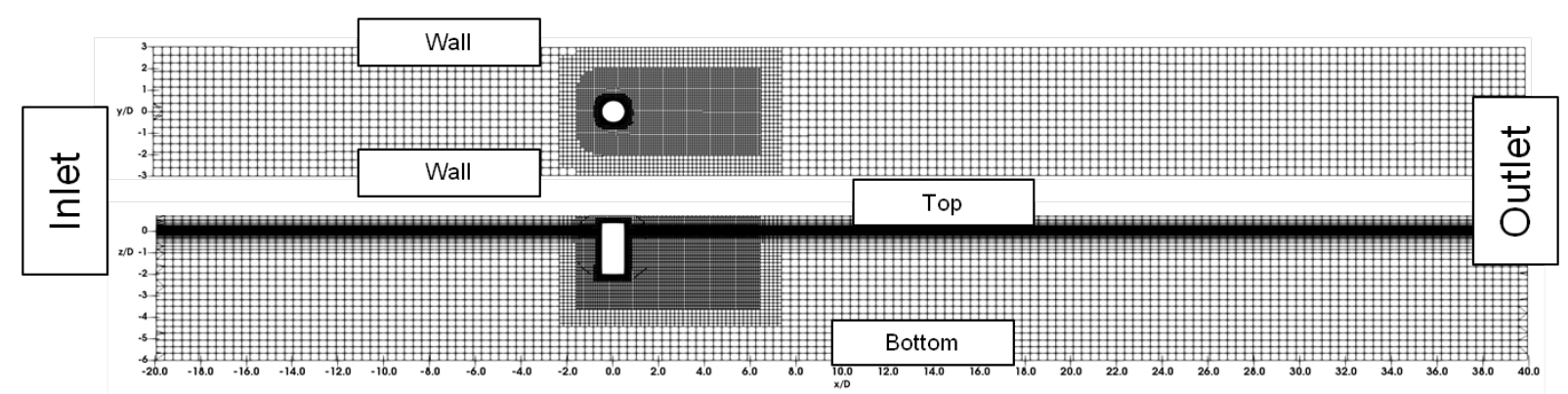

Figure 5.3: Domain of the FS cases.

The inlet surface was modeled as a BCInflow, on which the velocity was constant and equals $V$. The turbulence quantities on the inlet surface were given as turbulence intensity of $1 \%$, and eddy viscosity ratio of one. The other quantities were extrapolated by zero ${ }^{\text {th }}$ order.

The outlet surface was set as a BC of pressure, on which the pressure is set as null. The other quantities were also zero ${ }^{\text {th }}$ order extrapolated.

The cylinder wall was modeled as a BCWall. On this BC, both, the tangential and normal components of the velocity vector were set equal to the wall velocity, i. e., null in this case (non-slip condition).

The side walls and bottom surfaces were configured to avoid that their developed boundary layers interfere on the flow over the cylinder. Thus, a Symmetry BC was chosen, in which the convective fluxes are zero.

There are two different top surfaces, depending on the case to be modeled. The case in which the free surface interface was modeled with the VoF method, the surface was modeled as a Pressure boundary condition, similar to the outlet surface, except that the fixed value of the pressure was given by $p_{a t m}$. In the other case, the top surface was also modeled as a Symmetry boundary condition.

\subsection{Grids and Temporal Discretization}

\subsubsection{Grids}

Four grids were generated, following the Section 4.5.5 recommendations. Figure 5.4 shows the grids of the symmetric cases in two views. One in the vicinity of the cylinder at $z=-0.5 D$ plane and a close-up view of the free end at $y=0$ plane. 


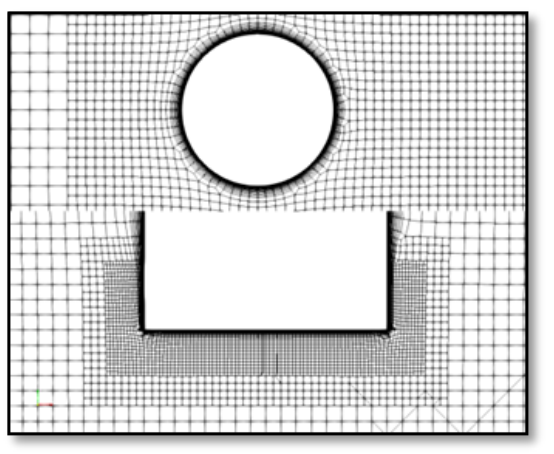

(a)

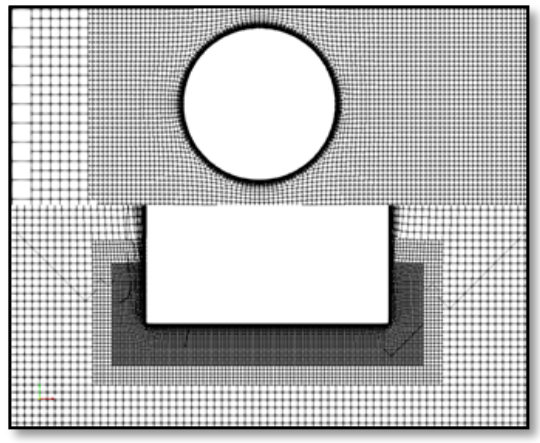

(c)

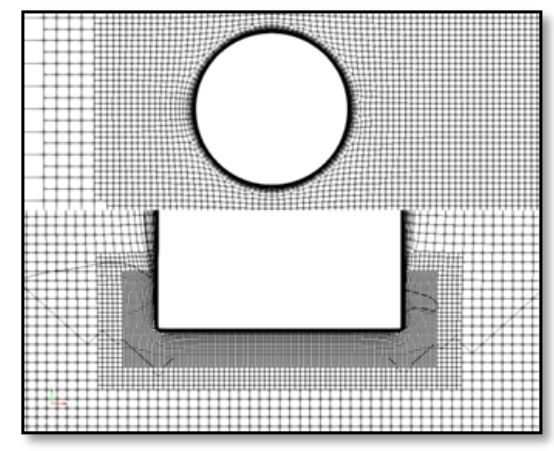

(b)

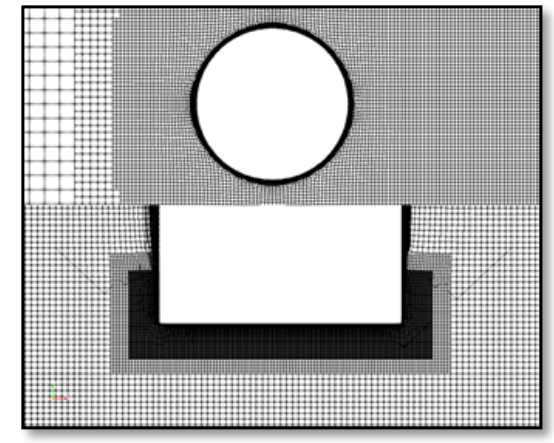

(d)

Figure 5.4: Zoom of the set of meshes for the grid refinement study: (a) Grid-0; (b) Grid-1; (c) Grid-2; (d) Grid-3

The nomenclature of the grids are showed in the figure above. The subscript 1, follows the formulation of the Section 4.5.5, and is associated to the coarser grid of the discretization analysis. The subscripts 2 and 3 are the finer grids, respectively. The subscript 0 concerns to the coarsest grid on the set. This grid aims to execute pre-tests such as iterative convergence and numerical sensitivity analysis, and is not considered in the discretization analysis. Table 3 shows the grid set used in the Symmetry case and its respective $y_{\max }^{+}$and $\lambda$ parameters.

Table 3: Grids size, $\lambda$ and $y^{+}$of the Symmetry case

\begin{tabular}{lccc} 
ID & Elements & $\lambda$ & $y_{\max }^{+}(\mathrm{EARSM})$ \\
\hline Grid-0 & 722,744 & 0.62 & 0.36 \\
Grid-1 & $3,062,141$ & 1.00 & 0.25 \\
Grid-2 & $5,819,077$ & 1.24 & 0.18 \\
Grid-3 & $12,279,588$ & 1.59 & 0.15 \\
\hline
\end{tabular}

Four grids were generated for the FS cases, aiming the grid discretization analysis. Differently from the Symmetry cases, the coarser grid, Grid-1, was used for the pre-tests. 
Figure 5.5 presents the four grids proposed fot the discretization analysis of this case.

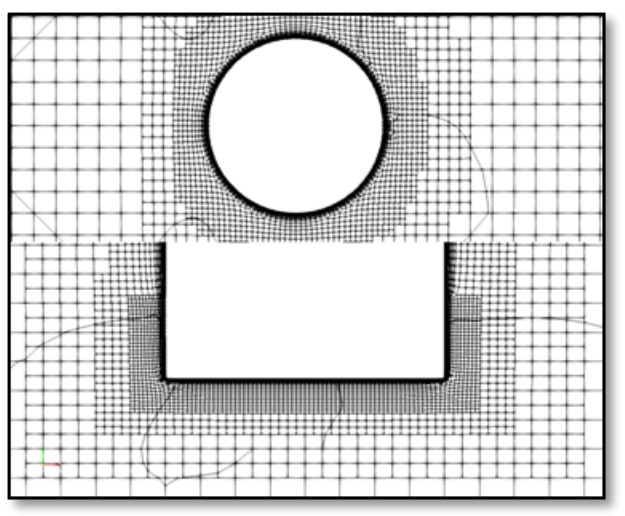

(a)

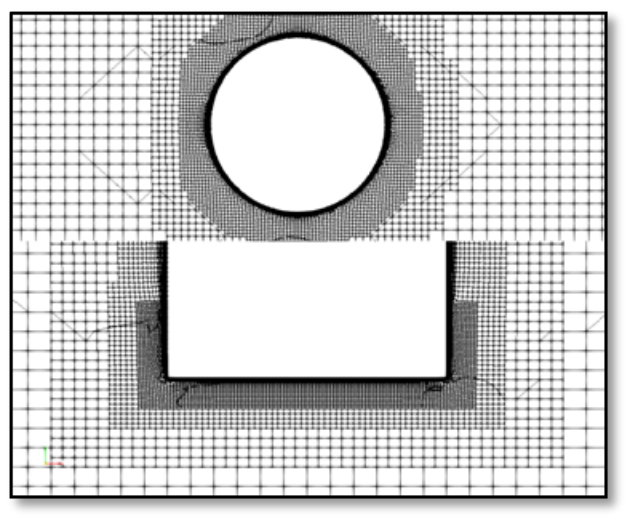

(c)

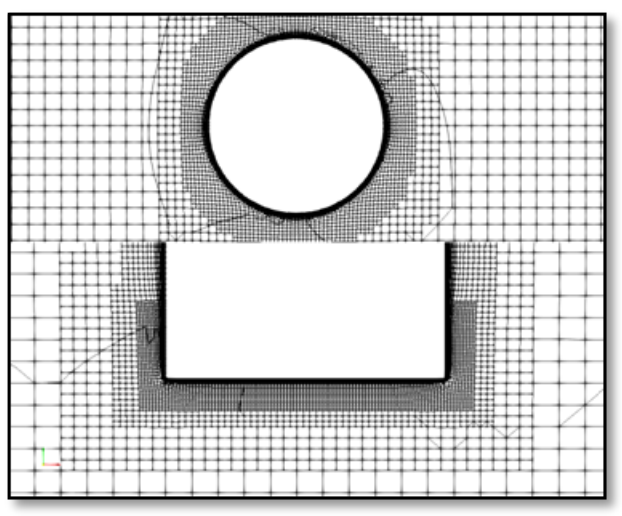

(b)

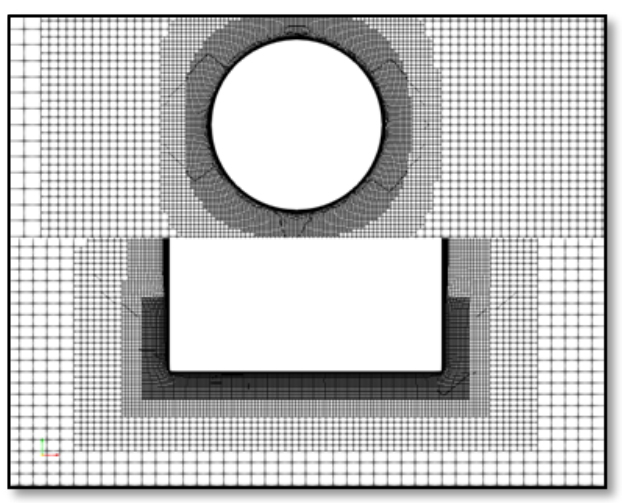

(d)

Figure 5.5: Zoom of the set of meshes for the grid refinement study of the FS case: (a) Grid-1; (b) Grid-2; (c) Grid-3; (d) Grid-4

Table 4 shows the number of cells, and $y_{\max }^{+}$of each case simulated.

Table 4: Grids size, $\lambda$ and $y^{+}$of the FS case

\begin{tabular}{lcccl} 
ID & Elements & $\lambda$ & $y_{\max }^{+}($EARSM $)$ & $y_{\max }^{+}($IDDES $)$ \\
\hline Grid-1 & $2,195,153$ & 1.00 & 0.27 & 0.37 \\
Grid-2 & $3,015,740$ & 1.11 & 0.24 & 0.29 \\
Grid-3 & $6,823,976$ & 1.45 & - & 0.26 \\
\hline
\end{tabular}

The VoF method is not efficient with the presence of hanging nodes on the interface air water. Thus, the free-surface region must have the most refined grids in the longitudinal direction, increasing considerably the number of cells. Additionally, as shown in (KLAIJ; HOEKSTRA; VAZ, 2018), the maximum Courant number in the free-surface interface region should be smaller than $\frac{1}{6}$ for a $2^{\text {nd }}$ order time discretization scheme. Both 
requirements were taken into account for the grid generation. Thus, due to the high computational cost of this case, Grid-4 was not simulated.

\subsubsection{Time Discretization}

Time discretization analysis is required to estimate the numerical discretization uncertainties. As aforementioned, this analysis is based on the variation of the time-step combined with a grid size. The time-step was set according to $T_{r e f}$, Table 5 .

Table 5: Time-step size chosen for the discretization analysis.

\begin{tabular}{lc} 
ID & time - step \\
\hline TS-1 & $\frac{T_{r e f}}{200}$ \\
TS-2 & $\frac{T_{r e f}}{400}$ \\
TS-3 & $\frac{T_{r e f}}{600}$ \\
TS-4 & $\frac{T_{r e f}}{800}$ \\
TS-5 & $\frac{T_{r e f}}{1000}$ \\
\hline
\end{tabular}

TS-5 was just used in the FS case, due to the larger number of elements, aiming to keep the maximum Courant number below 10.

\subsection{Numerical models and settings}

This section shows the main numerical model and settings used for the simulations.

An implicit three time level scheme was used for time discretization, which is a $2^{\text {nd }}$ order scheme. To solve the non-linear mass-momentum equations, a segregated approach was chosen with a SIMPLE ${ }^{1}$ solver.

The gradients terms of momentum, pressure and turbulence were solved with the Gauss method. The convective flux discretization of the momentum equations was modeled by the $2^{\text {nd }}$ order scheme total variation diminishing, TVD, method as can be seen in Klaij \& Vuik (2013). The turbulence convective flux discretization was solved by a

\footnotetext{
${ }^{1}$ More about SIMPLE solver can be seen in Ferziger \& Peric (2002)
} 
first order upwind method, UDS ${ }^{2}$. Finally, as already mentioned, the closure problem was modeled by the EARSM turbulence model. 


\section{VERIFICATION PROCEDURES AND COMPARISON WITH EXPERIMENTS}

This chapter presents a verification analysis on the numerical results to assure that numerical issues are controlled. Finally, a comparison between experimental data and the numerical results were done.

For sake of simplicity, the cases modeled with a symmetry boundary condition at the top surface were namely SYM cases, and the cases modeled with VoF method, VoF cases.

\subsection{Chapter Remarks}

Some definitions are important to be given before the presentation of this analysis. The drag and lift forces are dimensionless and presented as drag and lift coefficients, Equations 6.1 and 6.2.

$$
\begin{aligned}
& C_{x}(t)=\frac{2 F_{x}(t)}{\rho V^{2} D L} \\
& C_{y}(t)=\frac{2 F_{y}(t)}{\rho V^{2} D L}
\end{aligned}
$$

The reference area was defined with a projected area, $L \times D . C_{x}$ and $C_{y}$ were evaluated as integral results, on which the drag was calculated as time average, $\overline{C_{x}}$, and lift as root mean square, $C_{y, r m s}$.

Thereafter, pressure coefficient is given by Equation 6.3. Flow fields present the pressure coefficient as a time average of the flow after the stationary regime is reached. For the cases where the free surface was modeled with a symmetry boundary condition, $p_{\infty}$ was given by pressure at the free-stream region, i. e., zero. For the case modeled with 
VoF method, $p_{\infty}$ was the atmospheric pressure, $p_{a t m}$.

$$
C_{p}(t)=\frac{p(t)-p_{\infty}}{\frac{1}{2} \rho V^{2}}
$$

Vorticity fields were made dimensionless as showed in Equation 6.4.

$$
\omega_{i}^{\star}=\frac{\omega_{i} D}{V}
$$

$\omega$ is the vorticity and the subscript $i$ refers to each specific direction.

Components of the velocity were made dimensionless by the free-stream velocity, $V$, given by Equation 6.5.

$$
V_{i}^{\star}=\frac{V_{i}}{V_{\infty}}
$$

\subsection{Verification Procedures}

To assess the reliability of the results, a verification procedure was performed. Firstly, an analysis on the influence of the iterative convergence was done. Thereafter, an analysis on the stationarity of the lift forces time series was addressed.

To evaluate the uncertainties associated with the Navier-Stokes numerical discretization, a methodology proposed by Eça \& Hoekstra (2009) was followed. However, results obtained by the method presented in Section 4.5.3 showed very high levels of uncertainties. The reason for that is attributed to a small number of combinations, of grids and time steps, considered insufficient to estimate uncertainties properly. To estimate correctly the uncertainties following this method, finer grids and smaller time steps should have been used, which was not possible due to time and computational processing restrictions. Hence, the effective assessment of discretization uncertainties was not considered in the present work, being left as a recommendation for further research work.

\subsubsection{Iterative Convergence}

Iterative convergence analysis was carried out with the coarser set of grid and timestep for each case, i. e., Grid-0 for SYM cases and Grid-1 for VoF cases and times step, TS-1, for both. 


\subsubsection{EARSM - SYM case}

Convergence tolerance, $C T$, was varied to test the iterative residuals and $\overline{C_{x}}$ and $C_{y, r m s}$ were evaluated. Four simulations were accomplished for each case, varying $C T=10^{-5}$, $10^{-6}, 10^{-7}$ and $10^{-8}$ in a rms norm, $L_{r m s}$.

Analysis of the iterative errors were performed for the SYM case with EARSM to model the turbulence. Figure 6.1 shows the time series of drag and lift coefficients.

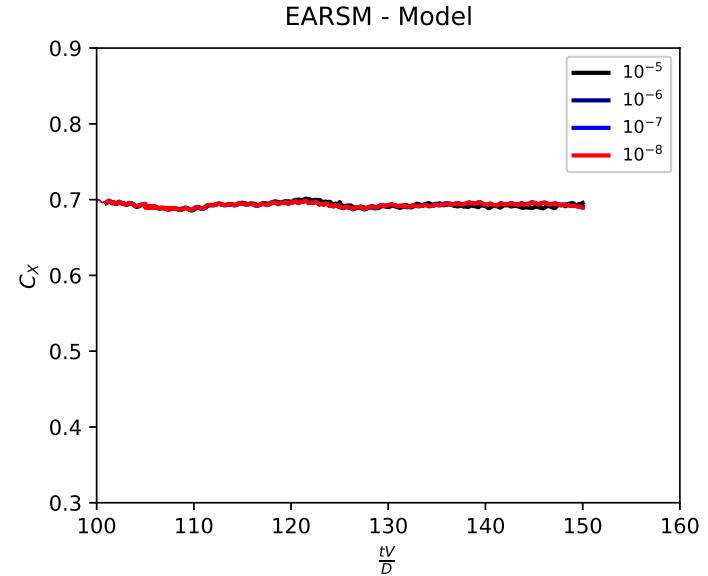

(a)

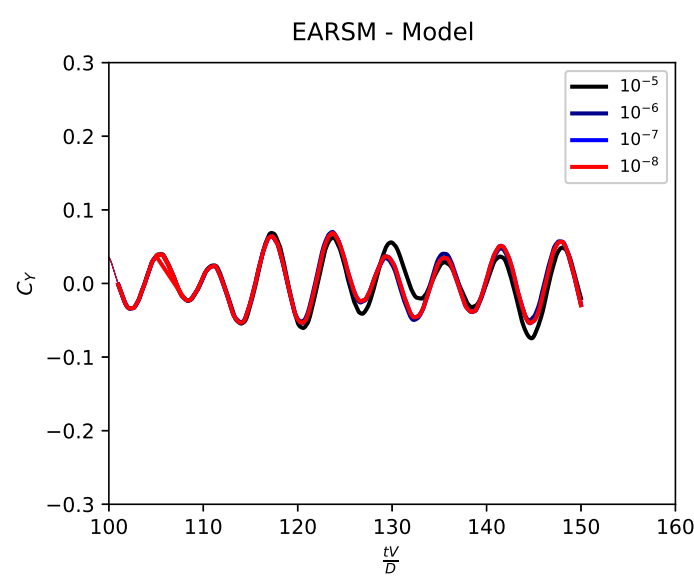

(b)

Figure 6.1: Temporal series of the SYM case with EARSM turbulence model for (a) Drag coefficient and (b) Lift coefficient

A small deviation between the $C T=10^{-5}$ and the others was noticed. Figure 6.2 shows the $\overline{C_{x}}$ and $C_{y, r m s}$ as function of $C T$. Variation of the lift forces was detected on the $C_{y, r m s} . \overline{C_{x}}$ only showed a small variation in the fourth decimal place. Thus, the CT chosen for the calculations was $C T=10^{-6}$, i. e., the simulation only proceeds to the next time step after all residuals reach $10^{-6}$. 


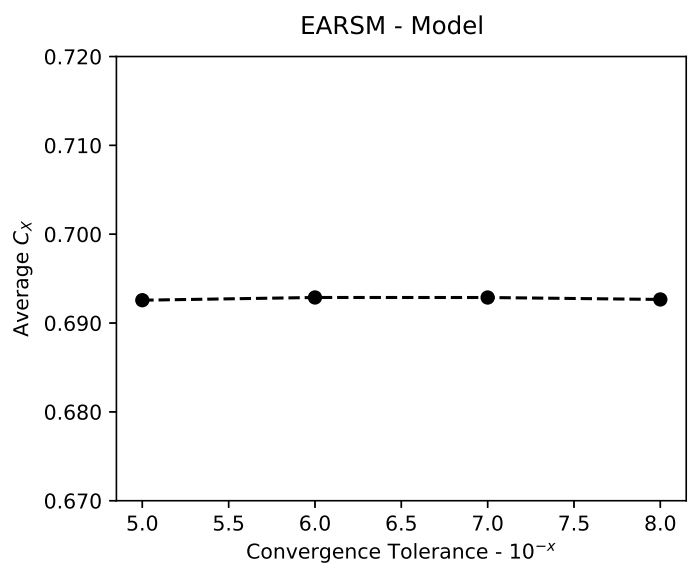

(a)

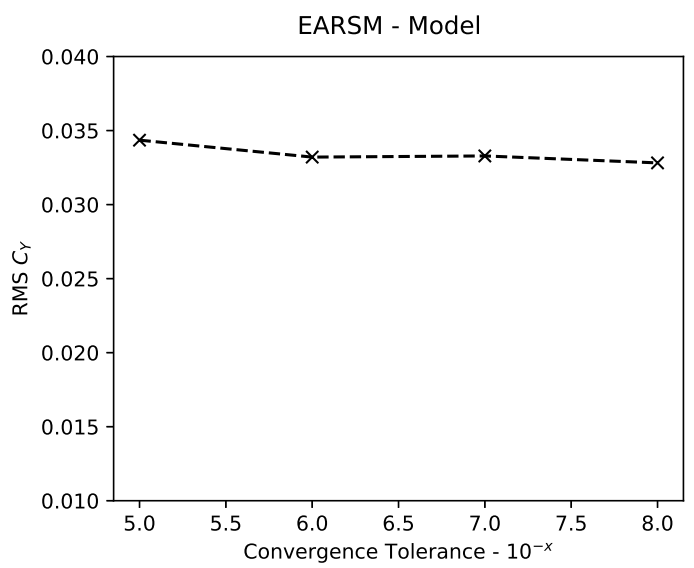

(b)

Figure 6.2: Integral results of the SYM case with EARSM turbulence model for (a)average drag and (b) rms of lift coefficients.

Finally, the residuals as functions of the outer iterations is presented in Figure 6.3 for a window of 100 iterations.

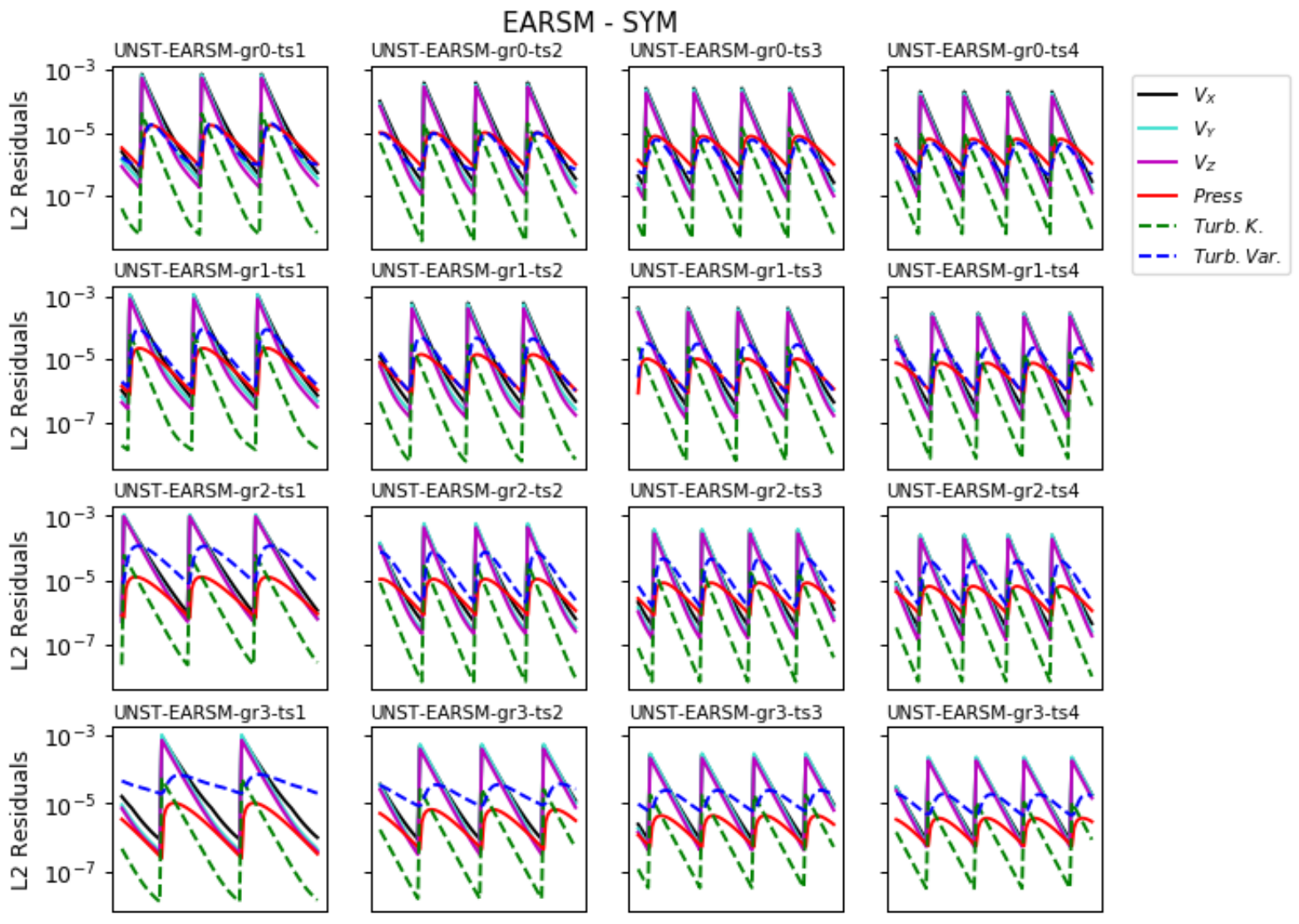

Figure 6.3: Residuals behavior of the EARSM-SYM calculations for the entire set of grids and time-step tested.

It is possible to observe that the residuals are well behaved, limited only by CT, 
without any stagnation.

\subsubsection{EARSM - VoF case}

CT was investigated in the VoF cases for $C T=10^{-4}, 10^{-5}, 10^{-6}, 10^{-7}$ and $10^{-8}$. Figure 6.4 shows the temporal series of the $C_{x}$ and $C_{y}$ of the VoF case which uses the EARSM as turbulence model.

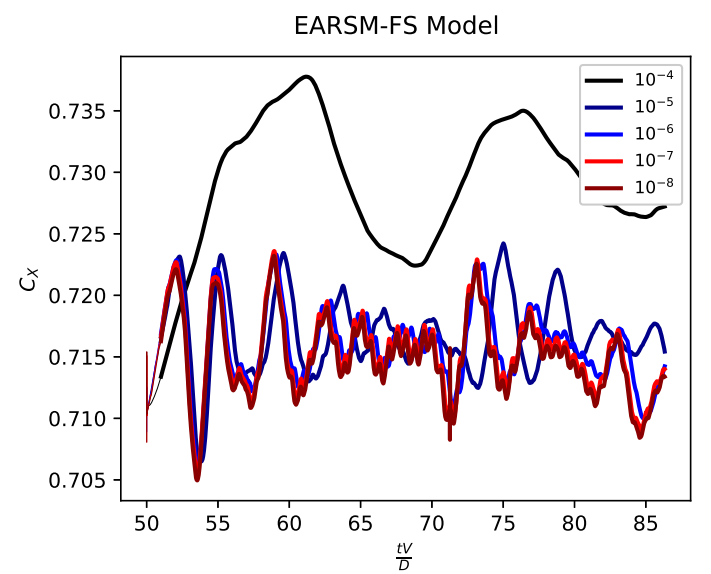

(a)

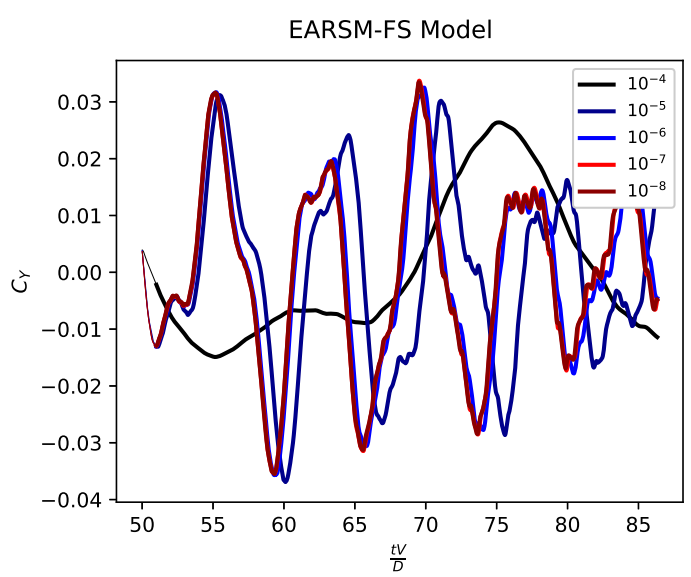

(b)

Figure 6.4: Temporal series of the VoF case with EARSM turbulence model for (a) Drag coefficient and (b) Lift coefficient

Large differences were observed in this case. $C T=10^{-4}$ presented a totally different behavior for both drag average or root mean square of lift. Neglecting iterative errors in this case can lead to a large influence on the results. A convergence behavior is identified from $\mathrm{CT}=10^{-6}$, as showed in Figure 6.5.

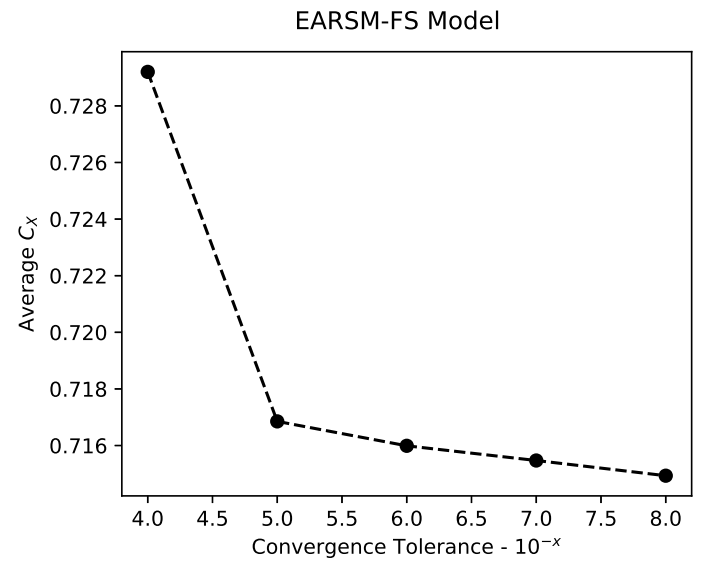

(a)

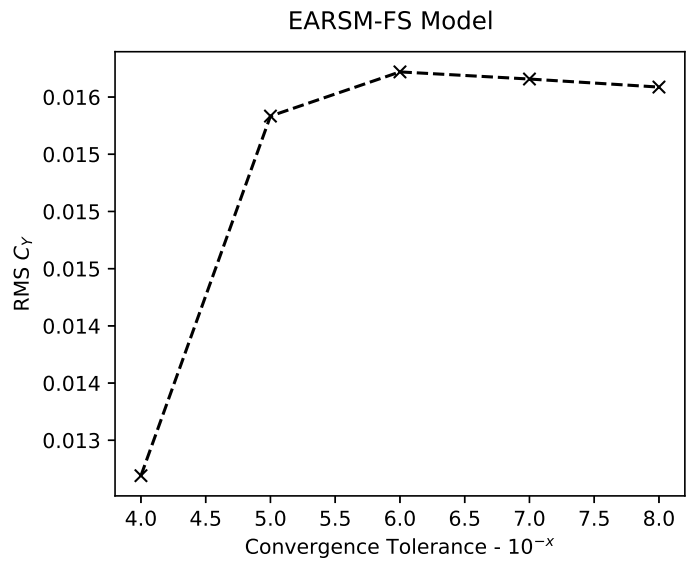

(b)

Figure 6.5: Integral results of the VoF case with EARSM turbulence model for (a)average drag of coefficient and (b) rms of lift coefficient. 
CT chosen for the calculations was $10^{-5}$, and Figure 6.6 shows the residuals behavior for the whole set of grids and time steps. The $\mathrm{x}$-axis is relative to the last 100 iterations.
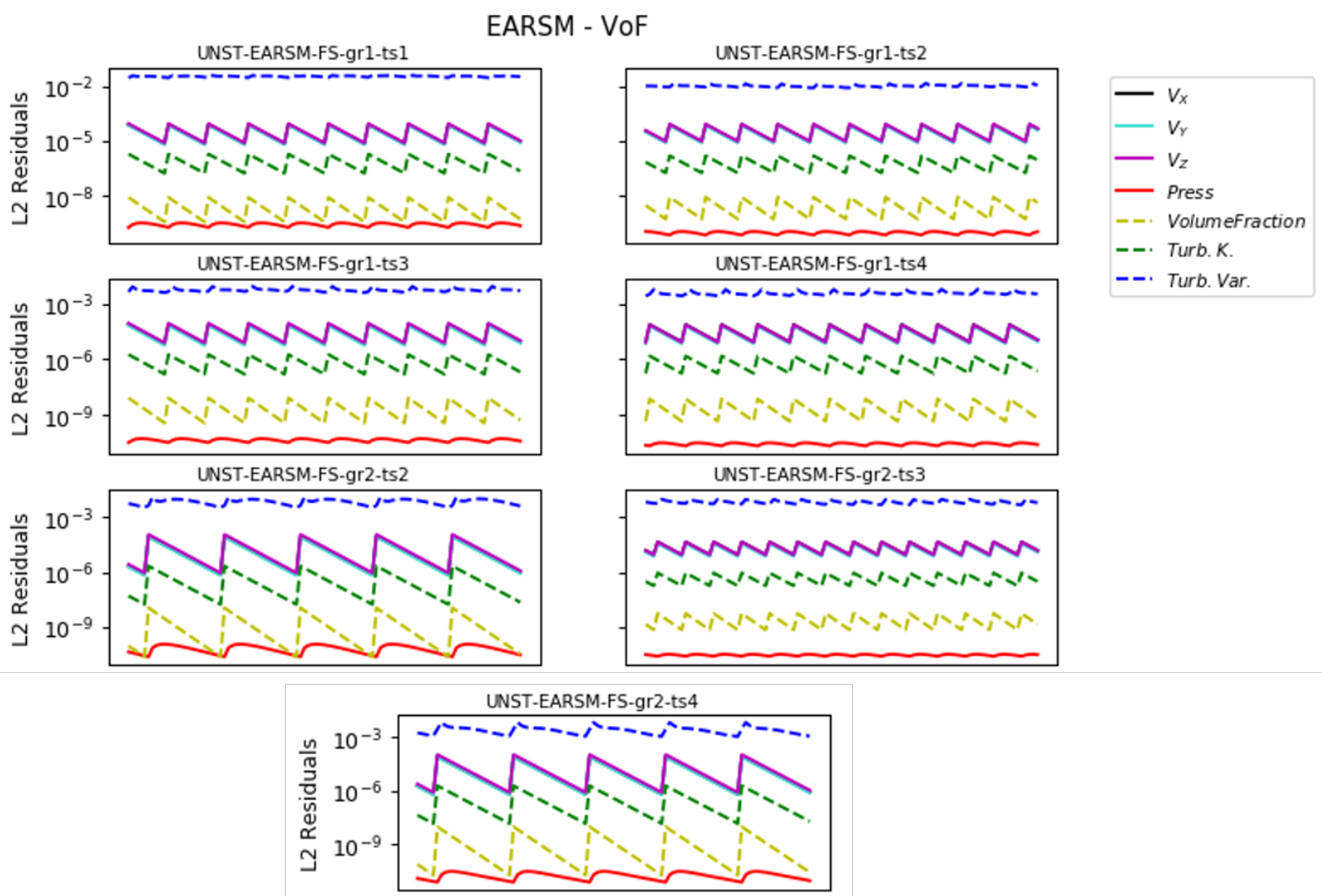

Figure 6.6: Residuals behavior of the EARSM-VoF calculations for the entire set of grids and time-step tested.

Iterative errors analysis of the VoF case with turbulence modeled with IDDES were evaluated. Time series of $C_{x}$ and $C_{y}$ are shown in Figure 6.7.

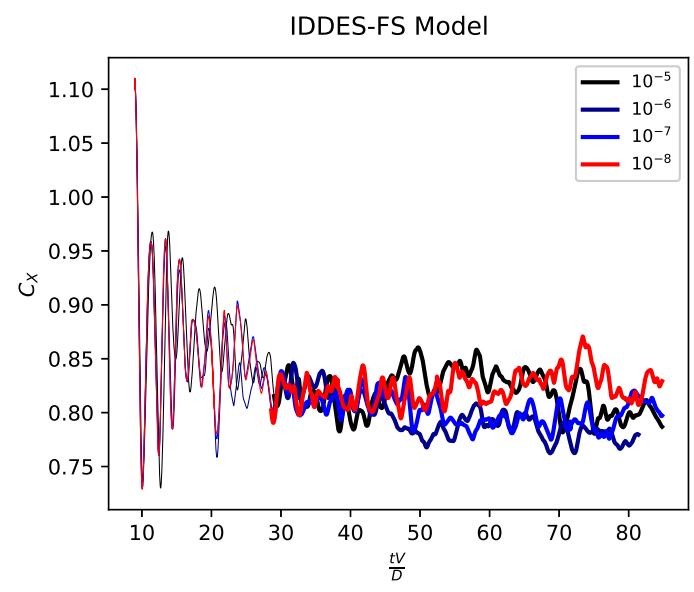

(a)

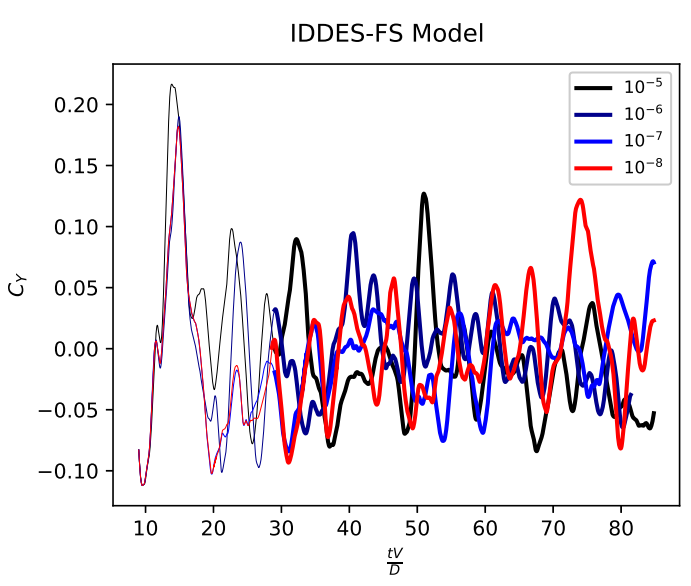

(b)

Figure 6.7: Temporal series of the VoF case with IDDES turbulence model for (a) Drag coefficient and (b) Lift coefficient 
The IDDES turbulence model showed aleatory behavior as CT changes. Integral results of $\overline{C_{x}}$ and $C_{y, r m s}$ were analyzed, Figure 6.8 .

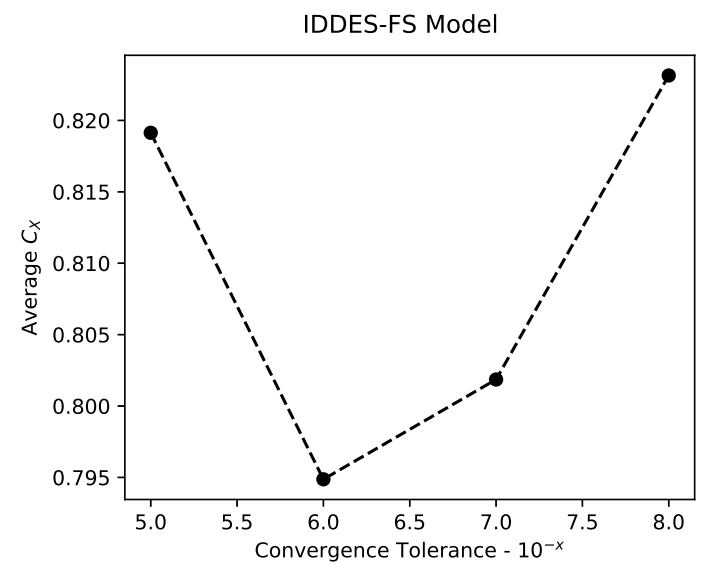

(a)

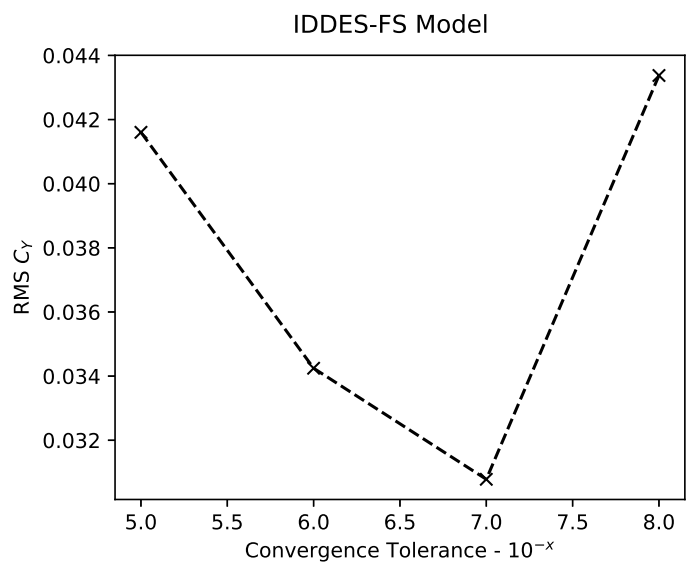

(b)

Figure 6.8: Integral results of the VoF case with IDDES turbulence model for (a)average drag of coefficient and (b) rms of lift coefficient.

Although no convergence behavior has been identified, the difference between the higher and small values presented are of $3 \%$ for the drag and $14 \%$ for the lift. Hence, we will assume an conservative $C T=10^{-6}$. Figure 6.9 shows the residuals behavior for the hole set of simulations.

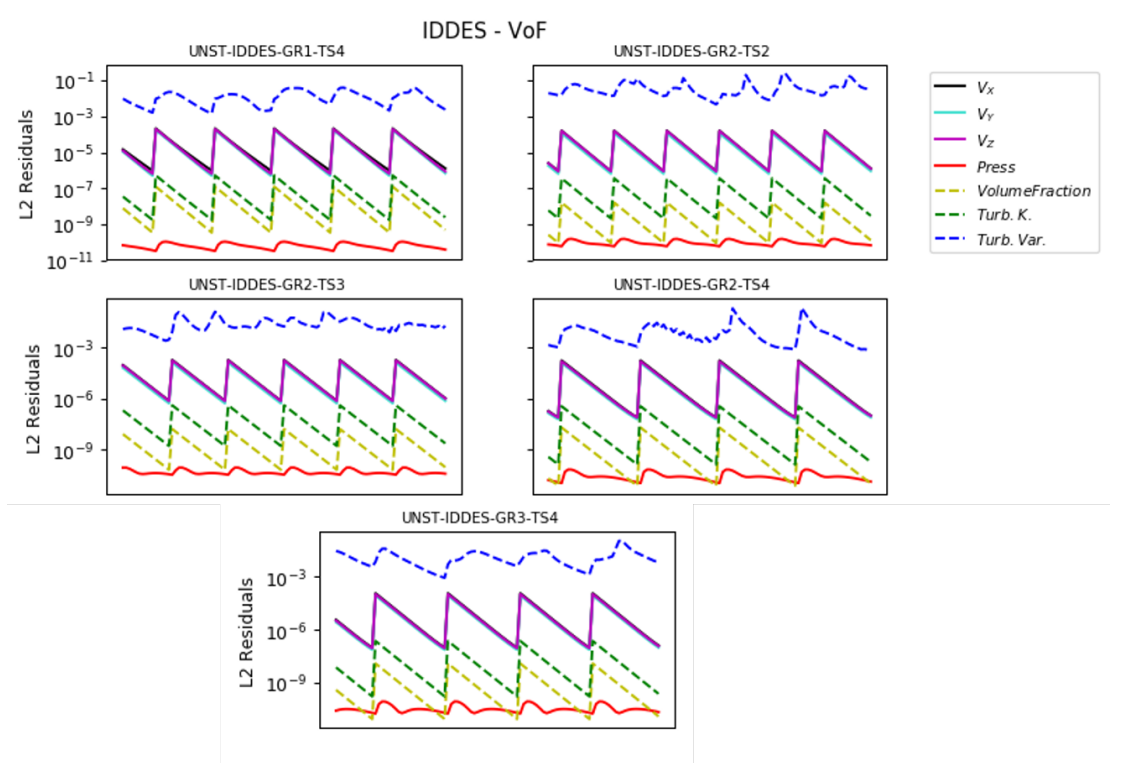

Figure 6.9: Residuals behavior of the IDDES-VoF calculations for the entire set of grids and time-step tested. 


\subsubsection{Signal Stationarity}

To evaluate the stationarity of the signal, a method proposed by (BROUWER; TUKKER; RIJSBERGEN, 2015) presented in 4.5.4 was performed. Start-up effects should be filtered from the time-series of lift coefficients. An analysis with the TST method was performed for both SYM and VoF cases.

\subsubsection{EARSM - VoF Case}

The original time series of $C_{y}$ was analyzed with TST-B scheme. Figure 6.10 shows the results of the analysis of the $C_{y}$ signal for the SYM case with the EARSM turbulence model used. TST-B on the original signals was performed to filter out the start-up instabilities.

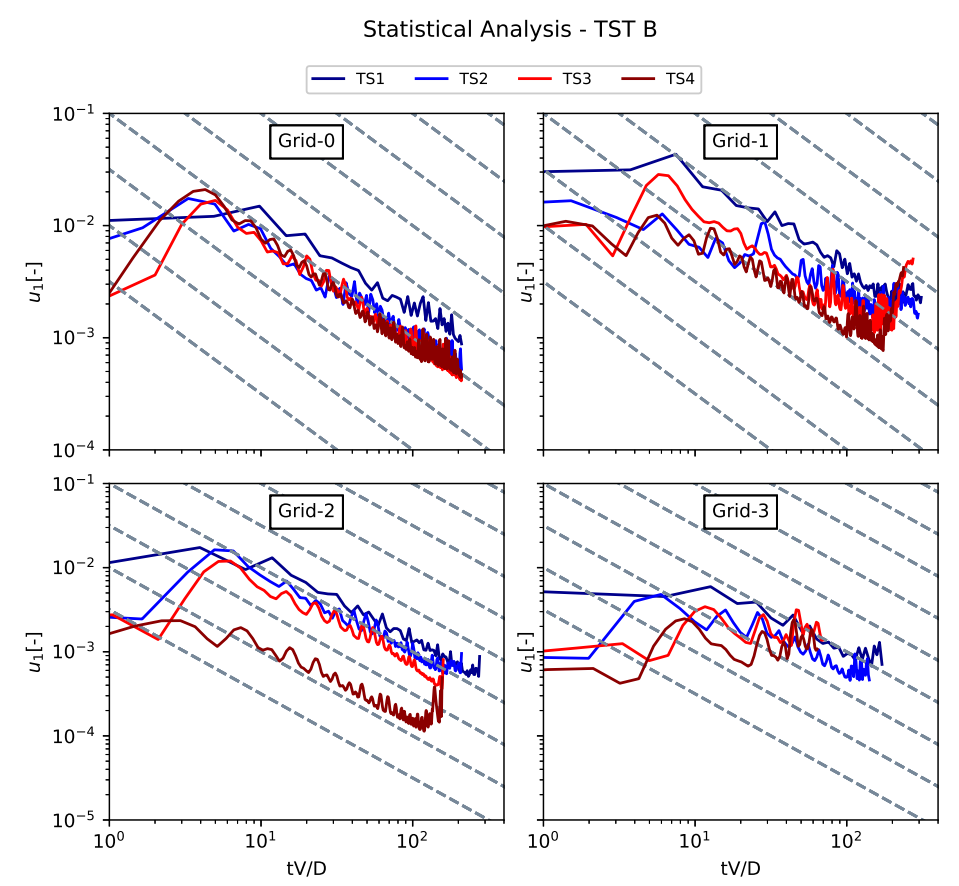

Figure 6.10: TST-B of the original signals of the SYM cases with EARSM turbulence model.

TST-B was applied in the signal filtered in order to check if the hockey-sticks were suppressed, Figure 6.11. 


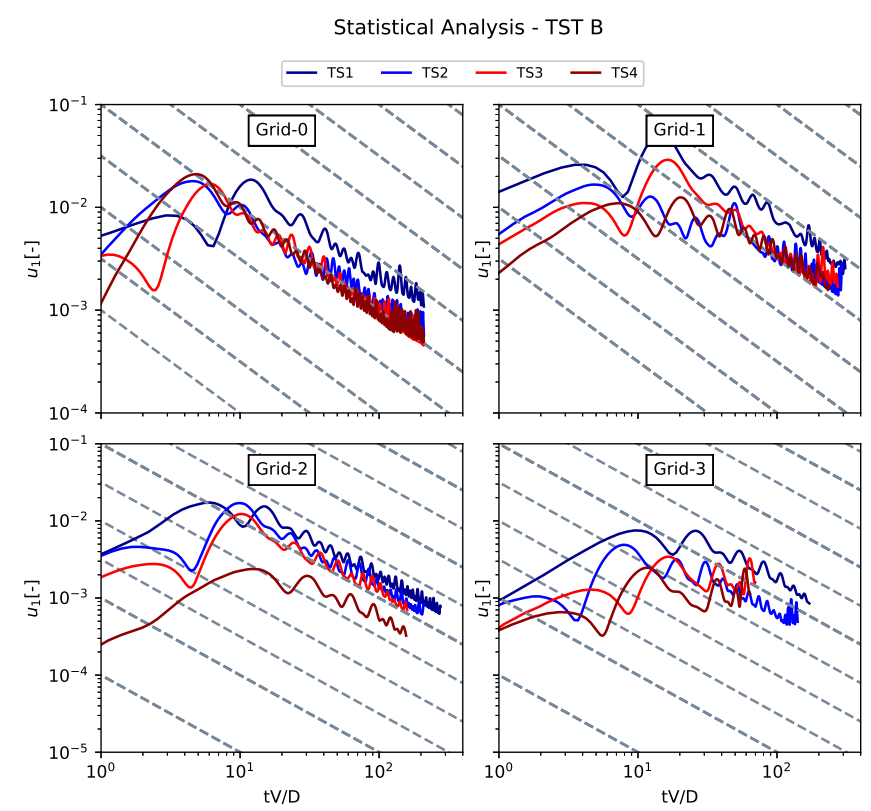

Figure 6.11: TST-B of the filtered signals of the SYM cases with EARSM turbulence model.

\subsubsection{EARSM - VoF case}

VoF cases with EARSM turbulence model were tested following the same approach above. TST-B of the lift time series was performed to identify the hockey-sticks regions, showed in Figure 6.12.

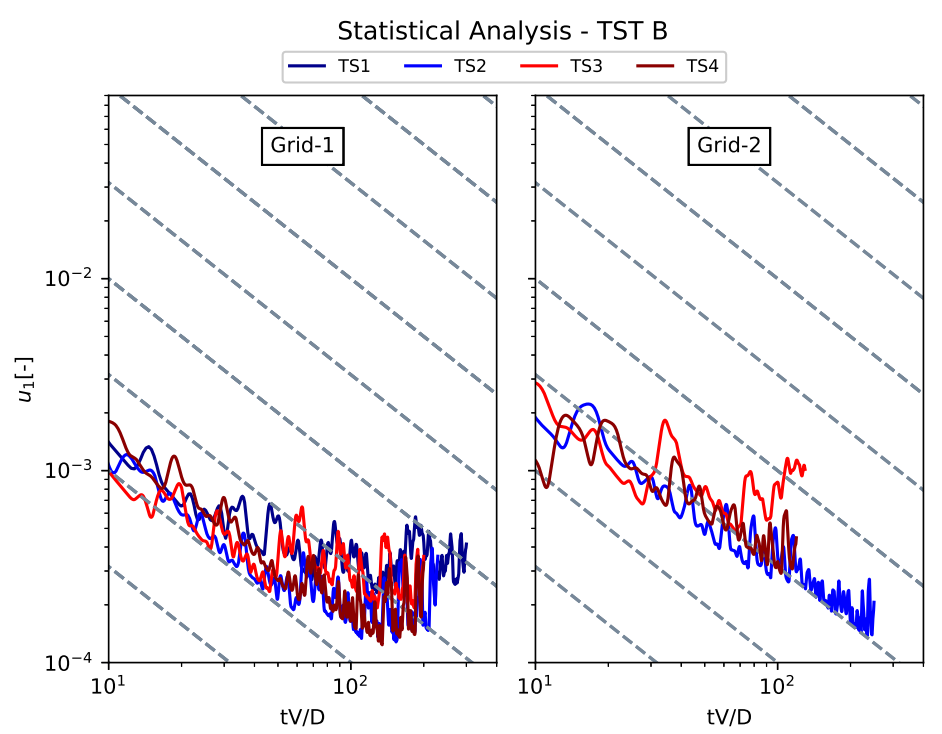

Figure 6.12: TST-B of the original signals of the VoF case with EARSM turbulence model.

The signals were filtered out at the optimal point and a new TST-B was executed to check if the non-stationarity of the signals had disappeared. Figure 6.13 shows that the hockey sticks regions were suppressed, except for the Grid-2 with TS-3. No stationarity 
was identified by the method in this case. To improve this results the time series should be larger.

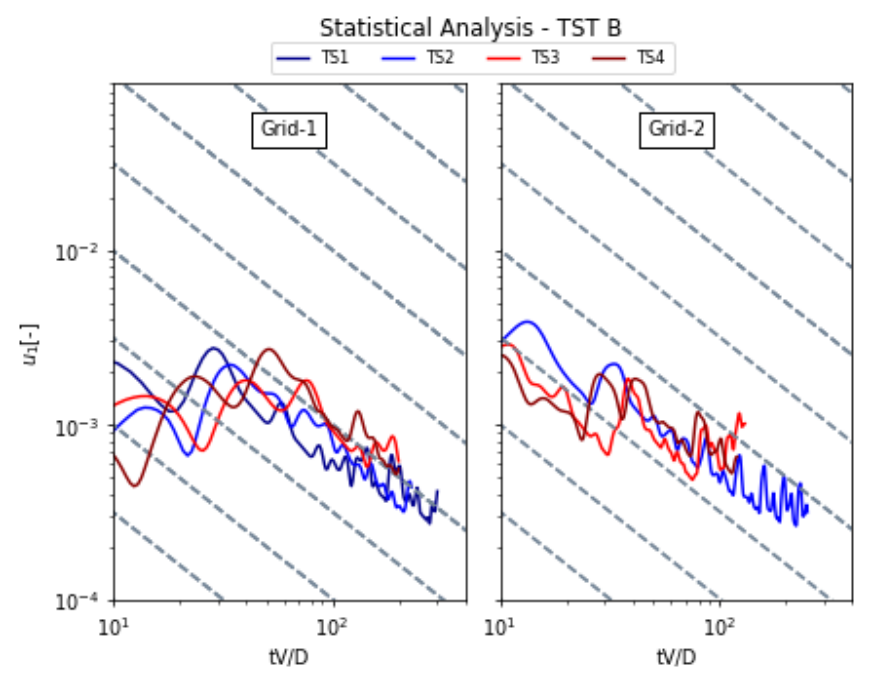

Figure 6.13: TST-B of the filtered signals of the VoF case with EARSM turbulence model.

Finally, the statistical analysis of the VoF case which uses the IDDES turbulence model was performed. To exclude start-up effects, TST-B analysis of the original signal was evaluated, showed in Figure 6.14.

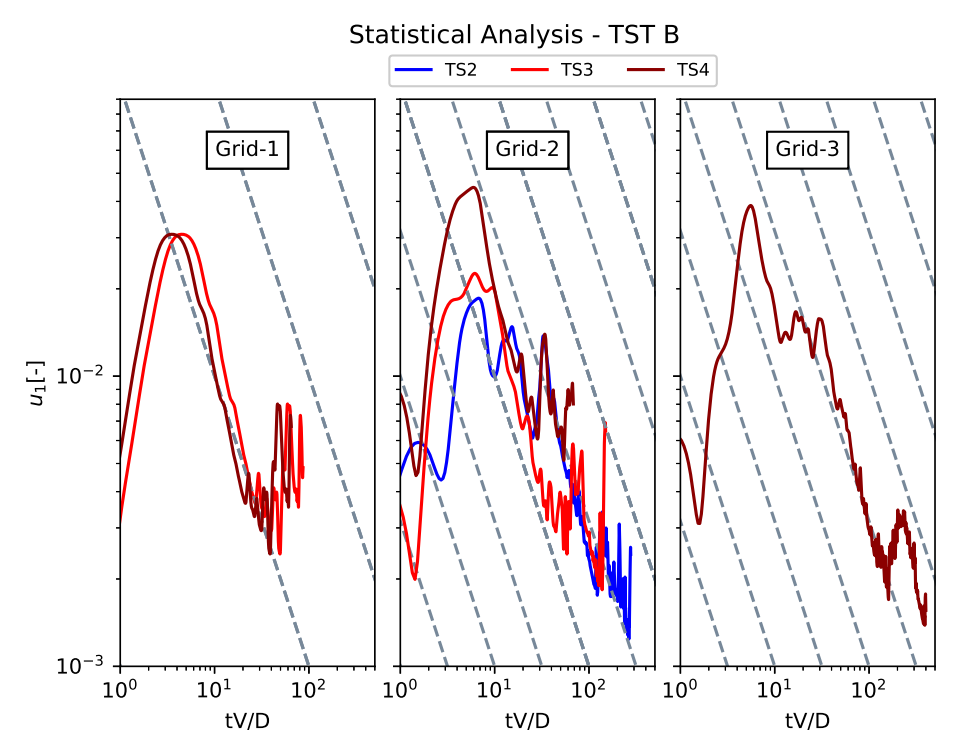

Figure 6.14: TST-B of the original signals of the VoF case with IDDES turbulence model.

Hockey sticks regions were not well characterized in the cases of Grid-2. Even so, instabilities in the beginning of the signals were filtered out and the TST-B was evaluated again, Figure 6.15 . 


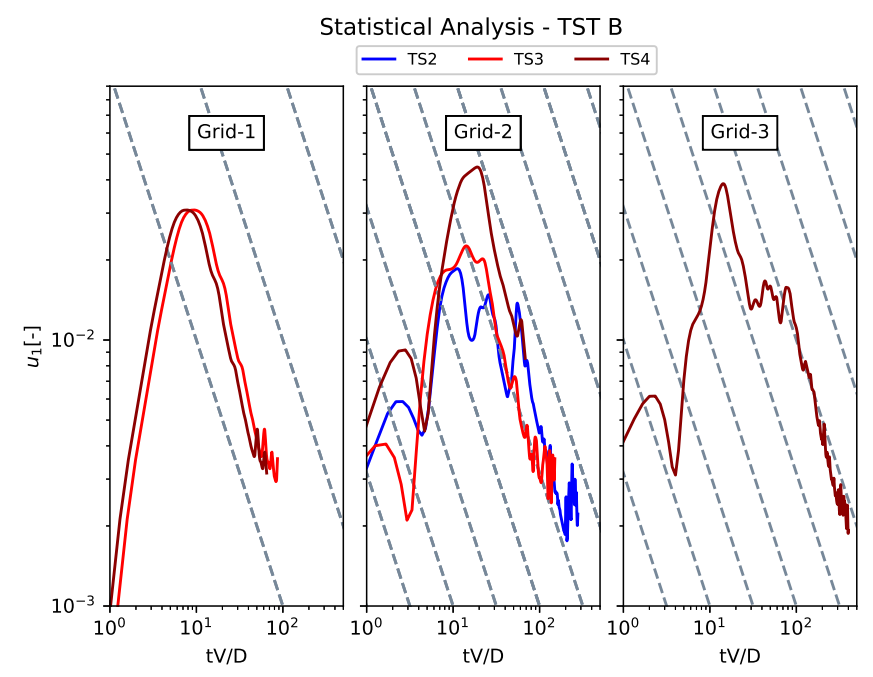

Figure 6.15: TST-B of the filtered signals of the VoF case with IDDES turbulence model.

Results of the TST-B applied to the filtered signals showed an agreement with the slope of minus one, proposed by the method. Non-stationarity of the signal was identified by the method even with a very random behavior presented by the IDDES cases.

\subsection{Comparison with Experimental Data}

\subsubsection{Experimental Uncertainty Analysis}

To assure reliability of the numerical results, experimental data from Gonçalves et al. (2015) were compared with numerical results. Experimental time series of drag and lift coefficients were analyzed with the TST method to evaluate the statistical errors associated to the finite length signal. Differently from numerical signals, experimental data usually also presents undesirable effects at the end of the time series that should be filtered from the original one. Thus, both TST-B and TST-A were evaluated for the original signals of the experimental data.

Firstly, TST was carried out for the original signal of $C_{x}$, and analyzed in both ways, TST-A, Figure 6.16, and TST-B, Figure 6.17. 


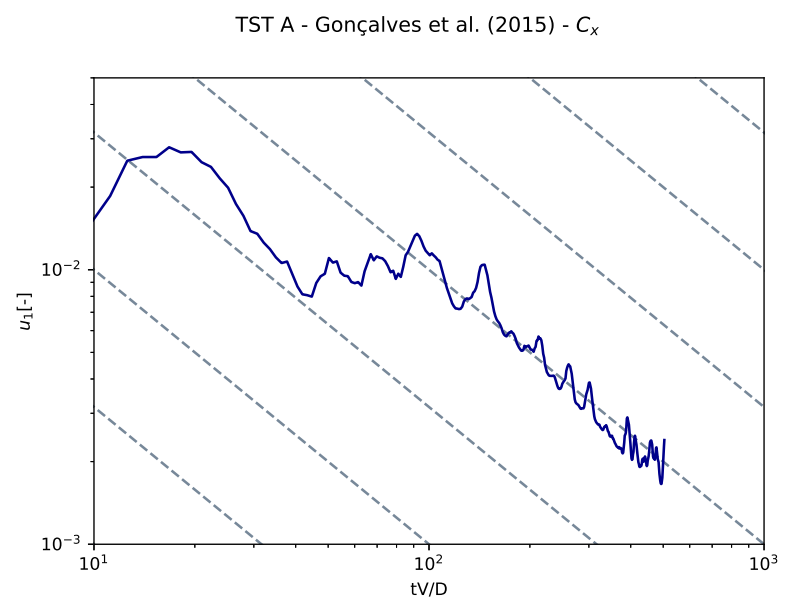

Figure 6.16: Experimental TST-A of the original signal of drag force. Source: Gonçalves et al. (2015)

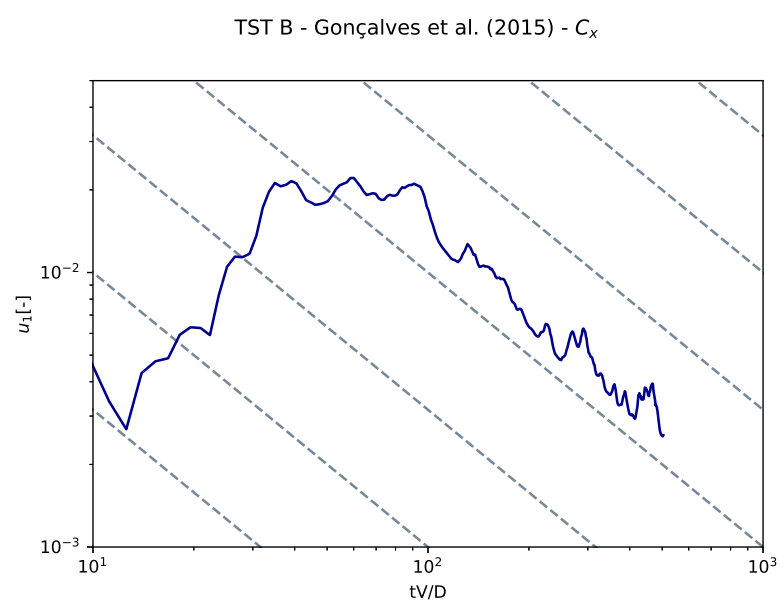

Figure 6.17: Experimental TST-B of the original signal of drag force. Source: Gonçalves et al. (2015)

From both TST-A and TST-B, no effects related to start-up or end effects were observed. Experimental uncertainty of $C_{x}$ was estimated based on the minimal uncertainty from the TST-A analysis, $u_{1}=2 \times 10^{-3}$.

Time series of the experimental lift forces were also investigated. Following the approach above, TST of the original signal are shown in Figures 6.18 and 6.19. 


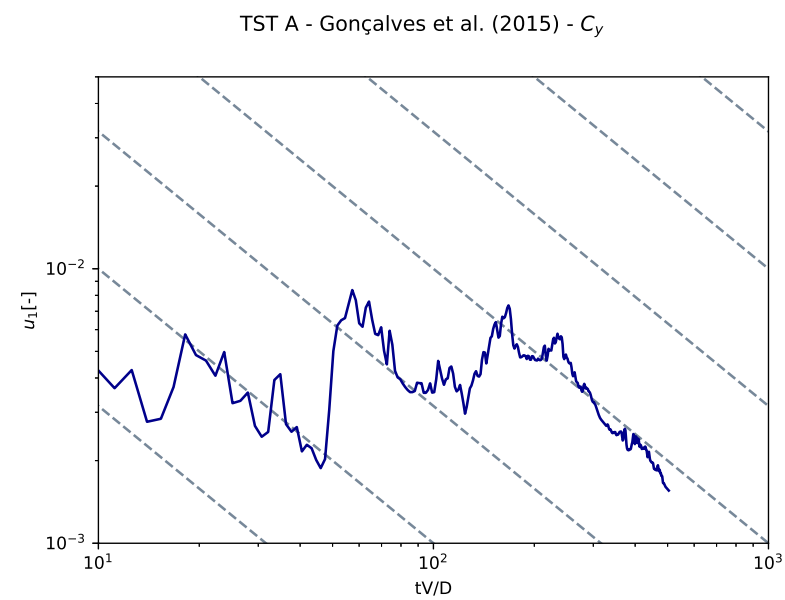

Figure 6.18: Experimental TST-A of the original signal of lift force. Source: Gonçalves et al. (2015)

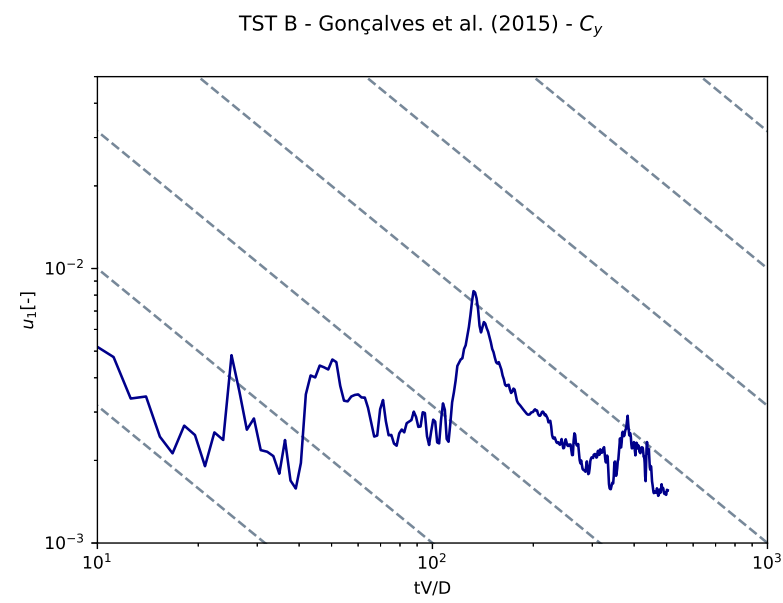

Figure 6.19: Experimental TST-B of the original signal of lift force. Source: Gonçalves et al. (2015)

A small hockey stick was observed in the TST-A. The TST-B was performed from the signal with the start-up effect filtered, Figure 6.20. 


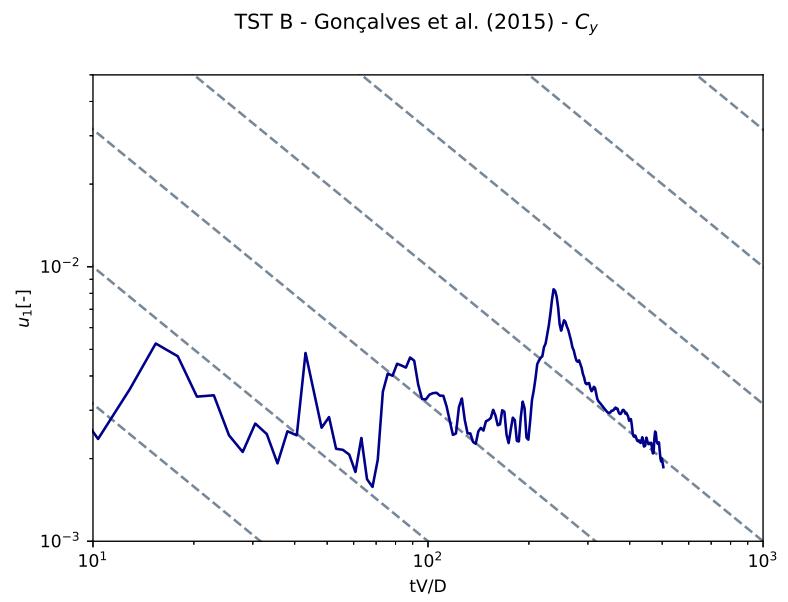

Figure 6.20: TST-B of the filtered signal of the lift force.

Start-up effects were extracted from time series of $C_{y}$. The uncertainty associated to the stationarity of the finite length signal was estimated based on TST-A of the filtered signal, Figure 6.21.

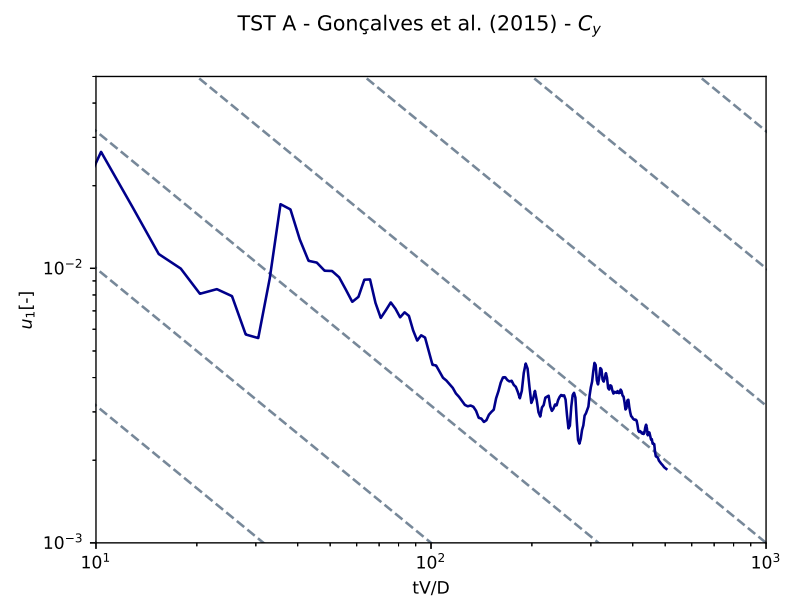

Figure 6.21: TST-A of the filtered signal of the lift force.

\subsubsection{Integral Quantities}

A comparison of $\overline{C_{x}}$ between numerical and experimental results is shown in Table 6. 
Case $\quad \overline{C_{x}} \quad$ Experimental

Relative difference(\%)

\begin{tabular}{ccc}
\hline Experimental (GONÇALVES et al., 2015) & 1.016 & - \\
SYM + EARSM & 0.698 & 31.299 \\
VoF + EARSM & 0.708 & 30.314 \\
VoF + IDDES & 0.813 & 19.980 \\
\hline
\end{tabular}

Table 6: Averaged drag coefficient comparison between numerical and experimental results.

Time average of drag forces obtained numerically showed $\overline{C_{x}}$ systematically smaller than experiments. Cases modeled with VoF method with IDDES turbulence models showed the best agreement, compared with the other cases. SYM case with EARSM turbulence model showed absolute values of $\overline{C_{x}}$ very similar to the VoF case with the same closure model.

A comparison of $C_{y, r m s}$ between the numerical and experimental results is shown in Table 7 .

$$
\text { Case } \quad C_{y, r m s} \quad \text { Experimental }
$$

Relative difference(\%)

\begin{tabular}{ccc}
\hline Experimental (GONÇALVES et al., 2015) & 0.063 & - \\
SYM + EARSM & 0.015 & 76.190 \\
VoF + EARSM & 0.006 & 90.476 \\
VoF + IDDES & & 23.809 \\
\hline
\end{tabular}

Table 7: Comparison between numerical and experimental results for root mean square of lift coefficients.

VoF case with IDDES presented $C_{y, r m s}$ closer to the experiments. Differently from the drag forces, SYM case with EARSM turbulence model presented fluctuations twice as larger as in the VoF case with the same turbulence model. The case in which the free surface was modeled with VoF method presented the smaller lift fluctuations, showing that the free surface modeling suppressed the lift fluctuations. However, it was not possible to distinguish whether this suppression is due to the physics of the free surface or due to some numerical modeling issue. 
Finally, Strouhal numbers obtained from a PSD analysis of lift coefficient time series were compared and showed in Table 8.

Case Strouhal Experimental

Relative difference(\%)

\begin{tabular}{ccc}
\hline Experimental (GONÇALVES et al., 2015) & 0.15 & - \\
SYM + EARSM & 0.173 & 15.33 \\
VoF + EARSM & 0.130 & 13.33 \\
VoF + IDDES & 0.153 & 2.00 \\
\hline
\end{tabular}

Table 8: Comparison between numerical and experimental results for Strouhal number.

Numerical results agreed well with the experiments. The cases using EARSM as turbulence model presented considerable difference for each free surface modeling approach, showing that the free surface has some influence on the frequency of the lift fluctuations. The VoF case with IDDES showed the smaller difference compared with experiments.

\subsubsection{Flow Fields}

To compare the results qualitatively, flow field maps generated from simulations were compared with experimental flow visualization obtained with PIV by Gonçalves et al. (2015). Flow fields were selected according with experimental data available. Firstly, magnitude of the velocity vector was plotted onto the $y=0$ plane. Figure 6.22 compared the four cases with experimental data.

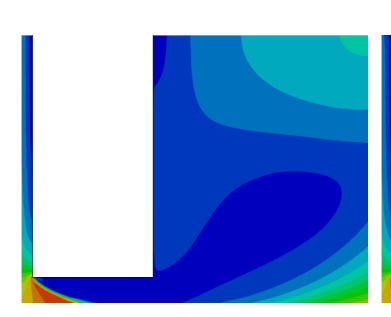

(a)

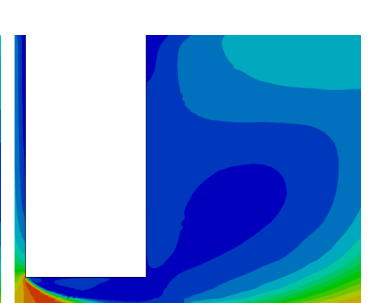

(b)

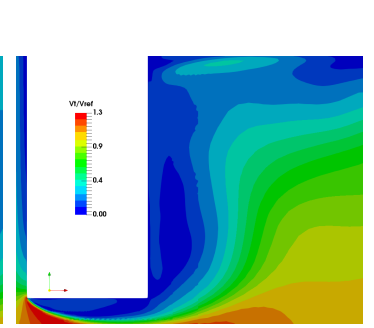

(c)

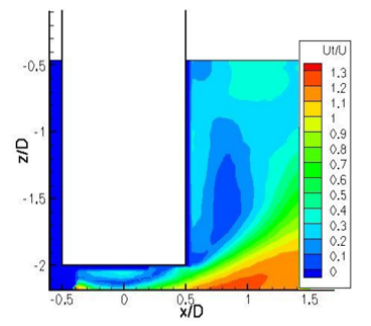

(d)

Figure 6.22: Magnitude velocity at $y=0$ plane: (a) EARSM-SYM; (b) EARSM-FS; (c) IDDESFS (d) Experimental Gonçalves et al. (2015)

EARSM cases presented pressure distributions different from experiments, with a downstream recirculating bubble placed further away than in the experiment. The VoF 
case with IDDES turbulence model showed better agreement with the experiments

The free stream component of the velocity was plotted with the streamlines and compared with the experiment. Figure 6.23 shows four cases simulated at the $y=0$ plane compared with experimental data.

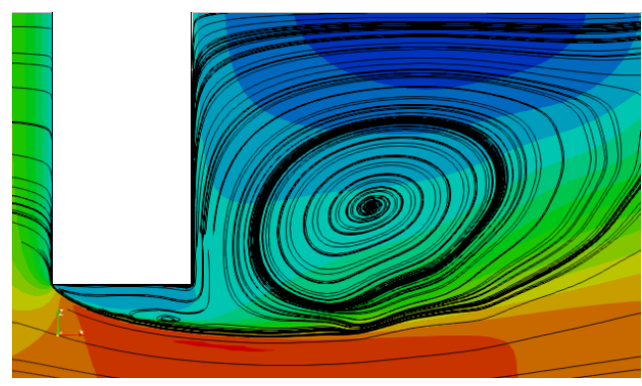

(a)

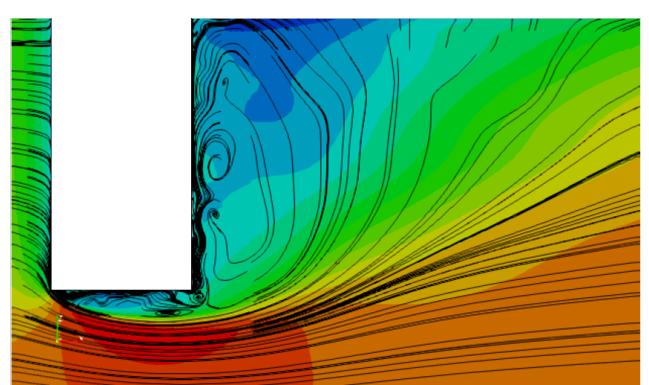

(c)

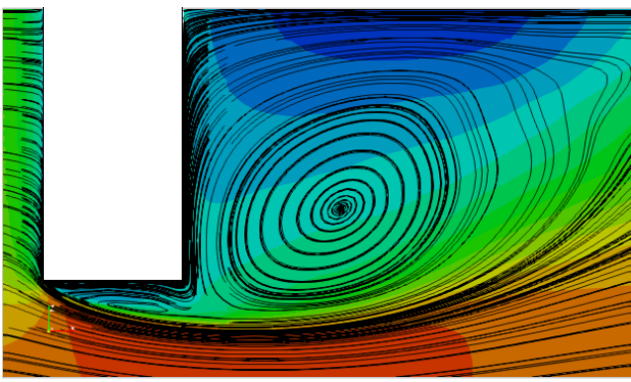

(b)

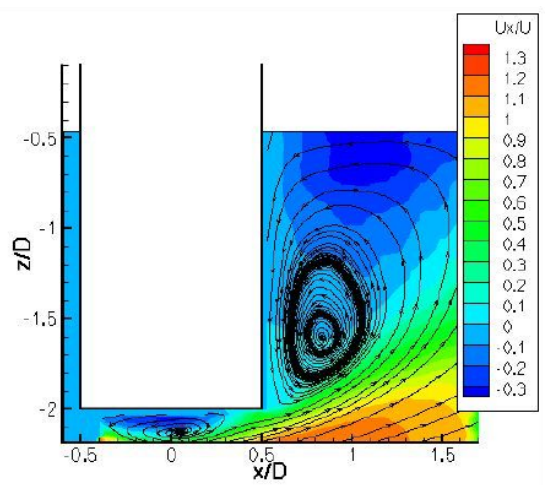

(d)

Figure 6.23: $\mathrm{x}$-velocity component map at the $\mathrm{y}=0$ plane and streamlines: (a) EARSM-SYM; (b) EARSM-FS; (c) IDDES-FS (d) Experimental Gonçalves et al. (2015);

Two recirculating bubbles were present in all cases. In the two cases with EARSM turbulence model, the bubble was placed at the same region, $1.25 \mathrm{D}$ distant from the cylinder center line. VoF case with IDDES turbulence model presented a downstream bubble closer to the cylinder, similar to the experiment.

The component of the velocity in the free stream direction and streamlines were compared at the mid z-plane. Figure 6.24 shows the flow field and streamlines corresponding to the four numerical cases compared with the experimental one. 


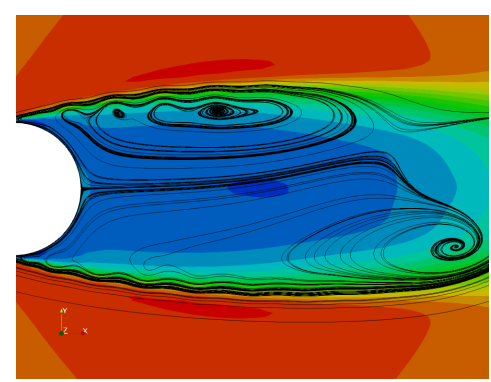

(a)

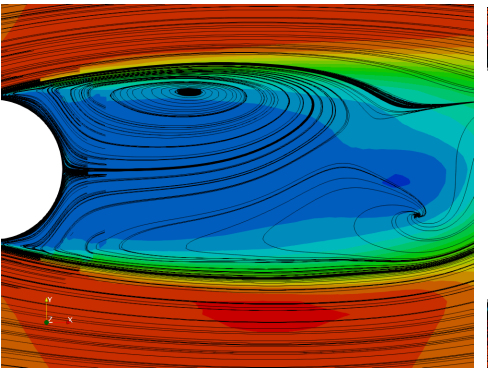

(b)

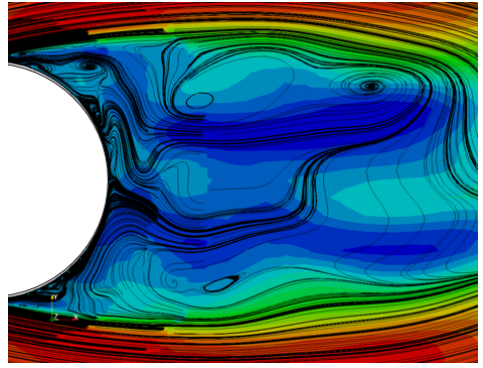

(c)

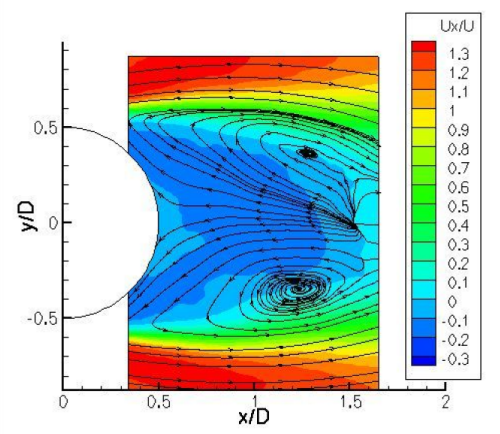

(d)

Figure 6.24: x-velocity component map at mid span and streamlines: (a) EARSM-SYM; (b) EARSM-FS; (c) IDDES-FS (d) Experimental Gonçalves et al. (2015);

Experimental plot showed two vortical foci, with a slightly non-symmetrical pattern with respect to the centerline, at circa 1.25 diameters downstream of the cylinder. Both VoF and SYM cases with EARSM turbulence model presented similar results, with streamlines asymmetrical and two vortical foci, one placed approximately at $1 D$ downstream to the cylinder and the second distant 2D. No characteristic foci of vorticity may be clearly seen in the FS case with IDDES. Small vortices were observed close to the cylinder wall and placed at one and two diameters downstream of the cylinder. 


\section{$7 \quad$ DISCUSSION}

This chapter presents a discussion of the influence of the free end and the free surface on the flow around a finite cylinder. Results are presented as velocity and vorticity flow fields and three-dimensional flow visualizations.

\subsection{Pressure Coefficient}

The pressure coefficient was evaluated for the three cases tested. Figure 7.1 presents pressure fields onto the $y=0$ plane.

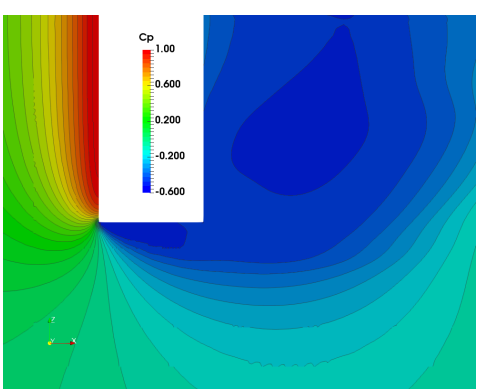

(a)

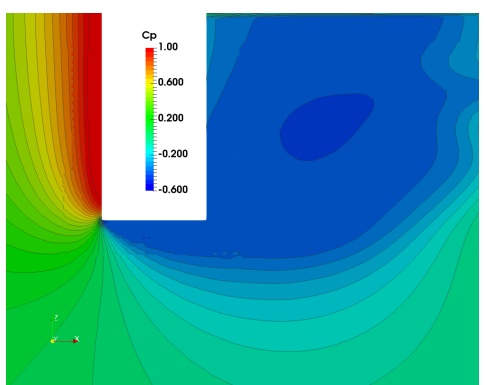

(b)

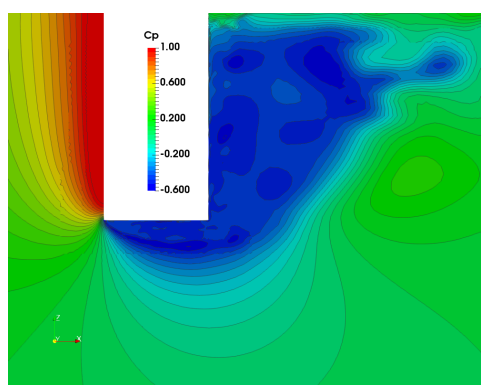

(c)

Figure 7.1: Time averaged $C_{p}$ maps onto the $\mathrm{y}=0$ plane for (a) EARSM-SYM; (b) EARSM-FS; (c) IDDES-FS

Pressure fields showed similar results for both cases modeled with EARSM turbulence model. A recirculating bubble was positioned approximately two diameters downstream the cylinder. The cases modeled with EARSM and VoF showed less intense low-pressure at the free end region. The recirculating bubble is not clearly evident, showing that the free surface may affect the free end region.

On the other hand, in the case modeled with IDDES, low pressure regions are somewhat disperse if compared to the previous cases. The low-pressure region downstream the cylinder is located closer to the cylinder when compared with the EARSM cases.

Figure 7.2 shows time average $C_{p}$ maps onto four z-plane sections, $z / L=0,-0.4,-0.8,-1$ 
for the three cases tested.

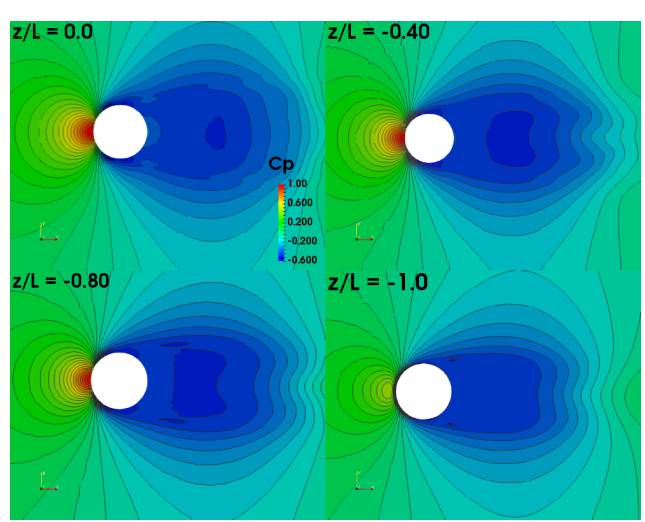

(a)

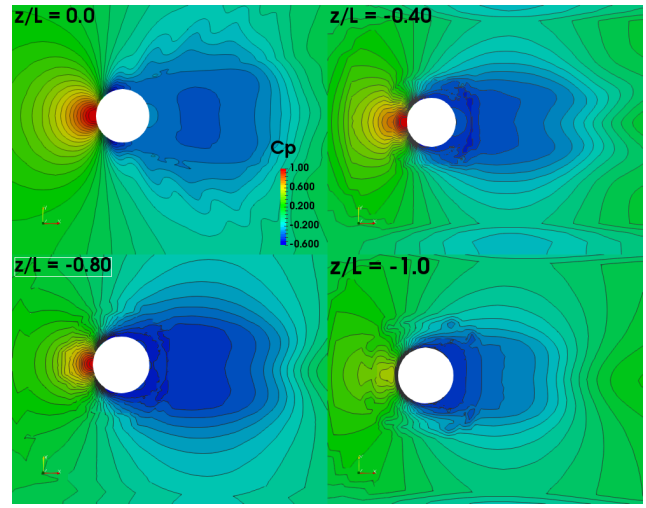

(b)

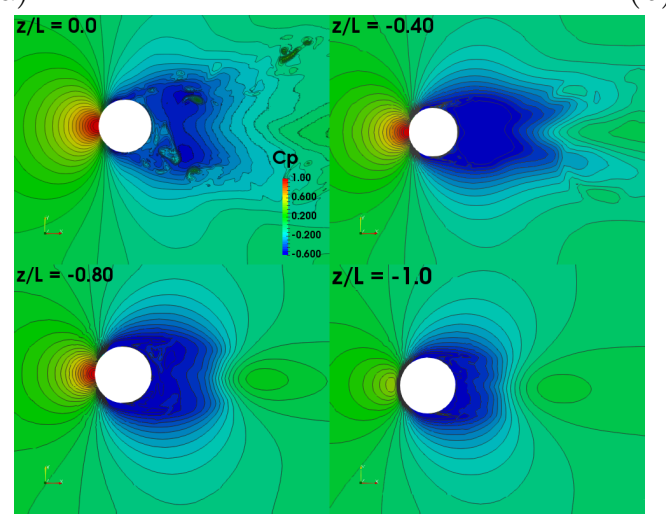

(c)

Figure 7.2: Time averaged $C_{p}$ maps onto the $\mathrm{z}=0$ plane for (a) EARSM-SYM; (b) EARSM-FS; (c) IDDES-FS

The cases modeled with EARSM showed different results. On the free end slice, the case modeled with symmetry boundary condition showed a low pressure region distant approximately 1.5 diameters downstream the cylinder center line. A C-type profile on the pressure fields is seen in the three slices closer to the free surface, for both EARSM cases. This behavior shows that the tip vortex dominate the area near the free end and starts to be involved by the side vortices at $z / L=-0.8$.

The IDDES case showed a C-type region of low-pressure already at the free end slice. In this turbulence model, an interaction between the side and tip vortices is present close to the free end, showing why the recirculate region at the Figure 7.1-c the circulating bubble is not well characterized. Additionally, a substantial variation on the pressure fields along the spanwise direction can be seen. 


\subsection{Vorticity Fields}

Figure 7.3 shows the $y$-vorticity at the $y=0$ plane.

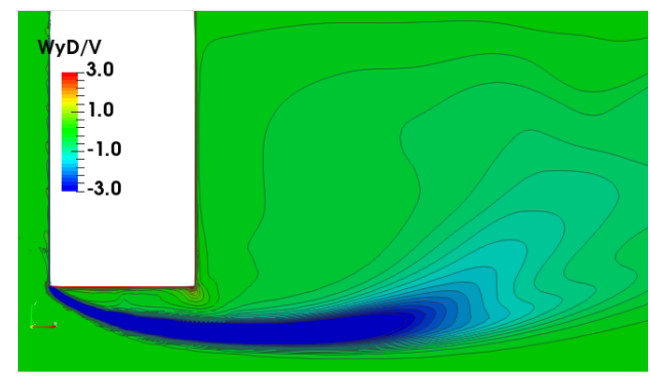

(a)

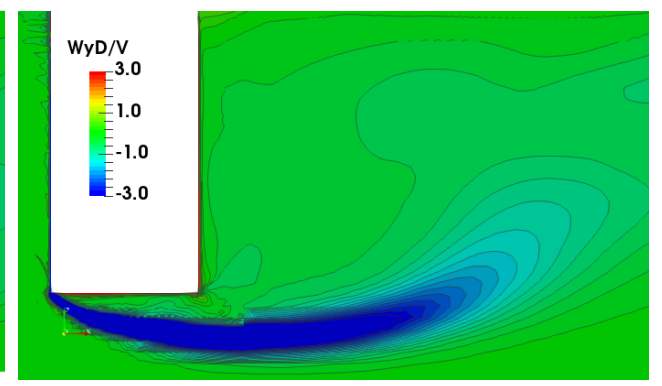

(b)

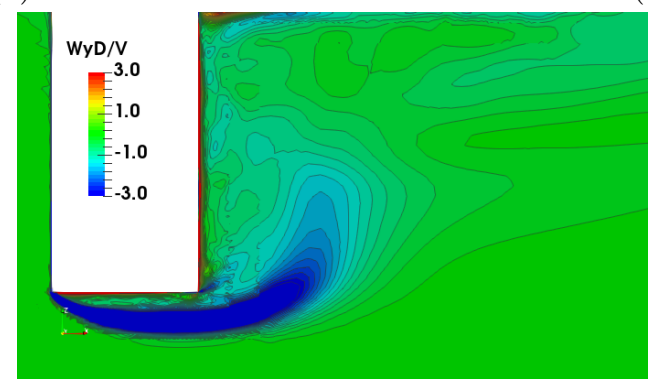

(c)

Figure 7.3: Time averaged $\frac{W_{y} D}{V}$ intensity onto the $\mathrm{y}=0$ plane for (a) EARSM-SYM; (b) EARSMFS; (c) IDDES-FS

EARSM cases showed similar results for both free surface approaches. Tip-vortices are long and start to be diffused at approximately three diameters from the cylinder centerline. This could be seen on the pressure plots, on which the downstream recirculating bubble coreappears at two diameters from the cylinder surface.

The IDDES case presented the tip vortices being attracted by the side vortex close to the cylinder, consistent with the low pressure region close do the cylinder. The diffusion of tip vortices shows that the influence of the secondary separated flow starts to lost influence and indicating is weaker and indicates that the vortex shedding starts to dominate the flow behavior. This is consistent with the experimental observations by Kawamura et al. (1984), who afirm that there is no vortex shedding close to the free end, and as the aspect ratio increases, the vortex shedding dominate the flow behavior.

Time average fields of z-vorticity were calculated and plotted at four z-planes along the cylinder length, Figure 7.4. 


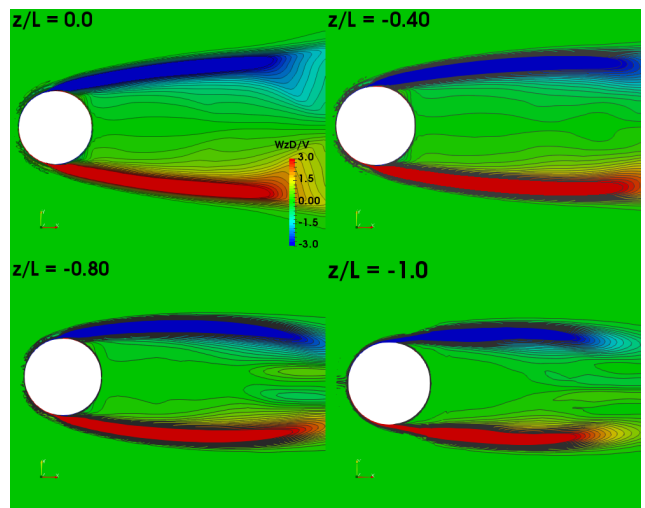

(a)

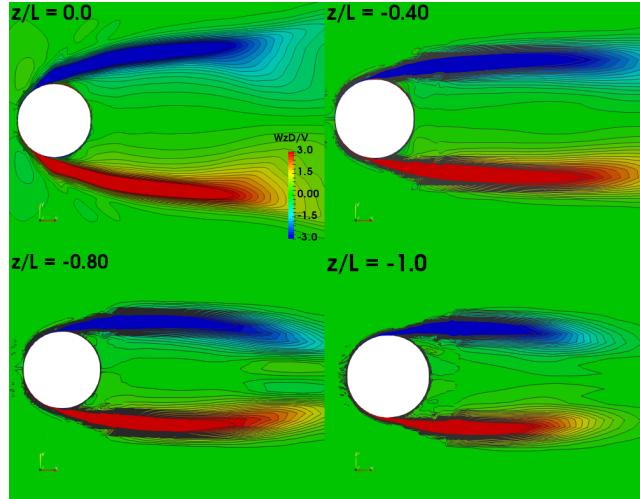

(b)

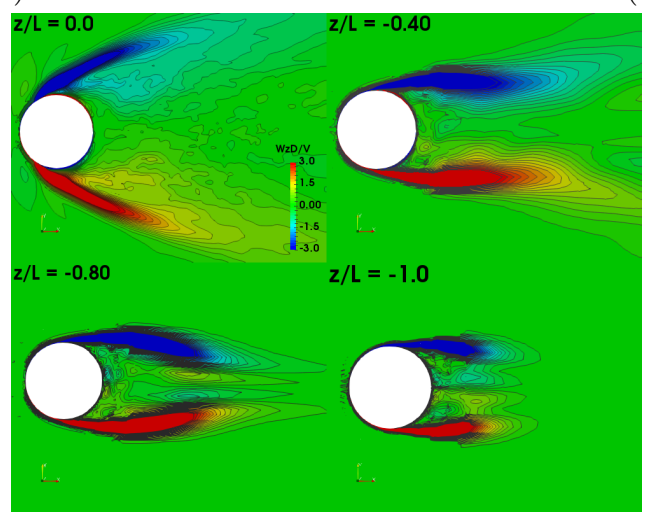

(c)

Figure 7.4: Time averaged $\frac{W_{z} D}{V}$ intensity onto the $\mathrm{z}=0$ plane for (a) EARSM-SYM; (b) EARSMFS; (c) IDDES-FS

Both EARSM cases showed small spanwise sensibility for the wake length. The long shear layers at the free end slice indicate that the side vortices are stronger than the tip vortices, dominating the flow pattern in these cases.

On the other hand, IDDES results showed a considerable spanwise dependence, mainly at the free surface region slice, indicating that the side vortices are transported by the waves reflected by the cylinder. At the free end slice is possible to see small shear layers and a second pair of vortices in the inner region of the wake, probably a pair of tip-vortices.

Instantaneous z-vorticity maps onto z-plane sections are presented in Figure 7.5. 


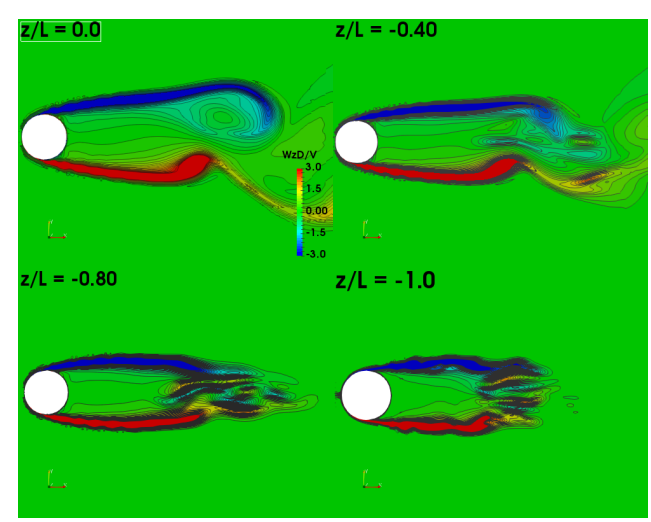

(a)

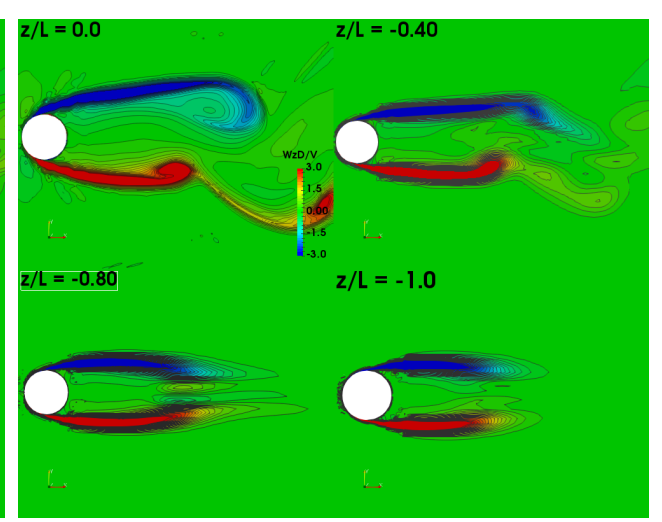

(b)

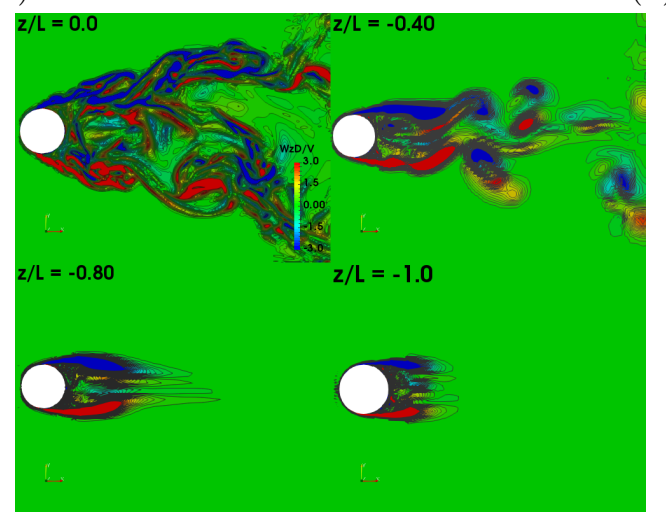

(c)

Figure 7.5: Instantaneous $\frac{W_{z} D}{V}$ intensity onto the $\mathrm{z}=0$, plane for (a) EARSM-SYM; (b) EARSMFS; (c) IDDES-FS

Theses plots show that, besides in different intensities, vortex shedding dominates the flow for the two slices closer to the free surface. The EARSM case with SYM boundary condition shows a second pair of vortices at the inner part of the wake, three diameters distant from the cylinder centerline. This agreed with Figure 7.3.

EARSM cases show that the vortex shedding starts at approximately $x / D=3$; whereas for IDDES at $x / D=1$. This means that with the EARSM models the turbulence regime is reached further in the wake than with the IDDES one.

\subsection{Three-dimensional Vortical Structures}

This section presents an analysis of three-dimensional vortical structures on the flow around a finite cylinder. To identify such structures, the method $Q$ of vortex identification was used. Hence, $Q=3$ iso-surfaces were plotted, colored by the dimensionless $V^{*}$, enabling vortical structures to be visualized.

Figure 7.6 shows three-dimensional vortical structures for the EARSM turbulence 
model with the symmetry boundary condition at the free surface.

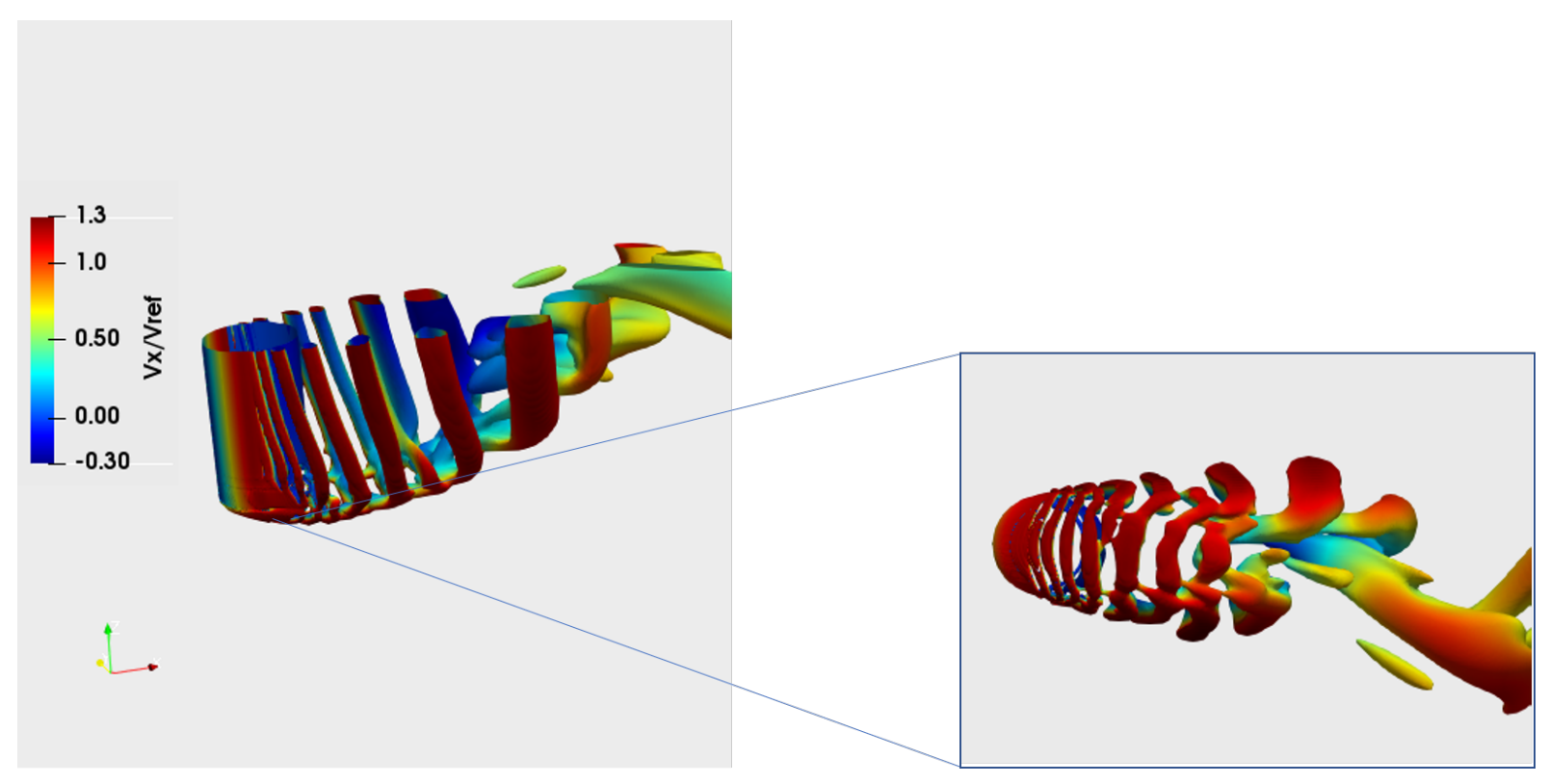

Figure 7.6: $Q=3$ iso-surfaces, colored by $V^{*}$, for the case with EARSM and SYM - Left: Perspective view; Right: Zoom of the free end region.

For the EARSM case with symmetry boundary condition, the tip and side vortices detach from the cylinder smoothly as an arch-type structure. This vortical structure loses its form as the flow becomes more turbulent and the vortex shedding starts. Threedimensionalities on the flow are small and motivated mainly by the free end vortex detachments.

Figure 7.7 shows three-dimensional structures for the case modeled with the EARSM turbulence model and FS boundary condition. 


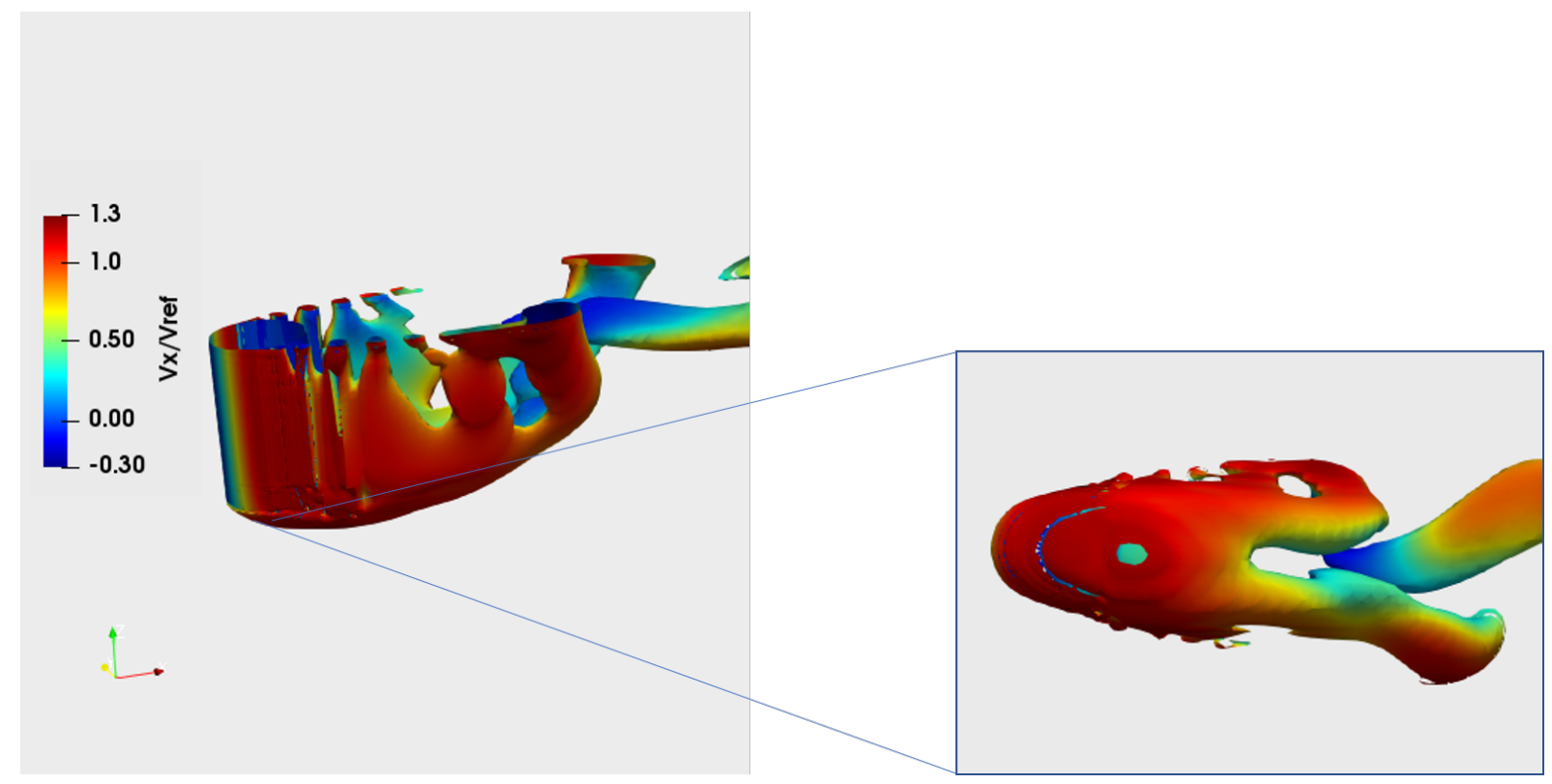

Figure 7.7: $Q=3$ iso-surfaces, colored by $V^{*}$, for the case with EARSM and VoF - Left: Perspective view; Right: Zoom of the free end region.

The EARSM with VoF agreed with the case with the same turbulence model and symmetry boundary condition approach. However, three-dimensional vortical structures in this case presented large scales.

Figure 7.8 refers to the IDDES case with free surface effects modeled with the VoF method.

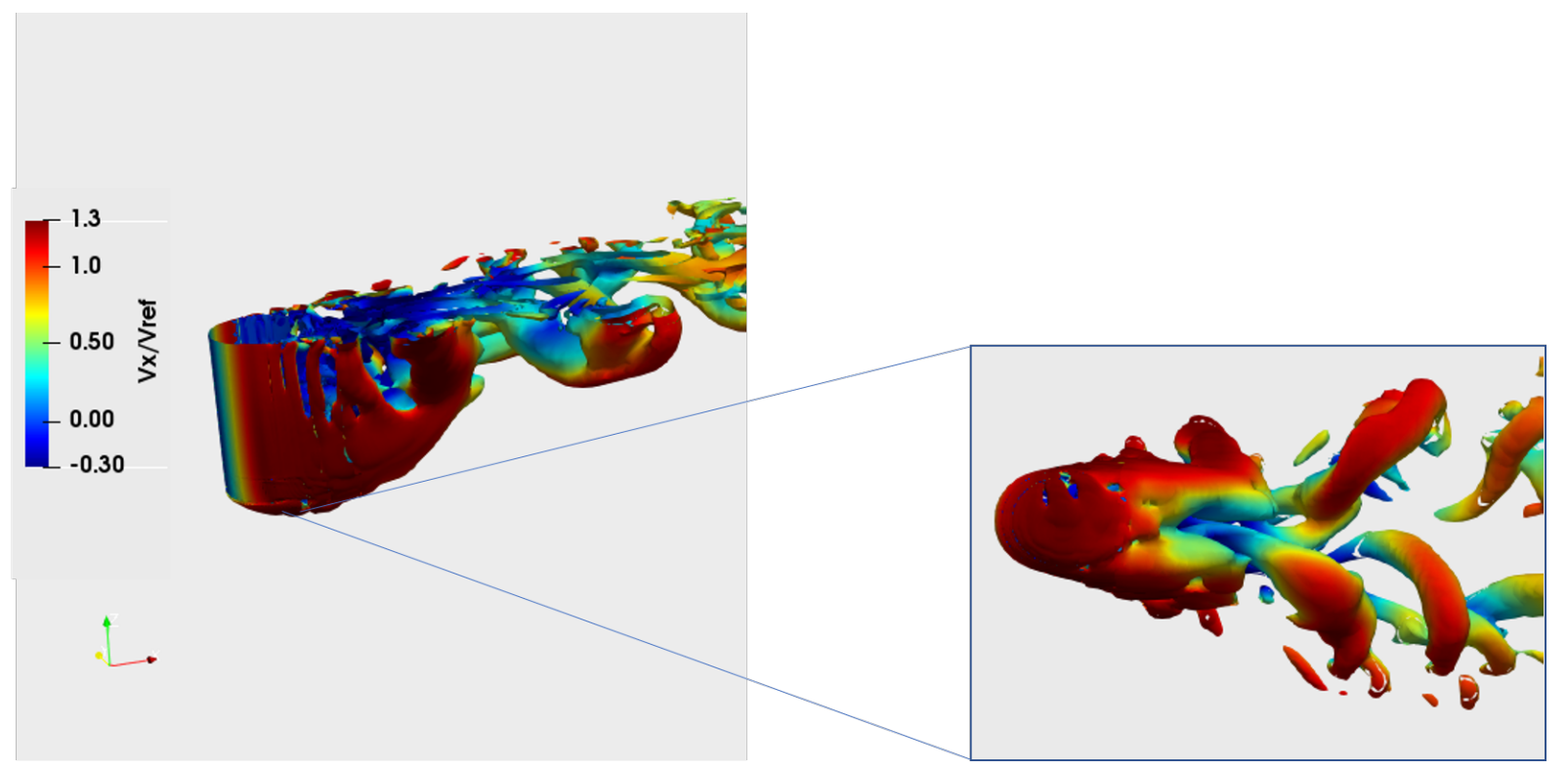

Figure 7.8: $Q=3$ iso-surfaces, colored by $V^{*}$, for the case with IDDES and VoF - Left: Perspective view; Right: Zoom of the free end region.

Differently from the last two cases, IDDES turbulence model deals with the problem 
distinctly. The flow reaches the turbulence regime as soon as detaches from the cylinder. This agrees with the near cylinder circulation bubble. Nonetheless, vortex shedding starts also close the cylinder. This confirms why the lift fluctuations are higher for this case, as seen in Table 7 . This case was also the one presenting better agreement with the experiments, regarding drag coefficient, and Strouhal number and flow fields. It may be concluded that, among the three models, the IDDES with FS is the one that generates $3 \mathrm{D}$ vortical structures closer to the experimental measures.

Tip vortices showed a different behavior when compared with the EARSM cases. Vortices are originated at the free end surface in three different formations. Two regions are shown, in which the tip vortices interact with the side vortices and detach from the cylinder as a tornado-like vortex, reaching the free surface. The other formation is a tip vortex that loops over the free end and moves towards the free surface before the ones which interact with the side vortices. 


\section{CONCLUSIONS}

\subsection{Thesis Overview}

The flow around finite length cylinders has been investigated since the beginning of the last century. Several authors have addressed this problem experimentally, mostly of them carried out in wind tunnels. However, its numerical investigation is a recent topic of interest of the academic community, motivated by the increasing power of computational resources and by the astonishing improvements made in numerical methods and algorithms. Additionally, the study of the free surface piercing cylinder is even more rare, with few experimental and numerical studies approaching this case. This thesis presented a numerical investigation of the flow around a low-aspect ratio cylinder, aiming at understanding aspects of turbulence modeling, effects of the free end and free surface on the three-dimensional turbulent flow.

Different numerical models were tested, followed by a methodology of verification and validation. Two approaches to deal with the free surface piercing issue were tested: a double body symmetry condition at the top surface, and an approach that model the material interface between water and air with the VoF method.

Integral results of $\overline{C_{x}}, C_{y, r m s}$, and Strouhal number were presented together with their respective uncertainties. Firstly, an iterative convergence analysis was performed. Cases modeled with EARSM turbulence model showed asymptotic convergence as the convergence tolerance varies. IDDES turbulence model case showed an aleatory behavior. However, the deviation between the results was small enough that may be neglected. All the convergence tolerance were then chosen in a conservative way, and the controlled residuals were presented.

Thereafter, an evaluation of the stationarity of the lift time series signal was done. This step was based on a new method proposed by Brouwer, Tukker \& Rijsbergen (2015), as an alternative to the intuitive approach commonly used by the academic community. 
The last step of the proposed verification procedures was the discretization analysis. However, the set of grids and time-steps simulated for this analysis were considered insufficient for a proper assessment of the discretization uncertainties using the method introduced in Section 4.5.3. The high processing times required for the cases simulated have shown that the computational infrastructure available was insufficient to simulate cases with finer meshes and time-steps. Therefore, discretization uncertainties were not assessed in the present work.

\subsection{Main Conclusions}

Results were compared with experimental data from Gonçalves et al. (2015). Experimental and numerical results were compared. IDDES showed results systematically closer to experiments than EARSM cases. Drag coefficients showed a deviation of around $30 \%$ with experiments for the EARSM cases, whilst in the IDDES case this difference was around 19\%. The lift variation of the IDDES was also the one that most agreed with experiments. The EARSM results deviation was given mainly by the distance on which the shedding effects starts, and consequently implying less influence on the forces behavior.

Pressure and vorticity flow fields were presented at the $\mathrm{y}=0$ plane of symmetry and at four distinct z-plane sections taken spanwise. The downstream recirculating bubbles in the cases modeled with EARSM turbulence model were formed approximately two diameters downstream the cylinder. Instantaneous vorticity fields showed that the detachment of shedding vortices starts at that same distance. Thus, it was concluded that for this turbulence model, the wake reaches a turbulent regime at approximately two diameters of distance from the cylinder centerline.

Position of the recirculating bubbles in the cases with IDDES model were the closest to experiments. A strong spanwise dependence was observed in this cases. At the free surface interface region the wake was widely diffused, while at the free end, tip vortices dominated the wake pattern, suppressing the shedding vortices.

Finally, three-dimensional vortical structures were presented for the three cases, aiming to understand how tip vortices interact with the side ones. For the cases with EARSM turbulence model, the vortices interact at the free end surface and detach from the cylinder as an arch-type vortex. This formation starts to vanish when the flow reaches the turbulent regime and the shedding phenomenon starts dominating the flow behavior. On 
the other hand, the IDDES turbulence model showed that the side and tip vortices detached from three different points at the free end surface. Two interacting with the side vortices and one from the central part of the surface. This agrees with Palau-Salvador et al. (2010), maps at the free end surface.

\subsection{Further Studies Recommendations}

Following the results presented in this thesis, some aspects not fully investigated are left as recommendation for further research work. Verification procedures require a proper assessment of uncertainties associated with the numerical discretization. Finer grids and time-steps are required to a proper estimation.

Another aspect that deserves further investigation is the free surface effect, herein modeled with SYM boundary condition for the IDDES turbulence model.

Finally, an investigation on the aspect-ratio of the cylinders is recommended, varying the parameter according with experimental results of Gonçalves et al. (2015). 


\section{REFERENCES}

ASSI, G. R. d. S. Estudo experimental do efeito de interferência no escoamento ao redor de cilindros alinhados. 276 p. PhD (Thesis) - University of São Paulo, 2005.

BABAN, F.; SO, R. M.; ÖTÜGEN, M. V. Unsteady forces on circular cylinders in a cross-flow. Experiments in Fluids, v. 7, n. 5, p. 293-302, 1989. ISSN 07234864.

BATCHELOR, G. K. An introduction to fluid dynamics. Cambridge. [s.n.], 1967. 615 p. ISBN 0521663962. Available from Internet:〈https://www.cambridge.org/core/books/ an-introduction-to-fluid-dynamics/18AA1576B9C579CE25621E80F9266993〉.

BEARMAN, P. Vortex Shedding from Oscillating Bluff Bodies. Annual Review of Fluid Mechanics, v. 16, n. 1, p. 195-222, 1984. ISSN 00664189. Available from Internet: 〈http://fluid.annualreviews.org/cgi/doi/10.1146/annurev.fluid.16.1.195〉.

BENITZ, M. A.; CARLSON, D. W.; SEYED-AGHAZADEH, B.; MODARRESSADEGHI, Y.; LACKNER, M. A.; SCHMIDT, D. P. CFD simulations and experimental measurements of flow past free-surface piercing, finite length cylinders with varying aspect ratios. Computers and Fluids, Elsevier Ltd, v. 136, p. 247-259, 2016. ISSN 00457930. Available from Internet:〈http://dx.doi.org/10.1016/j.compfluid.2016.06.013〉.

BROUWER, J.; TUKKER, J.; RIJSBERGEN, M. van. Uncertainty Analysis and Stationarity Test of Finite Length Time Series Signals. 4th International Conference on Advanced Model Measurement Technology for the Maritime Industry, 2015.

BROUWER, J.; TUKKER, J.; RIJSBERGEN, M. X. van. Uncertainty analysis of finite length measurement signals. 3rd International Conference on Advanced Model Measurement Technology for the Maritime Industry, n. February 2016, 2013.

BURMESTER, S.; GUEYDON, S.; VAZ, G.; MOCTAR, B. Surge Decay Simulations of a Semi-Submersible Floating Offshore Wind Turbine. NuTTS-2017, Wageningen, the Netherlands, v. 1, n. 1, p. 1-6, 2017.

CREPIER, P. Ship Resistance Prediction - Verification and Validation Exercise on Unstructured Grids Ship Resistence Prediction: Verification and Validation Exercise on Unstructured Grids. p. 365-376, 2017. Available from Internet: 〈http://www.marin.nl〉.

EÇA, L.; HOEKSTRA, M. Evaluation of numerical error estimation based on grid refinement studies with the method of the manufactured solutions. Computers and Fluids, Elsevier Ltd, v. 38, n. 8, p. 1580-1591, 2009. ISSN 00457930. Available from Internet:〈http://dx.doi.org/10.1016/j.complluid.2009.01.003〉.

EÇA, L.; HOEKSTRA, M. A procedure for the estimation of the numerical uncertainty of CFD calculations based on grid refinement studies. Journal of Computational Physics, Elsevier Inc., v. 262, p. 104-130, 2014. ISSN 00219991. Available from Internet: $\langle$ http://dx.doi.org/10.1016/j.jcp.2014.01.006〉. 
EÇA, L.; OÑTE, E.; GARCÍA-ESPINOSA, J. MARINE 2011, IV International Conference on Computational Methods in Marine Engineering. [s.n.], 2013. v. 29. ISBN 978-94-007-6142-1. Available from Internet:〈http://link.springer.com/10.1007/ 978-94-007-6143-8>.

EÇA, L.; PEREIRA, F. S.; VAZ, G. Viscous flow simulations at high Reynolds numbers without wall functions: Is yplus minor than one enough for the near-wall cells? Computers $\&$ Fluids, v. 170, p. 157-175, jul 2018. ISSN 00457930. Available from Internet:〈https://linkinghub.elsevier.com/retrieve/pii/S0045793018302299〉.

EÇA, L.; VAZ, G.; ROSETTI, G.; PEREIRA, F. On the Numerical Prediction of the Flow Around Smooth Circular Cylinders. In: Volume 2: CFD and VIV. ASME, 2014. p. V002T08A013. ISBN 978-0-7918-4540-0. Available from Internet: 〈http://proceedings. asmedigitalcollection.asme.org/proceeding.aspx?doi=10.1115/OMAE2014-23230〉.

FARIVAR, D. J. Turbulent uniform flow around cylinders of finite length. AIAA Journal, v. 19, n. 3, p. 275-281, 1981. ISSN 0001-1452. Available from Internet: 〈http://arc.aiaa.org/doi/abs/10.2514/3.7771〉.

FERZIGER, J. H.; PERIC, M. Computational Methods for Fluid Dynamics. [S.l.: s.n.], 2002. 423 p. ISSN 08981221. ISBN 3540420746.

FRÖHLICH, J.; RODI, W. LES of the flow around a circular cylinder of finite height. International Journal of Heat and Fluid Flow, v. 25, n. 3, p. 537-548, jun 2004. ISSN 0142727X. Available from Internet:〈http://linkinghub.elsevier.com/retrieve/pii/ S0142727X0400027X〉.

GHARRAEE, B.; ESKILSSON, C.; BENSOW, R. E.; VAZ, G. Numerical simulation of cavitation on horizontal axis tidal current turbine. In: Proceedings of ISOPE. [S.l.: s.n.], 2015 .

GONÇALVES, R. T.; FRANZINI, G. R.; ROSETTI, G. F.; MENEGHINI, J. R.; FUJARRA, A. L. Flow around circular cylinders with very low aspect ratio. Journal of Fluids and Structures, 2015. ISSN 10958622.

GRITSKEVICH, M. S.; GARBARUK, A. V.; SCHÜTZE, J.; MENTER, F. R. Development of DDES and IDDES formulations for the $\mathrm{k}-\omega$ shear stress transport model. Flow, Turbulence and Combustion, v. 88, n. 3, p. 431-449, 2012. ISSN 13866184.

HAWKES, J.; TURNOCK, S.; COX, S.; PHILIPS, A.; VAZ, G. Performance Analysis of Massively-Parallel Computational Fluid Dynamics. 11th International Conference on Hydrodynamics (ICHD2014), Singapore, n. Ichd, p. 1-8, 2014.

HELLSTEN, A. New two-equations turbulence model for aerodynimic flows. $187 \mathrm{p}$. PhD (Thesis) - Helsinki University of Technology, 2004. Available from Internet: 〈http://lib.tkk.fi/Diss/2004/isbn9512269341/〉.

HIRT, C.; NICHOLS, B. Volume of fluid (VOF) method for the dynamics of free boundaries. Journal of Computational Physics, v. 39, n. 1, p. 201-225, jan 1981. ISSN 00219991. Available from Internet:〈http://linkinghub.elsevier.com/retrieve/pii/ $0021999181901455\rangle$. 
HOLMÉN, V. Methods for Vortex Identification. PhD (Thesis), 2012.

JONGSMA, S.; WEIDE, E. van der; WINDT, J. Implementation and Verification of a Partitioned Strong Coupling Fluid-Structure Interaction Approach in a Finite Volume Method. Ichd, M, 2016.

KARMAN, T. von. On the Statistical Theory of Turbulence. Proceedings of the National Academy of Sciences, v. 23, n. 2, p. 98-105, feb 1937. ISSN 0027-8424. Available from Internet:〈http://www.pnas.org/cgi/doi/10.1073/pnas.23.2.98〉.

KAWAMURA, T.; HIWADA, M.; HIBINO, T.; MABUCHI, I.; KUMADA, M. Flow around finite circular cylinder on a flat plate. Bulletin of JSME, v. 27, n. 232, p. 2142-2151, 1984. ISSN 00213764.

KLAIJ, C. M.; HOEKSTRA, M.; VAZ, G. Design, analysis and verification of a volume-of-fluid model with interface-capturing scheme. Computers and Fluids, 2018. ISSN 00457930.

KLAIJ, C. M.; VUIK, C. SIMPLE-type preconditioners for cell-centered, colocated finite volume discretization of incompressible Reynolds-averaged Navier-Stokes equations. International Journal for Numerical Methods in Fluids, v. 71, n. 7, p. 830-849, mar 2013. ISSN 02712091. Available from Internet:〈http://doi.wiley.com/10.1002/fld.3686〉.

LEDER, A.; OF, D.; RISING, B.; FINITE, I. N.; MEDIA, I. 3D-Flow Structures Behind Truncated Circular Cylinders. In: Volume 2: Symposia, Parts A, B, and C. [S.l.: s.n.], 2003. ISBN 0-7918-3697-5.

MCELMAN, S.; GOUPEE, A. Simulation and Development of a Wind-Wave Facility for Scale. In: . [S.l.: s.n.], 2016. p. 1-10.

MENTER, F. R. Two-equation eddy-viscosity turbulence models for engineering applications. AIAA Journal, v. 32, n. 8, p. 1598-1605, 1994. ISSN 0001-1452. Available from Internet: 〈http://arc.aiaa.org/doi/10.2514/3.12149〉.

OKAMOTO, S.; SUNABASHIRI, Y. Vortex Shedding from a Circular-Cylinder of Finite Length Placed on a Ground Plane. Journal of Fluids Engineering-Transactions of the Asme, v. 114, n. 4, p. 512-521, 1992.

OKAMOTO, T.; YAGITA, M. The Experimental investigation on the flo past a circular cylinder of finite length placed normal to the plane surface in a uniform stream. JSME annual meeting, v. 16, n. 95, p. 805-814, 1973. ISSN 00213764. Available from Internet: $\langle$ http://ci.nii.ac.jp/naid/110004071651/〉.

PALAU-SALVADOR, G.; STOESSER, T.; FRÖHLICH, J.; KAPPLER, M.; RODI, W. Large eddy simulations and experiments of flow around finite-height cylinders. [S.l.: s.n.], 2010. v. 84. 239-275 p. ISSN 13866184. ISBN 1049400992.

PATTENDEN, R. J.; BRESSLOFF, N. W.; TURNOCK, S. R.; ZHANG, X. Unsteady simulations of the flow around a short surface-mounted cylinder. International Journal for Numerical Methods in Fluids, v. 53, n. 6, p. 895-914, 2007. ISSN 02712091. 
PATTENDEN, R. J.; TURNOCK, S. R.; ZHANG, X. Measurements of the flow over a low-aspect-ratio cylinder mounted on a ground plane. Experiments in Fluids, v. 39, n. 1, p. 10-21, 2005. ISSN 07234864.

PEREIRA, F. S. Towards Predictive Scale-Resolving Simulations of Turbulent External Flows. 274 p. PhD (Thesis) — University of Lisboa, 2018.

RAMÍREZ-MACÍAS, J. A.; BRONGERS, P.; RÚA, S.; VÁSQUEZ, R. E. Hydrodynamic modelling for the remotely operated vehicle Visor3 using CFD. IFAC-PapersOnLine, v. 49, n. 23, p. 187-192, 2016. ISSN 24058963. Available from Internet:〈https://linkinghub.elsevier.com/retrieve/pii/S2405896316319280〉.

REYNOLDS, O. An Experimental Investigation of the Circumstances Which Determine Whether the Motion of Water Shall Be Direct or Sinuous, and of the Law of Resistance in Parallel Channels. Philosophical Transactions of the Royal Society of London, 1883. ISSN 0261-0523.

REYNOLDS, O. On the Dynamical Theory of Incompressible Viscous Fluids and the Determination of the Criterion. Philosophical Transactions of the Royal Society A: Mathematical, Physical and Engineering Sciences, 1895. ISSN 1364-503X.

ROACHE, P. J. Verification of codes and calculations. AIAA Journal, 1998. ISSN 0001-1452.

ROSETTI, G. F. Improvements in the Numerical Modeling of Turbulence and Fluid-Structure Interaction for the Vortex-Induced Vibrations of a Rigid Cylinder. $251 \mathrm{p}$. PhD (Thesis) — University of São Paulo, 2015.

ROSETTI, G. F.; VAZ, G.; FUJARRA, A. L. C. URANS Calculations for Smooth Circular Cylinder Flow in a Wide Range of Reynolds Numbers: Solution Verification and Validation. In: Volume 5: Ocean Engineering; CFD and VIV. [S.l.: s.n.], 2012. ISBN 978-0-7918-4492-2. ISSN 0098-2202.

ROSETTI, G. F.; VAZ, G.; HOEKSTRA, M.; GONÇALVES, R. T.; FUJARRA, A. L. C. CFD Calculations for Free-Surface-Piercing Low Aspect Ratio Circular Cylinder With Solution Verification and Comparison With Experiments. In: Volume 7: CFD and VIV. ASME, 2013. p. V007T08A056. ISBN 978-0-7918-5541-6. Available from Internet: 〈http://proceedings.asmedigitalcollection.asme.org/proceeding.aspx?doi=10. 1115/OMAE2013-10963〉.

SARODE, R. S.; GAI, S. L.; RAMESH, C. K.; AERODYNAMICS, I. Flow around circular- and square-section models of finite height in a turbulent shear flow. Journal of Wind Engineering and Industrial Aerodynamics, v. 8, p. 223-230, 1981. ISSN 01676105. Available from Internet: 〈https://www.sciencedirect.com/science/article/pii/ $0167610581900222\rangle$.

SCHMITT, F. G. About Boussinesq's turbulent viscosity hypothesis: historical remarks and a direct evaluation of its validity. 2007.

SLAOUTI, A.; GERRARD, J. H. An Experimental Investigation of the End Effects on the Wake of a Circular-Cylinder Towed through Water at Low Reynolds-Numbers. Journal of Fluid Mechanics, v. 112, n. Nov, p. 297-314, 1981. 
SMAGORINSKY, J. General circulation experiments with the primitive equations. Part I: The basic experiment. Monthly Weather Review, v. 91, n. 3, p. 99-164, 1963. ISSN 0036-8075.

SUMNER, D. Flow above the free end of a surface-mounted finite-height circular cylinder: A review. Lecture Notes in Mechanical Engineering, Elsevier, v. 43, p. 41-63, 2013. ISSN 21954364. Available from Internet:〈http://dx.doi.org/10.1016/j.jfluidstructs. 2013.08.007〉.

TANEDA, S. Experimental Investigation of the Wakes behind Cylinders and Plates at Low Reynolds Numbers. Journal of the Physical Society of Japan, v. 11, n. 3, 1956.

TEZDUYAR, T. E. Advanced Computational Techniques for Moving Boundaries and Interfaces. Proceedings of the 6th World Congress on Computational Mechanics, 2004. ISSN 00457825.

Van Dyke, M. An album of fluid motion. Parabolic Press Stanford, 1982.

VAZ, G.; JAOUEN, F.; HOEKSTRA, M. Free-surface viscous flow computations. Validation of URANS code FRESCO. In: 28th International Conference on Ocean, Offshore and Arctic Engineering. ASME, 2009. p. 1-13. ISBN 9780791843451. Available from Internet: 〈http://proceedings.asmedigitalcollection.asme.org/proceeding.aspx? articleid $=1625164\rangle$.

WILCOX, D. Turbulence modeling for CFD. [s.n.], 1993. v. 93. 2905 p. ISSN 0022-1120. ISBN 0963605100. Available from Internet: 〈http://www.amazon.com/ Turbulence-Modeling-Third-David-Wilcox/dp/1928729088〉.

ZDRAVKOVICH, M. M. Flow Around Circular Cylinders: Volume 1: Fundamentals. New York: Oxford University Press, 1997. ISBN 0198563965.

ZDRAVKOVICH, M. M. Flow Around Circular Cylinders: Volume 2: Applications. New York: Oxford University Press, 2003. ISBN 0198565615. 